INSTITUTO DE PESQUISAS ENERGÉTICAS E NUCLEARES

Autarquia associada à Universidade de São Paulo

\title{
ESTUDO DO EFEITO DA RADIAÇÃO IONIZANTE EM COMPÓSITOS DE POLIPROPILENO/PÓ DE MADEIRA USANDO TITANATO DE BÁRIO COMO AGENTE DE ACOPLAGEM
}

MARITZA ELIZA PÉREZ ULLOA

Dissertação apresentada como parte dos requisitos para obtenção do Grau de Mestre em Ciências na Área de Tecnologia Nuclear - Aplicações.

Orientador:

Prof. Dr. Leonardo Gondim de Andrade e Silva 
A Deus,

Que sempre esteve presente,

Ao meu Pai Guillermo,

À minha irmã Marcela,

E ao meu companheiro Anderson,

Por toda a compreensão e carinho.

Especialmente à memória de minha mãe Maritza, sempre dedicada à família e a principal fonte de motivação deste trabalho. 


\section{AGRADECIMENTOS}

Ao Dr. Leonardo Gondim de Andrade e Silva pela orientação deste trabalho.

À Dra Leila Figueiredo Miranda pelo incentivo e autorização na utilização do laboratório de Materiais.

À Polibrasil

À Pinhopó Madeira e Moagem Ltda.

À Certronic Ind. e Com. Ltda.

À Bandeirante Química Ltda.

Ao CNPq, pela bolsa de mestrado.

À Universidade Mackenzie, pela utilização dos equipamentos do laboratório.

Ao IPEN, pela oportunidade de realizar este trabalho.

Ao Djalma pelos ensaios de tração.

Aos laboratoristas Luiz, Liuba, Cleber, José Carlos pela ajuda na obtenção das amostras. Aos Engenheiros Carlos e Elizabeth, pelas irradiações das amostras.

Ao Engenheiro Anderson, pela sua importante colaboração, seu incentivo e compreensão no decorrer deste trabalho.

Aos meus Pais pelo carinho e incentivo constante.

Á minha irmã e sua importante colaboração na realização das etapas finais do trabalho.

A todos que contribuíram para a realização deste trabalho. 


\title{
ESTUDO DO EFEITO DA RADIAÇÃO IONIZANTE EM COMPÓSITOS DE POLIPROPILENO/PÓ DE MADEIRA USANDO TITANATO DE BÁRIO COMO AGENTE DE ACOPLAGEM
}

\author{
Maritza Eliza Pérez Ulloa
}

\begin{abstract}
RESUMO
Este trabalho teve por objetivo o estudo dos efeitos da radiação ionizante nas propriedades de compósitos de pó de madeira em matriz de polipropileno, utilizando o titanato de bário como agente de acoplagem e o monômero reativo diacrilato de tripropileno glicol (TPDGA). Foi utilizado como fonte de radiação o acelerador de elétrons. Foram investigadas as propriedades físicas dos compostos virgens, bem como do compósito polipropileno/pó de madeira, com e sem a adição de titanato de bário e do monômero TPDGA. Os compósitos desenvolvidos foram preparados a partir do tratamento da carga, incorporando os aditivos ao reforço pó de madeira, seguindo-se a fusão do polipropileno e a mistura dos materiais do compósito na calandra. Posteriormente foram moldados corposde-prova por injeção para serem irradiados e utilizados nos ensaios mecânicos e térmicos. Foram determinadas as propriedades mecânicas dos compostos desenvolvidos (tração, dureza, impacto e índice de fluidez), bem como as propriedades térmicas (HDT e Vicat). As composições investigadas foram polipropileno/pó de madeira, polipropileno/pó de madeira com titanato de bário, polipropileno/pó de madeira com titanato de bário e TPDGA, utilizando concentrações de 10\%, 15\% e 20\% de pó de madeira no polipropileno. As amostras foram separadas em grupos para serem irradiadas com doses de 10kGy e 20kGy nas amostras do ensaio de tração além dessas doses foram utilizadas doses de $15 \mathrm{kGy}$ e $25 \mathrm{kGy}$ para ser observado o comportamento da amostra frente ao aumento da radiação. Estas doses foram escolhidas para mostrar que com baixas doses o material compósito apresenta reticulação, o que representa uma opção viável comercialmente. Houve uma redução do índice de fluidez para os compostos contendo pó de madeira, sendo esta redução mais efetiva na presença de TiBa. O tratamento superficial utilizando o monômero TPDGA influenciou nas amostras dos compósitos, pois este agiu como plastificante tornando as amostras mais fáceis de processar aumentando a mobilidade entre
\end{abstract}


as macromoléculas, diminuindo assim a viscosidade e aumentando o índice de fluidez tanto nas amostras irradiadas como as não irradiadas. Os resultados obtidos para ensaio de resistência à tração indicam um acréscimo da propriedade, o aumento ocorreu tanto nas amostras WF/PP quanto nas amostras com TiBa e TPDGA, devido à formação de ligações cruzadas (reticulação) em decorrência da radiação. A incorporação de pó de madeira no polipropileno resultou na diminuição da resistência ao impacto. O decréscimo desta propriedade pode ter acontecido devido à presença de reforço pó de madeira que pode atuar como concentrador de tensão e como conseqüência a redução de resistência ao impacto. Houve um acréscimo na dureza dos compósitos contendo pó de madeira. O acréscimo na dureza foi significativo nos compósitos WF/PP que não foram irradiados. O acréscimo se deu principalmente nas composições de 20\%WF/PP, isso porque quanto maior a quantidade de carga maior o módulo de dureza. Nas amostras irradiadas a dureza aumentou devido à oxidação da madeira frente à radiação. Observou-se que em alguns casos o aumento na dose de radiação não influenciou significativamente na variação da temperatura de deflexão térmica dos compósitos indicando que houve reticulação entre as moléculas promovido pelo TPDGA, e uma melhoria na adesão entre interfaces promovido pelo titanato. No ensaio de temperatura de amolecimento Vicat os resultados apresentados foram muito próximos ao PP puro, como os resultados não mostraram diferenças significativas, pode-se considerar a temperatura dos compósitos a mesma do PP puro. A radiação ionizante interagiu no material compósito reticulando o PP e oxidando a madeira, observando-se assim um acréscimo em algumas propriedades e o decréscimo em outras. 


\title{
STUDY OF THE EFFECT OF IONIZING RADIATION ON COMPOSITES OF WOOD FLOUR IN POLYPROPYLENE MATRIX USING BARIUM TITANATE AS COUPLING AGENT
}

\author{
Maritza Eliza Pérez Ulloa
}

\begin{abstract}
The purpose of this work was to study the effects of ionizing radiation on the properties of wood flour composites in polypropylene matrix, using barium titanate as a coupling agent and the reactive monomer tripropylene glycol diacrylate (TPDGA). An electron accelerator was used in the study as the radiation source. The physical properties of virgin compounds and of the polypropylene/wood flour composite, with and without barium titanate and TPDGA addition, were investigated. The composites were developed from the load treatment, which first consisted of incorporating additives to the wood flour reinforcement and after that, the fusion process of polypropylene and composite mixing in a "calander". Subsequently, the samples to be irradiated and submitted to thermal and mechanical assays were molded by injection. The mechanical properties (hardness, impact resistance and molten fluidity index (MFI)), as well as the thermal properties (HDT and Vicat) of the composites were determined. The investigated compositions consisted of polypropylene/wood flour, polypropylene/wood flour with barium titanate and polypropylene/wood flour with barium titanate and TPDGA, using different wood flour concentrations of $10 \%, 15 \%$ and $20 \%$ in the polypropylene matrix. The samples were separated in groups and irradiated to doses of $10 \mathrm{kGy}$ and $20 \mathrm{kGy}$ in the samples of the essays of traction. Besides these doses, it was also used doses of 15kGy and 25kGy to be observed the behavior of the sample of the sample due to the increase of the radiation. These doses were chosed to show that with low doses the composite material presents reticulation, what represents a viable commercial option. There was a reduction of the flow rate for the composites containing wood flour, being this reduction more effective in the presence of TiBa. The superficial treatment using TPDGA monomer influence in the composite samples because it acted as a plastic additive becoming the sample easier to be processed, increasing the mobility among the macromolecules, so that decreasing the
\end{abstract}


viscosity and increasing the flow rate. The results obtained from the essay of the resistance to traction showed an addition of the property. The increase occurred both in the samples with no additives. The radiation modified the composite material occurring the formation of crosslinkings. The incorporation of wood flour to the propylene resulted to the decrease of the resistance to the impact. The decrease of this property can be occurred because of the presence of wood flour can act as a tension concentrator, and consequently, reduces the impact strength. There was an addition in the hardness of the composites which had wood flour. The addition in the hardness was meaningful to the composites WF/PP, that because the bigger the amount of load, the bigger the module of hardness. In the irradiated samples, the hardness increase due to the wood oxidation, face to the radiation. It was observed that in some cases the increase in the radiation dose, did not influenced meaningfully in the variation of the temperature of thermal deflection of the composites indicating that there was crosslinking among the molecules promoted by TPDGA, and an improvement in the adhesion among interfaces promoted by the titanate. In the essay of temperature of softening Vicat, results presented were quite closed to pure PP and the results were not meaningful, the temperature of the composites can be considered the same of the pure PP. The ionizing radiation interacted in the composite material crosslinking the PP and oxidating the wood, what shows an increasement in some proprieties and decreasement in others. 


\section{SUMÁRIO}

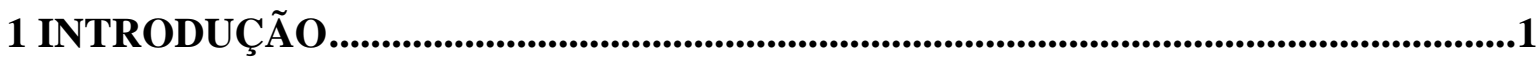

2 INTERAÇÃO DA RADIAÇÃO IONIZANTE COM A MATÉRIA .............................3

2.1 INTERAÇÃO DA RADIAÇÃO IONIZANTE EM MATERIAIS POLIMÉRICOS .......3

2.1.1 Cisão da cadeia principal (degradação) .........................................................................

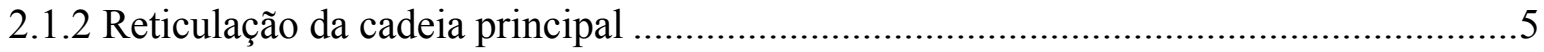

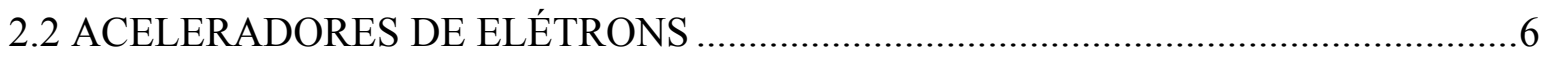

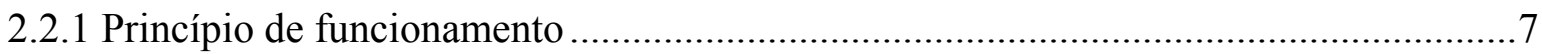

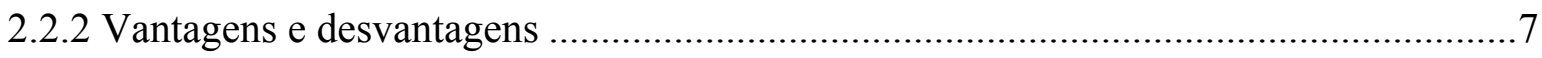

2.3 APLICAÇÃO DA RADIAÇÃO IONIZANTE EM COMPÓSITOS ............................... 8

2.3.1 Aplicação da radiação ionizante em WPCs ............................................................... 8

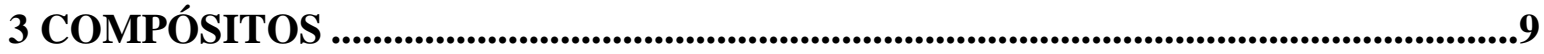

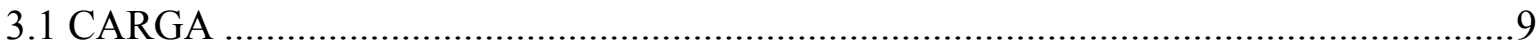

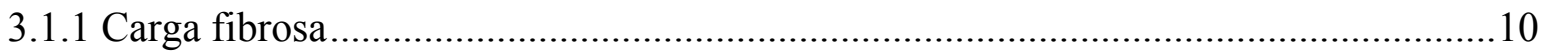

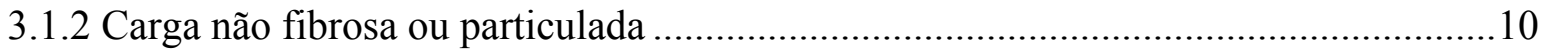

3.2 PROPRIEDADES DOS COMPÓSITOS INDIVIDUAIS E COMPOSIÇÃO................11

3.3 GRAU DE INTERAÇÃO ENTRE AS FASES ..........................................................12

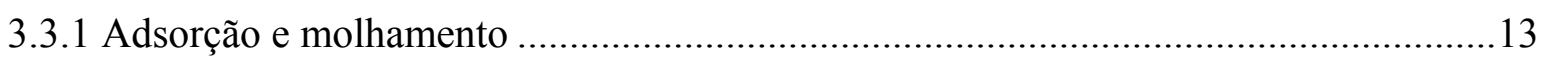

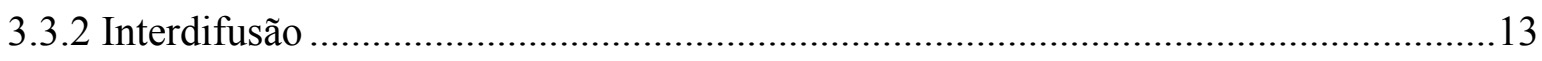

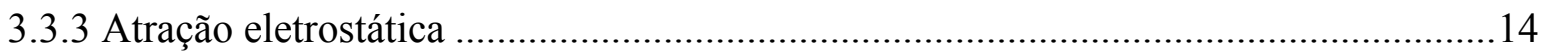

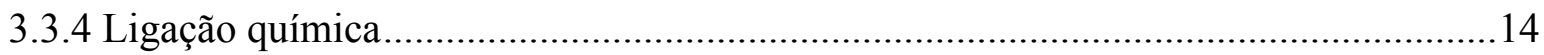

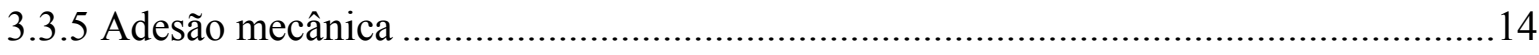

3.3.6 Razão de aspecto e porosidade da carga ....................................................................14

3.4 GRAU DE MISTURA ENTRE OS COMPONENTES .......................................... 15

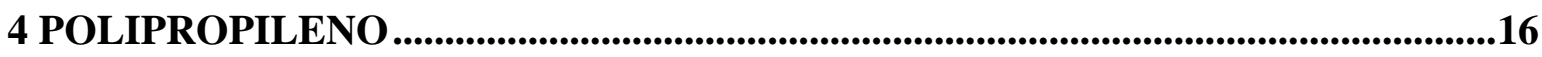

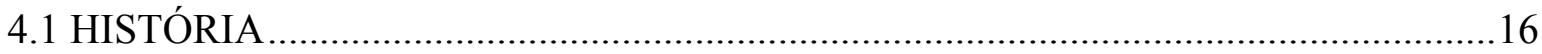

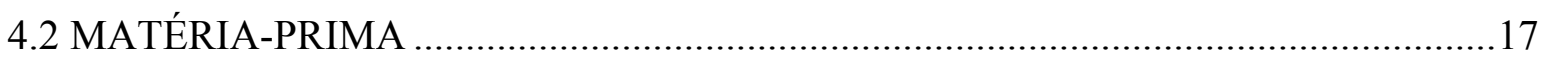

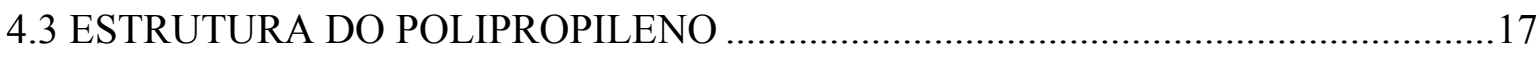

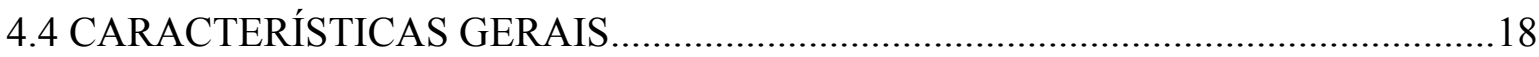


4.4.1 Pontos fortes .18

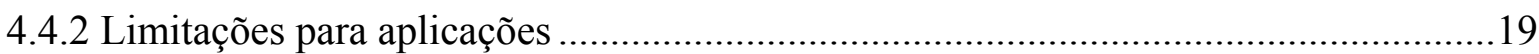

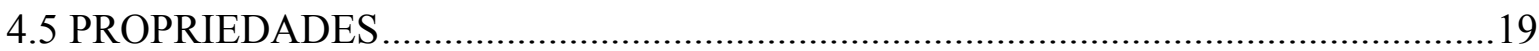

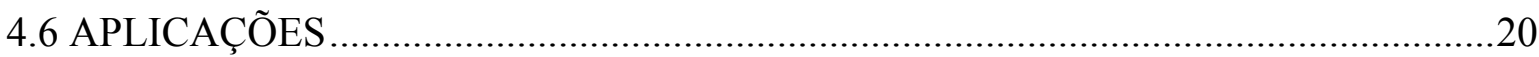

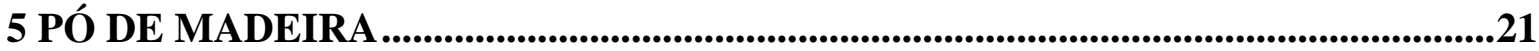

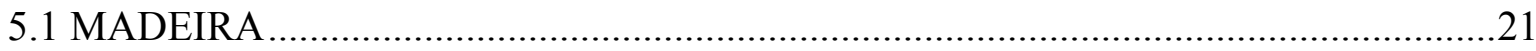

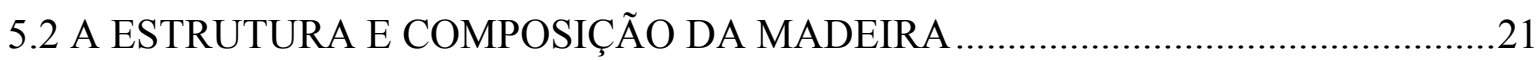

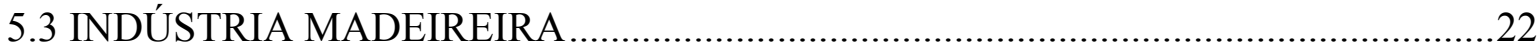

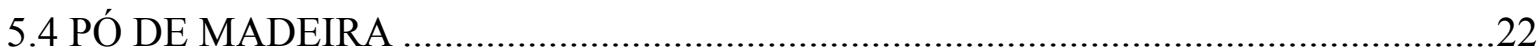

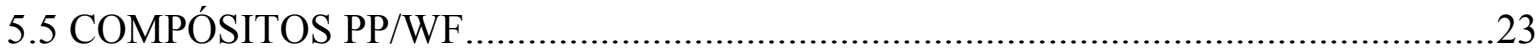

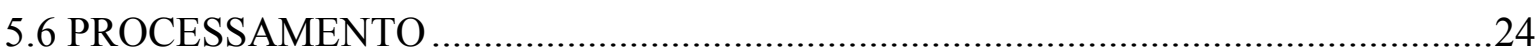

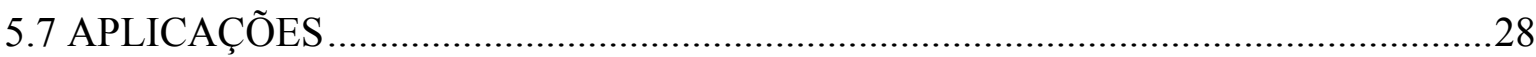

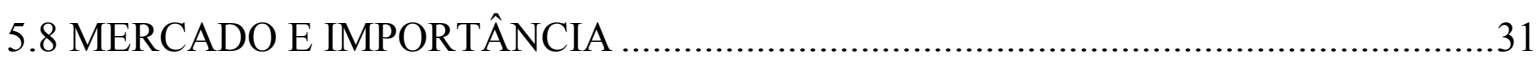

6 TRATAMENTO SUPERFICIAL DAS CARGAS ...................................................35

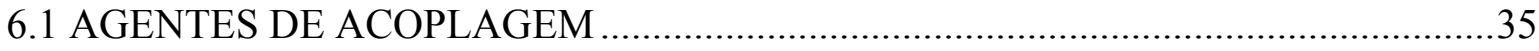

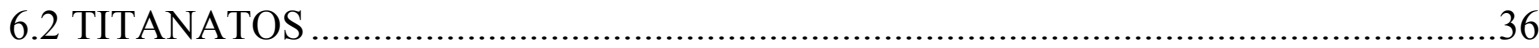

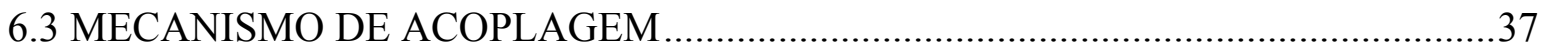

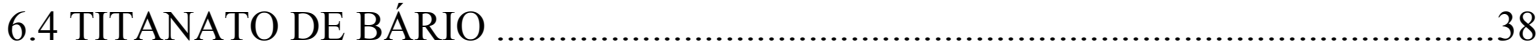

6.5 MONÔMERO REATIVO - DIACRILATO DE TRIPROPILENO GLICOL ................39

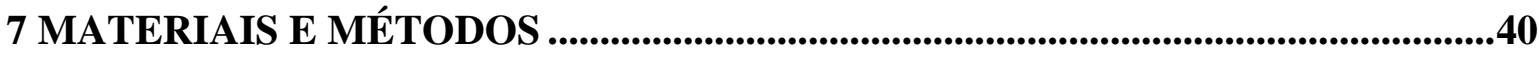

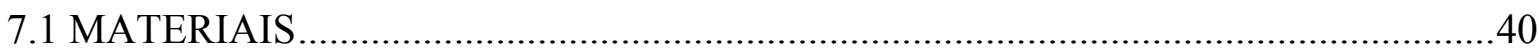

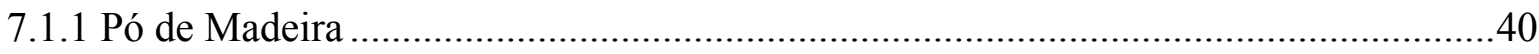

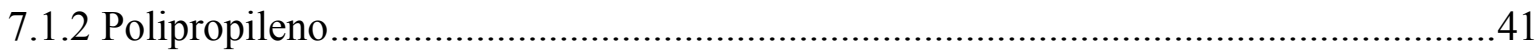

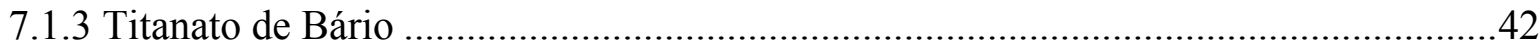

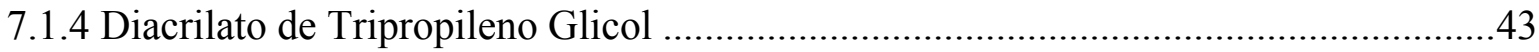

7.2 TÉCNICA DE PREPARAÇÃO DAS AMOSTRAS......................................................4

7.3 TRATAMENTO DA CARGA PÓ DE MADEIRA COM O AGENTE DE

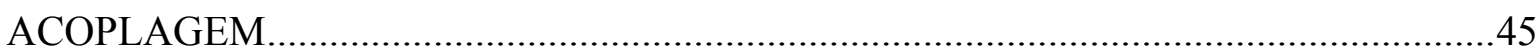

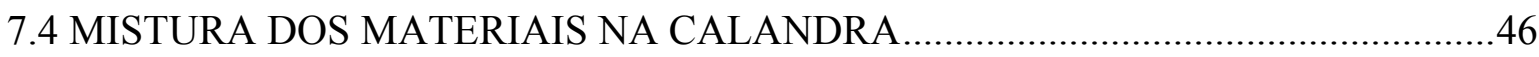

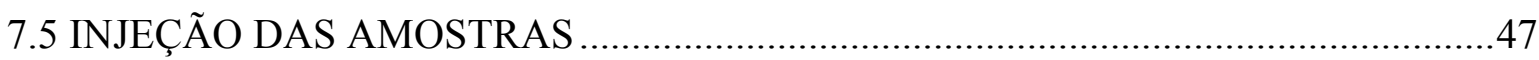

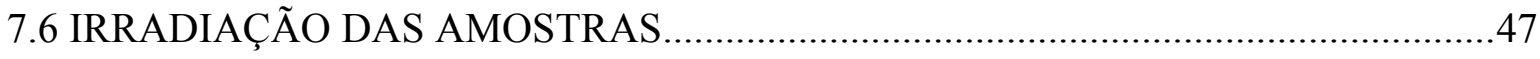

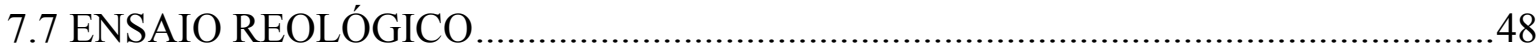




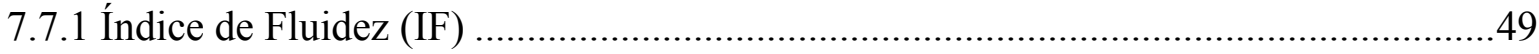

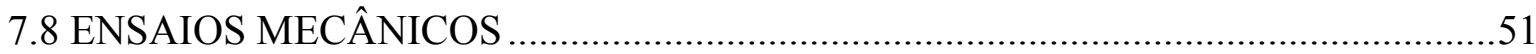

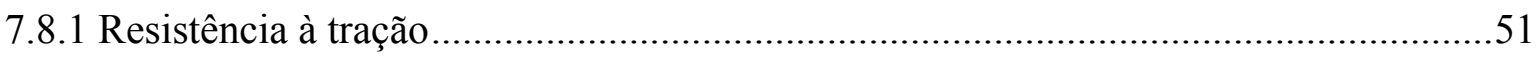

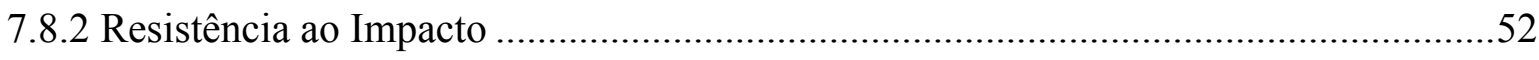

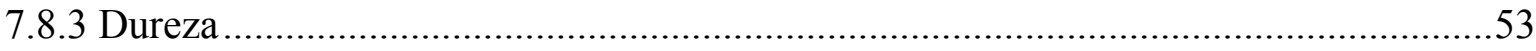

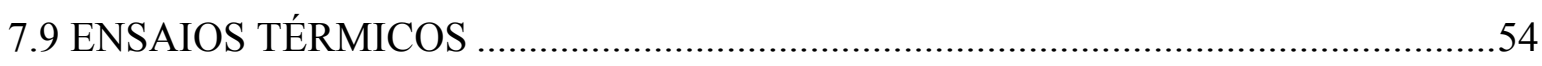

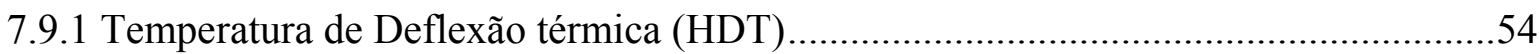

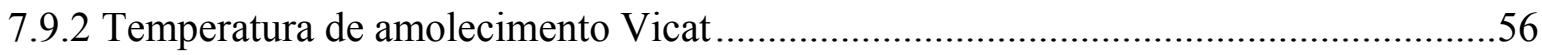

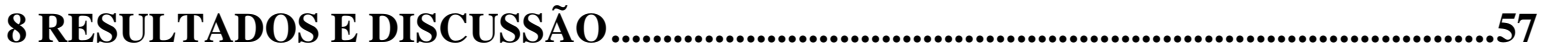

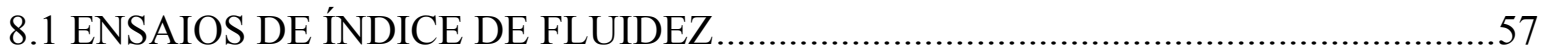

8.2 ENSAIOS DE RESISTÊNCIA À TRAÇÃO ...........................................................61

8.3 ENSAIOS DE RESISTÊNCIA AO IMPACTO ........................................................

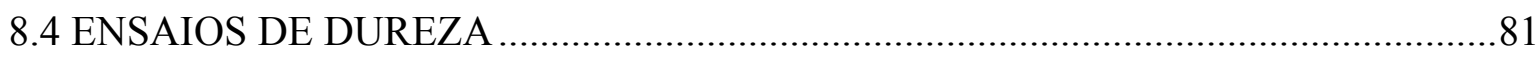

8.5 ENSAIOS DE TEMPERATURA DE DEFLEXÃO TÉRMICA (HDT) .......................90

8.6 ENSAIOS DE TEMPERATURA DE AMOLECIMENTO VICAT............................99

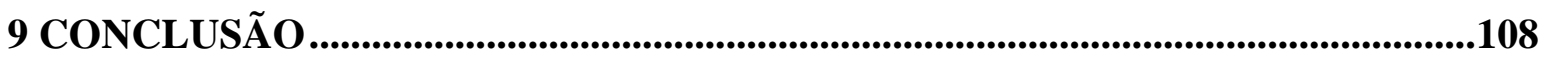

REFERÊNCIAS BIBLIOGRÁFICAS........................................................................110 


\section{LISTA DE TABELAS}

Tabela 1 - Informações técnicas do pó de madeira............................................................ 40

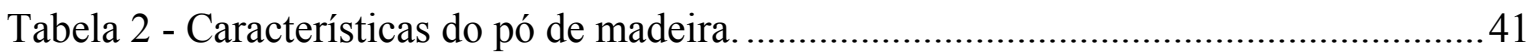

Tabela 3 - Propriedades físicas do polipropileno................................................................ 41

Tabela 4 - Características do titanato de bário tipo A............................................................42

Tabela 5 - Propriedades químicas do titanato de bário tipo A............................................. 42

Tabela 6 - Características do diacrilato de tripropileno glicol .............................................43

Tabela 7 - Composição em peso dos materiais constituintes do compósito.........................45

Tabela 8 - Índice de fluidez (g/10min) das amostras de PP (puro) e de diferentes

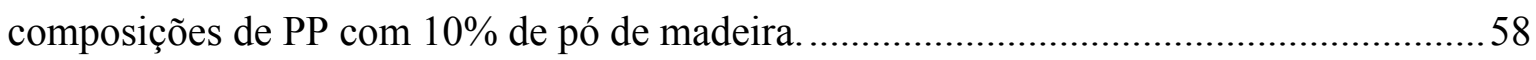

Tabela 9 - Índice de fluidez (g/10min) das amostras de PP (puro) e de diferentes

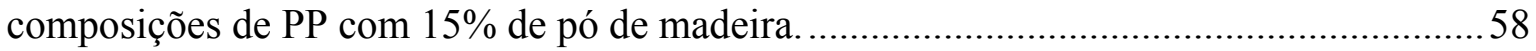

Tabela 10 - Índice de fluidez (g/10min) das amostras de PP (puro) e de diferentes

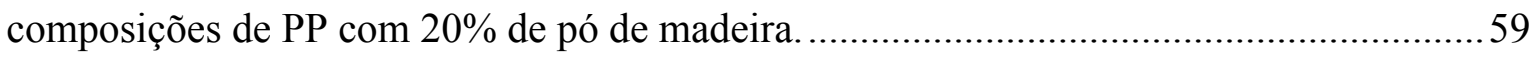

Tabela 11 - Resistência à tração $(\mathrm{MPa})$ do PP (puro) das amostras irradiadas e não irradiadas.

Tabela 12 - Resistência à tração $(\mathrm{MPa})$ das amostras com 10\%WF/PP irradiadas e não irradiadas.

Tabela 13 - Resistência à tração $(\mathrm{MPa})$ das amostras com 10\%WF+TiBa/PP irradiadas e não irradiadas.

Tabela 14 - Resistência à tração $(\mathrm{MPa})$ das amostras com 10\%WF+TiBa+TPDGA/PP irradiadas e não irradiadas.

Tabela 15 - Porcentagem de aumento da resistência à tração para as diferentes composições com $10 \%$ WF submetidas a diferentes doses de radiação em relação ao PP (puro) não irradiado.

Tabela 16 - Resistência à tração $(\mathrm{MPa})$ das amostras com 15\%WF/PP irradiadas e não irradiadas.

Tabela 17 - Resistência à tração $(\mathrm{MPa})$ das amostras com 15\%WF+TiBa/PP irradiadas e não irradiadas.

Tabela 18 - Resistência à tração $(\mathrm{MPa})$ das amostras com 15\%WF+TiBa+TPDGA/PP irradiadas e não irradiadas. 
Tabela 19 - Porcentagem de aumento da resistência à tração para as diferentes composições com 15\%WF submetidas a diferentes doses de radiação em relação ao PP (puro) não irradiado.

Tabela 20 - Resistência à tração $(\mathrm{MPa})$ das amostras com 20\%WF/PP irradiadas e não irradiadas. 68

Tabela 21 - Resistência à tração $(\mathrm{MPa})$ das amostras com 20\%WF+TiBa/PP irradiadas e não irradiadas. 68

Tabela 22 - Resistência à tração $(\mathrm{MPa})$ das amostras com 20\%WF+TiBa+TPDGA/PP irradiadas e não irradiadas.

Tabela 23 - Porcentagem de aumento da resistência à tração para as diferentes composições com $20 \% \mathrm{WF}$ submetidas a diferentes doses de radiação em relação ao PP (puro) não irradiado.

Tabela 24 - Resistência ao impacto $(\mathrm{J} / \mathrm{m})$ das amostras de PP irradiadas e não irradiadas. 72 Tabela 25 - Resistência ao impacto $(\mathrm{J} / \mathrm{m})$ das amostras de 10\%WF/PP irradiadas e não irradiadas

Tabela 26 - Resistência ao impacto $(\mathrm{J} / \mathrm{m})$ das amostras de 10\%WF+TiBa/PP irradiadas e não irradiadas.

Tabela 27 - Resistência ao impacto $(\mathrm{J} / \mathrm{m})$ das amostras de 10\%WF+TiBa+TPDGA/PP irradiadas e não irradiadas.

Tabela 28 - Porcentagem de decréscimo da resistência ao impacto para as diferentes composições com 10\%WF submetidas a diferentes doses de radiação em relação ao PP (puro) não irradiado.

Tabela 29 - Resistência ao impacto $(\mathrm{J} / \mathrm{m})$ das amostras de 15\%WF/PP irradiadas e não irradiadas

Tabela 30 - Resistência ao impacto $(\mathrm{J} / \mathrm{m})$ das amostras de 15\%WF+TiBa/PP irradiadas e não irradiadas. 76

Tabela 31 - Resistência ao impacto $(\mathrm{J} / \mathrm{m})$ das amostras de 15\%WF+TiBa+TPDGA/PP irradiadas e não irradiadas.

Tabela 32 - Porcentagem de decréscimo da resistência ao impacto para as diferentes composições de $15 \% \mathrm{WF}$ submetidas a diferentes doses de radiação em relação ao PP (puro) não irradiado.

Tabela 33 - Resistência ao impacto $(\mathrm{J} / \mathrm{m})$ das amostras de 20\%WF/PP irradiadas e não irradiadas. 
Tabela 34 - Resistência ao impacto $(\mathrm{J} / \mathrm{m})$ das amostras de 20\%WF+TiBa/PP irradiadas e não irradiadas.

Tabela 35 - Resistência ao impacto (J/m) das amostras de 20\%WF+TiBa+TPDGA/PP irradiadas e não irradiadas.

Tabela 36 - Porcentagem de decréscimo da resistência ao impacto para as diferentes composições com $20 \% \mathrm{WF}$ submetidas a diferentes doses de radiação em relação ao PP (puro) não irradiado. 80

Tabela 37 - Dureza Shore D das amostras de PP (puro) irradiadas e não irradiadas. 81

Tabela 38 - Dureza Shore D das amostras de 10\%WF/PP irradiadas e não irradiadas. 82 Tabela 39 - Dureza Shore D das amostras de 10\%WF+TiBa/PP irradiadas e não irradiadas.

Tabela 40 - Dureza Shore D das amostras de 10\%WF+TiBa+TPDGA/PP irradiadas e não irradiadas.

Tabela 41 - Porcentagem de aumento da dureza para as diferentes composições com $10 \%$ WF submetidas a diferentes doses de radiação em relação ao PP (puro) não irradiado.

Tabela 42 - Dureza Shore D das amostras de 15\%WF/PP irradiadas e não irradiadas.

Tabela 43 - Dureza Shore D das amostras 15\%WF+TiBa/PP irradiadas e não irradiadas.. 85 Tabela 44 - Dureza Shore D das amostras de 15\%WF+TiBa+TPDGA/PP irradiadas e não irradiadas.

Tabela 45 - Porcentagem de aumento da dureza para as diferentes composições com 15\%WF submetidas a diferentes doses de radiação em relação ao PP (puro) não irradiado.

Tabela 46 - Dureza Shore D das amostras de 20\%WF/PP irradiadas e não irradiadas. .......87 Tabela 47 - Dureza Shore D das amostras 20\%WF+TiBa/PP irradiadas e não irradiadas.. 87 Tabela 48 - Dureza Shore D das amostras de 20\%WF+TiBa+TPDGA/PP irradiadas e não irradiadas 88

Tabela 49 - Porcentagem de aumento da dureza para as diferentes composições com 20\%WF submetidas a diferentes doses de radiação em relação ao PP (puro) não irradiado.

Tabela 50 - Temperatura de deflexão térmica $\left({ }^{\circ} \mathrm{C}\right)$ - HDT para amostras de PP (puro) irradiadas e não irradiadas.

Tabela 51 - Temperatura de deflexão térmica $\left({ }^{\circ} \mathrm{C}\right)$ - das amostras de 10\%WF/PP irradiadas e não irradiadas. 
Tabela 52 - Temperatura de deflexão térmica $\left({ }^{\circ} \mathrm{C}\right)$ - das amostras de $10 \% \mathrm{WF}+\mathrm{TiBa} / \mathrm{PP}$ amostras irradiadas e não irradiadas.

Tabela 53 - Temperatura de deflexão térmica $\left({ }^{\circ} \mathrm{C}\right)$ - das amostras de $10 \% \mathrm{WF}+\mathrm{TiBa}+\mathrm{TPDGA} / \mathrm{PP}$ irradiadas e não irradiadas

Tabela 54 - Porcentagem dos resultados do ensaio de HDT para as diferentes composições com 10\%WF submetidas a diferentes doses de radiação em relação ao PP (puro) não irradiado.

Tabela 55 - Temperatura de deflexão térmica $\left({ }^{\circ} \mathrm{C}\right)$ - das amostras de 15\%WF/PP irradiadas e não irradiadas.

Tabela 56 - Temperatura de deflexão térmica $\left({ }^{\circ} \mathrm{C}\right)$ - das amostras de $15 \% \mathrm{WF}+\mathrm{TiBa} / \mathrm{PP}$ irradiadas e não irradiadas.

Tabela 57 - Temperatura de deflexão térmica $\left({ }^{\circ} \mathrm{C}\right)$ - das amostras de $15 \% \mathrm{WF}+\mathrm{TiBa}+\mathrm{TPDGA} / \mathrm{PP}$ irradiadas e não irradiadas. 94

Tabela 58 - Porcentagem dos resultados do ensaio de HDT para as diferentes composições com 15\%WF submetidas a diferentes doses de radiação em relação ao PP (puro) não irradiado.

Tabela 59 - Temperatura de deflexão térmica $\left({ }^{\circ} \mathrm{C}\right)$ das amostras de 20\%WF/PP irradiadas e não irradiadas.

Tabela 60 - Temperatura de deflexão térmica $\left({ }^{\circ} \mathrm{C}\right)$ das amostras de $20 \% \mathrm{WF}+\mathrm{TiBa} / \mathrm{PP}$ irradiadas e não irradiadas. 96

Tabela 61 - Temperatura de deflexão térmica $\left({ }^{\circ} \mathrm{C}\right)$ das amostras de $20 \% \mathrm{WF}+\mathrm{TiBa}+\mathrm{TPDGA} / \mathrm{PP}$ irradiadas e não irradiadas 96

Tabela 62 - Porcentagem dos resultados do ensaio de HDT para as diferentes composições com $20 \%$ WF submetidas a diferentes doses de radiação em relação ao PP (puro) não irradiado.

Tabela 63 - Temperatura de Amolecimento Vicat $\left({ }^{\circ} \mathrm{C}\right)$ das amostras de PP (puro) em amostras irradiadas e não irradiadas .

Tabela 64 - Temperatura de amolecimento Vicat $\left({ }^{\circ} \mathrm{C}\right)$ das amostras de 10\%WF/PP irradiadas e não irradiadas.

Tabela 65 - Temperatura de amolecimento Vicat $\left({ }^{\circ} \mathrm{C}\right)$ das amostras de $10 \% \mathrm{WF}+\mathrm{TiBa} / \mathrm{PP}$ irradiadas e não irradiadas.

Tabela 66 - Temperatura de amolecimento Vicat $\left({ }^{\circ} \mathrm{C}\right)$ das amostras de $10 \% \mathrm{WF}+\mathrm{TiBa}+\mathrm{TPDGA} / \mathrm{PP}$ irradiadas e não irradiadas 
Tabela 67 -. Porcentagem de decréscimo da temperatura de amolecimento Vicat para as diferentes composições com $10 \%$ WF submetidas a diferentes doses de radiação em relação ao PP (puro) não irradiado.

Tabela 68 - Temperatura de amolecimento Vicat $\left({ }^{\circ} \mathrm{C}\right)$ das amostras de 15\%WF/PP irradiadas e não irradiadas. 103

Tabela 69 - Temperatura de amolecimento Vicat $\left({ }^{\circ} \mathrm{C}\right)$ das amostras de $15 \% \mathrm{WF}+\mathrm{TiBa} / \mathrm{PP}$ irradiadas e não irradiadas. 103

Tabela 70 - Temperatura de amolecimento Vicat $\left({ }^{\circ} \mathrm{C}\right)$ das amostras de $15 \% \mathrm{WF}+\mathrm{TiBa}+\mathrm{TPDGA} / \mathrm{PP}$ irradiadas e não irradiadas 103

Tabela 71 -. Porcentagem de decréscimo da temperatura de amolecimento Vicat para as diferentes composições com $15 \%$ WF submetidas a diferentes doses de radiação em relação ao PP (puro) não irradiado. 105

Tabela 72 - Temperatura de amolecimento Vicat $\left({ }^{\circ} \mathrm{C}\right)$ das amostras de 20\%WF/PP irradiadas e não irradiadas. 105

Tabela 73 - Temperatura de amolecimento Vicat $\left({ }^{\circ} \mathrm{C}\right)$ das amostras de $20 \% \mathrm{WF}+\mathrm{TiBa} / \mathrm{PP}$ irradiadas e não irradiadas. 105

Tabela 74 - Temperatura de amolecimento Vicat $\left({ }^{\circ} \mathrm{C}\right)$ das amostras de $20 \% \mathrm{WF}+\mathrm{TiBa}+\mathrm{TPDGA} / \mathrm{PP}$ irradiadas e não irradiadas. 106

Tabela 75 -. Porcentagem de decréscimo da temperatura de amolecimento Vicat para as diferentes composições com $20 \%$ WF submetidas a diferentes doses de radiação em relação ao PP (puro) não irradiado. 107 


\section{LISTA DE FIGURAS}

Figura 1 - Mecanismo de produção de ligações cruzadas em polímeros: Reticulação...........6

Figura 2 - Gráfico do módulo de elasticidade versus fração volumétrica da carga.............. 12

Figura 3 - Unidade estrutural do polipropileno …........................................................ 17

Figura 4 - Formas diferentes de estéreo-isômeros do polipropileno (a), (b) e (c). ............. 18

Figuras 5a, 5b, 5c, 5d e 5e - Ilustrações de aplicações do compósito em decks, em corrimão e em guarda corpo.

Figuras 6a, 6b, 6c, 6d e 6e - Ilustrações de outras aplicações do compósito em decks, em corrimão e em guarda corpo

Figura 7 - Perfis diversos 29

Figura 8 - Revestimento e "siding". 29

Figuras 9a, 9b - Perfis de acabamento como rodapés e batentes de portas. 29

Figura 10a, 10b- Chapas e perfis. 30

Figuras 11a, 11b - Pallets fabricados pela empresa Ecoblock. 30

Figuras 12a, 12b - Marcos de porta e forros fabricados pela empresa Ecoblock. 30

Figuras 13a, 13b -Bancos fabricados pela empresa Ecoblock. 31

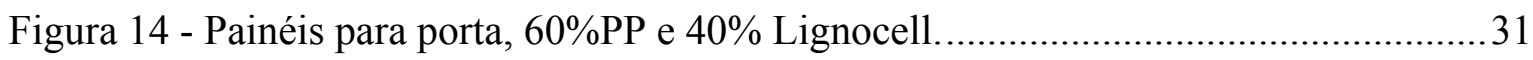

Figura 15 - Mercado dos compósitos polímero/madeira nos EUA. .................................... 32

Figura 16 - Distribuição do mercado dos compósitos polímero/madeira nos EUA.............32

Figura 17 - Previsão da demanda dos compósitos polímero/madeira na América do Norte.

Figura 18 - Distribuição do mercado dos compósitos polímero/madeira na Europa............33

Figura 19 - Previsão da demanda dos compósitos polímero/madeira na Europa. ................33

Figura 20 - Comparação entre a madeira e as fibras naturais na Europa e nos EUA...........34

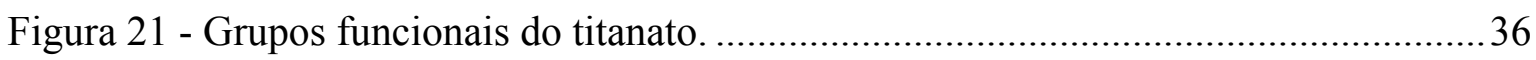

Figura 22- Fórmula geral dos agentes de acoplagem titanato e reação de tratamento superficial.

Figura 23 - Efeito da dispersão do agente de acoplagem no aglomerado inorgânico com o

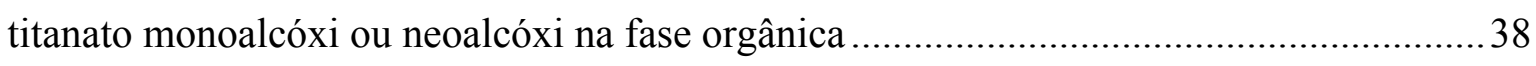

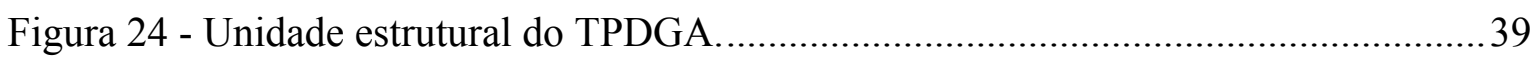

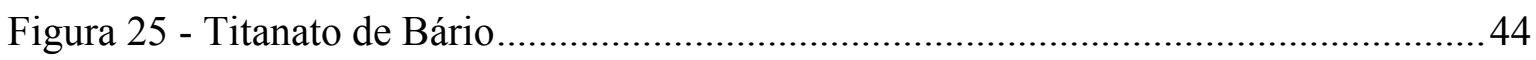

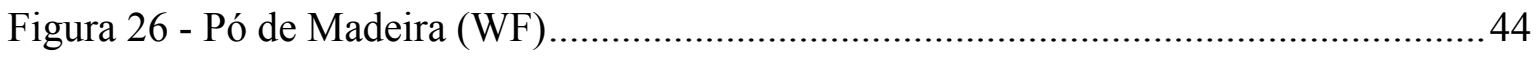


Figura 27 - Polipropileno (PP).

Figura 28 - Compósito WF/PP.

Figura 29 - Calandra, modelo C 400-3 da Universidade Presbiteriana Mackenzie............. 46

Figura 30 - Injetora modelo Primax 65R da Universidade Presbiteriana Mackenzie. …....47

Figura 31 - Acelerador de elétrons do CTR-IPEN, Dynamitron JOB 188 ........................48

Figura 32 - Extrusion Plastometer da Universidade Mackenzie.........................................50

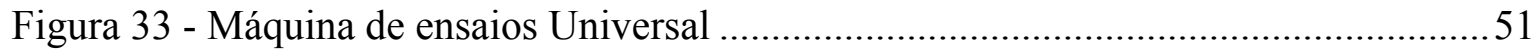

Figura 34 - Máquina de ensaios de impacto Charpy, modelo 892 da Universidade Mackenzie. 53

Figura 35 - Durômetro Analógico Pacifc Transducer Corp. 2301. 54

Figura 36 - Equipamento utilizado para o ensaios de temperatura de deflexão ao calor e ponto de amolecimento Vicat. 55

Figura 37 - Índice de fluidez para as diferentes composições de PP estudadas. 59

Figura 38 - Resultados do ensaio de resistência à tração das amostras de PP irradiadas e não irradiadas.

Figura 39 - Resistência à tração das amostras das de PP (puro) e de diferentes composições de PP com 10\%WF irradiadas e não irradiadas.

Figura 40 - Resistência à tração das amostras de PP (puro) e de diferentes composições de PP com 15\%WF irradiadas e não irradiadas.

Figura 41 - Resistência à tração das amostras de PP (puro) e de diferentes composições de PP com 20\%WF irradiadas e não irradiadas em relação ao PP.

Figura 42 - Resistência ao impacto das amostras de PP irradiadas e não irradiadas. .72 Figura 43 - Resistência ao impacto das amostras de PP (puro) e de diferentes composições de PP com 10\%WF irradiadas e não irradiadas.

Figura 44 - Resistência ao impacto das amostras de PP (puro) e de diferentes composições de PP com 15\%WF irradiadas e não irradiadas.

Figura 45 - Resistência ao impacto das amostras de PP (puro) e de diferentes composições de PP com $20 \%$ WF irradiadas e não irradiadas.

Figura 46 - Dureza das amostras de PP irradiadas e não irradiadas. 82

Figura 47 - Dureza das amostras de PP (puro) e de diferentes composições de PP com $10 \%$ WF irradiadas e não irradiadas.

Figura 48 - Dureza das amostras de PP (puro) e de diferentes composições de 15\%WF irradiadas e não irradiadas. 86

Figura 49 - Dureza das amostras de PP (puro) e de diferentes composições de PP com .... 88 
$20 \% \mathrm{WF}$ irradiadas e não irradiadas.

Figura 50 - Temperatura de deflexão térmica - HDT das amostras de PP (puro) irradiadas e não irradiadas.

Figura 51 - Temperatura de deflexão térmica das amostras de PP (puro) e de diferentes composições de PP com 10\%WF irradiadas e não irradiadas.

Figura 52 - Temperatura de deflexão térmica das amostras de PP (puro) e de diferentes composições de PP com 15\%WF irradiadas e não irradiadas. 95

Figura 53 - Temperatura de deflexão térmica das amostras de PP (puro) e de diferentes composições de PP com 20\%WF irradiadas e não irradiadas.

Figura 54 - Temperatura de amolecimento Vicat das amostras de PP irradiadas e não irradiadas.

Figura 55 - Temperatura de amolecimento Vicat das amostras de PP (puro) e de diferentes composições de PP com 10\%WF irradiadas e não irradiadas. 102

Figura 56 - Temperatura de amolecimento Vicat das amostras de PP (puro) e de diferentes composições de PP com 15\%WF irradiadas e não irradiadas. 104

Figura 57 - Temperatura de amolecimento Vicat das amostras de PP (puro) e de diferentes composições de PP com 20\%WF irradiadas e não irradiadas. 106 


\section{LISTA DE ABREVIAÇÕES}

WPC's - (Wood-plastic-composites) - Polímero com fibras de madeira

MDF - (Medium-density-fiberboard) - Painéis com resina termofixa

PP - Polipropileno

WF - (Wood-Flour) Pó de madeira

TiBa - Titanato de Bario

TPDGA - Diacrilato de Tripropileno Glicol

PEAD - Polietileno de alta densidade

$\mathrm{P}_{\mathrm{rf}}$ - Propriedades reforçantes do plástico reforçado

$\mathrm{P}_{\mathrm{f}}$ - Propriedades do material de reforço

$\mathrm{V}_{\mathrm{f}}$ - Fração volumétrica do reforço no compósito

$\mathrm{P}_{\mathrm{r}}$ - Propriedade do plástico sem reforço

$\mathrm{Al}\left(\mathrm{C}_{2} \mathrm{H}_{5}\right)_{3}$ - Trietil de alumínio

$\mathrm{TiCl}_{4}$ - Tetracloreto de titânio 


\section{INTRODUÇÃO}

Investimentos na síntese de novos polímeros demandam em altos custos financeiros. Assim a busca de novos materiais com custo baixo, bom desempenho e facilidade de operação, proporcionam condições para o investimento e o surgimento de técnicas para modificação de polímeros. A adição de cargas e reforços tem como objetivo obter compostos com melhores propriedades em relação à resina pura, constituindo de uma alternativa vantajosa comparado a outros processos como a copolimerização ou o desenvolvimento de novos polímeros (GARCIA, 1999).

A radiação também pode ser utilizada como alternativa no desenvolvimento de novos polímeros. A radiação ionizante é um processo capaz de modificar as propriedades de um material, sendo este um processo limpo uma vez que não se utiliza de reagentes químicos (ALBANO et al., 2001).

Os produtos "wood-plastic composites" (WPC's) são materiais que aliam um polímero termoplástico ou termofixo e um reforço orgânico que pode ser fibra ou farinha de madeira (CLEMONS, 2002). Estes compósitos ficaram conhecidos no mercado primeiramente pelos painéis de MDF ("medium-density-fiberboard”) que são constituídos de madeira e resina termofixa (CORREA et al., 2003).

O conhecimento da utilização de compósitos com carga orgânica de celulose teve início a partir da década de 70 pela indústria automobilística, os chamados "Woodstock", eram compósitos de polipropileno (PP) com farinha de madeira (WF) extrusados e laminados em chapas para revestimento interno de porta-malas de veículos (CLEMONS, 2002).

$\mathrm{Na}$ década de 90 surgiram inúmeros trabalhos acadêmicos nessa área e várias patentes foram desenvolvidas especialmente na área de construção civil e automobilística. No Brasil ainda não se observa interesse em empregar essa tecnologia, podendo ser o motivo desse desinteresse a falta de informações técnicas sobre esses materiais e processos, a falta de local de fornecimento de matéria-prima de qualidade, equipamento específico e desenvolvimento de mercado para atender a demanda (CORREA et al., 2003). 
É possível apresentar inúmeras vantagens para o compósito madeira-polímero entre as quais leveza, versatilidade, resistência à umidade e deterioração ambiental, resistência a pragas e insetos e o fato de poderem ser extrusados em perfis com formatos diversos. Também, apresentam melhor estabilidade dimensional, resistência a trincas, possui menor custo de manutenção, maior durabilidade em ambientes agressivos como marinas e piscinas, imitam o aspecto de madeira, dispensam o uso de proteção superficial como tintas e vernizes e são recicláveis (CORREA et al., 2003).

É comum utilizar aditivos em resinas poliméricas e também são utilizados em WPC's, estes materiais são adicionados em pequenas quantidades para aumento das propriedades (RABELLO, 2000). Nesta dissertação foi utilizado o agente de acoplagem titanato de bário (TiBa) e o aditivo diacrilato de tripropileno glicol (TPDGA).

$\mathrm{O}$ agente de acoplagem titanato de bário foi empregado com a função de proporcionar melhor interação entre o pó de madeira e a matriz polimérica. Sua estrutura permite que ligações químicas ocorram entre as duas interfaces, carga e matriz polimérica melhorando a adesão entre elas (ULLOA \& MAIORINO, 2003; GARCIA, 1999).

O TPDGA é um monômero usado como radical livre na polimerização. Foi incorporado ao compósito pó de madeira/polipropileno (WF/PP) com a função de auxiliar na interface matriz/carga principalmente após a radiação ionizante (CZVIKOVSZKY, 1996).

Foi também na década de 70 que surgiram as primeiras publicações com radiação ionizante em compósitos de madeira-polímero, apresentando resultados positivos. (WITT, 1977).

As modificações físico-químicas proporcionadas pela radiação completam este estudo que busca a melhoria das propriedades num compósito que aproveita resíduos celulósicos como reforço em polipropileno.

Dessa maneira o objetivo principal do presente trabalho foi estudar a influência da radiação ionizante nas propriedades do compósito de WF/PP usando titanato de bário como agente de acoplagem e também utilizando o monômero TPDGA.

Assim sendo estudou-se as propriedades por meio de ensaios mecânicos, térmicos e morfológicos de amostras de PP "virgem", WF/PP, WF/PP+TiBa, $\mathrm{WF} / \mathrm{PP}+\mathrm{TiBa}+\mathrm{TPDGA}$ não irradiados e destes compósitos irradiados utilizando como fonte de radiação o acelerador de elétrons. 


\section{INTERAÇÃO DA RADIAÇÃO IONIZANTE COM A MATÉRIA}

A radiação de energia alta pode provocar três efeitos principais quando interage com a matéria: mudança na estrutura nuclear com a criação de novos isótopos ou elementos, ou mudanças químicas como distúrbios da estrutura eletrônica, levando à ionização, excitação e captura de elétrons (CONCISE ENCYCLOPEDIA OF POLYMER PROCESSING AND APLICATION, 1992; SPINKS \& WOODS, 1990).

Em se tratando de processamento de polímeros o mais importante é o último grupo.

A radiação de energia alta ou ionizante inclui a eletromagnética como raios $\mathrm{X}$ e raios $\gamma$ e partículas como: partículas alfa $(\alpha)$, partículas beta $(\beta)$, elétrons, prótons $(p)$, nêutrons (n) e fragmentos de fissão. A principal característica da radiação de energia alta é causar ionização.

A ionização é a transferência de energia pela radiação ionizante à molécula, sendo suficiente para arrancar um elétron de seu orbital. Esta energia é maior que a energia de excitação, que é a necessária para passar um elétron de seu orbital de menor energia para um estado de maior energia (O’DONNELL \& SANGSTER, 1970).

A absorção de energia proveniente da radiação ionizante produzida por um feixe de elétrons ocorre devido às interações da radiação com a nuvem eletrônica do meio. Se os elétrons do feixe não tiverem energia suficiente, não atingem o núcleo, interagindo somente com a eletrosfera do átomo. Nesse caso a nuvem eletrônica age como uma proteção (blindagem), impedindo a aproximação dos elétrons junto ao núcleo (MIRANDA, 1999; EISENBERG \& RESNICK, 1988).

\subsection{INTERAÇÃO DA RADIAÇÃO IONIZANTE EM MATERIAIS POLIMÉRICOS}

A interação da radiação ionizante com a matéria promove eventos físicos, físico-químicos e químicos. No evento físico há transferência de energia produzindo excitações e ionizações. Espécies instáveis sofrem reações secundárias tanto 
espontaneamente como por colisão com moléculas vizinhas. No evento físico-químico existe a formação de espécies secundárias reativas como os radicais livres e no evento químico o sistema restabelece o equilíbrio térmico. As espécies continuam a reagir entre si ou com outras espécies.

O estudo feito sobre a radiação em polímeros concentra-se nas reações posteriores à formação de radicais livres que se formam quando existe a absorção da radiação ionizante. As modificações causadas pela radiação ionizante em polímeros são de grande interesse, no entanto estas alterações dependem das condições do processo, ou seja, do tipo de radiação, presença de oxigênio ou diferentes atmosferas, solventes, grau de cristalinidade e homogeneidade do material polimérico que irá absorver a energia, entre outras (LANDI, 2003; SPINKS \& WOODS, 1990; O’DONNELL \& SANGSTER, 1970).

Os principais efeitos causados em polímeros pela radiação ionizante são a cisão das ligações da cadeia principal (degradação) e a formação de ligações químicas entre moléculas poliméricas (reticulação) (O’DONNELL \& SANGSTER, 1970).

\subsubsection{Cisão da cadeia principal (degradação)}

Um dos processos que pode predominar quando a radiação ionizante interage com a cadeia polimérica é a cisão. Na cisão ocorre um rompimento aleatório das ligações químicas obtendo-se um polímero com menor massa molar. Há ainda a formação de gases e insaturação, com perda de suas propriedades mecânicas (FERRO, 2003).

O uso do símbolo G expressa o rendimento químico da radiação. Definiu-se G para um determinado sistema irradiado com rendimento químico absoluto expresso em função do número de eventos químicos individuais que ocorrem por $100 \mathrm{eV}$ de energia absorvida. Assim o grau de cisão molecular $\left(\mathrm{G}_{\text {cisão }}\right)$ é um número de cisões por $100 \mathrm{eV}$ de energia absorvida e pode ser determinado por diversas técnicas, tais como espalhamento de luz cromatográfica de permeação em gel e viscosidade de soluções diluída (O’DONNELL \& SANGSTER, 1970; SPINKS \& WOODS, 1990). 


\subsubsection{Reticulação da cadeia principal}

Este processo ocorre pela recombinação entre radicais formando redes tridimensionais do polímero irradiado. Na ligação cruzada as cadeias poliméricas se conectam por meio de ligações covalentes geradas por ligações químicas ou por radiação.

$\mathrm{Na}$ reticulação, existe um aumento, da massa molar, da resistência mecânica, das redes tridimensionais do sistema, da viscosidade e a diminuição da solubilidade do polímero irradiado e alteração na temperatura da transição vítrea da fase amorfa do polímero irradiado. Este mecanismo também depende da dose, taxa de dose, concentração, atmosfera de irradiação entre outros. Porém, a sensibilidade do polímero às mudanças de parâmetros depende do tipo e do tamanho das cadeias como também da morfologia do polímero (LANDI, 2003; O’DONNELL \& SANGSTER, 1970).

O número de reticulações é sempre acompanhado por um número de cisões, assim para determinar o número de reticulações $\left(G_{\text {reticulação número de reticulações por }}\right.$ $100 \mathrm{eV}$ de energia absorvida) da cadeia principal, utiliza-se o método de fração em gel na qual consiste da extração da fração solúvel que permite determinar a fração do polímero ou compósito que sofreu reticulação.

Na Figura 1 é mostrado o mecanismo de produção de ligações cruzadas via radicais livres.

a) Produção de radicais livres:

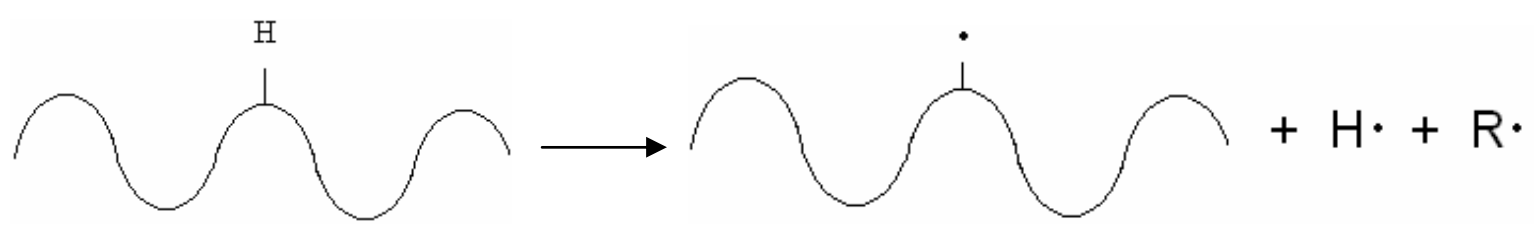

ou

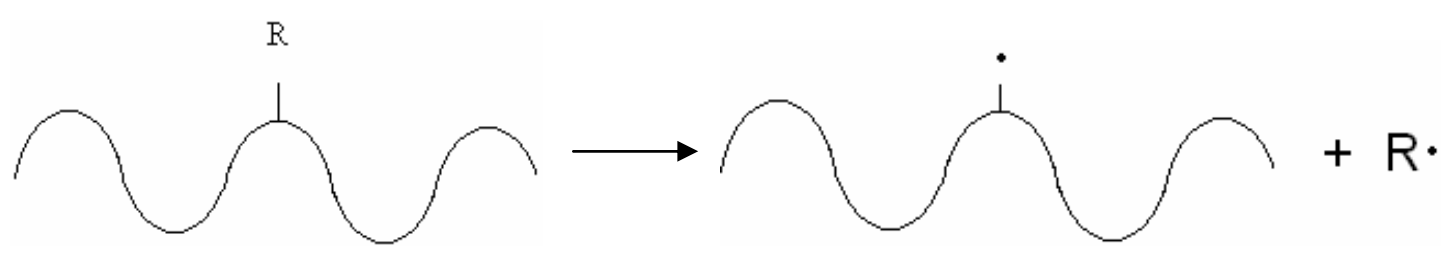


b) Produção de ligações cruzadas:
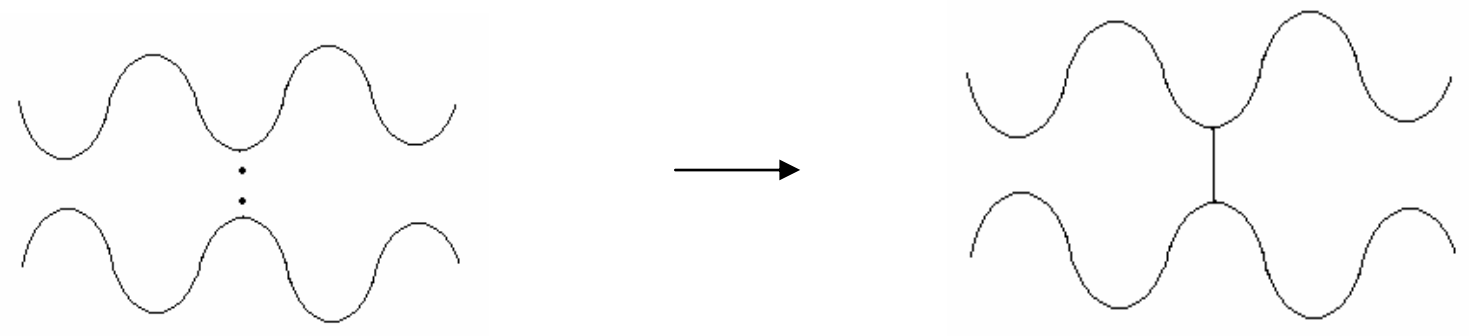

Figura 1 - Mecanismo de produção de ligações cruzadas em polímeros: Reticulação.

\subsection{ACELERADORES DE ELÉTRONS}

Neste trabalho foi utilizada como radiação ionizante a radiação proveniente de elétrons de energia alta (elétrons acelerados), denominados feixe de elétrons (“electron beam"), provenientes de acelerador de elétrons.

Os aceleradores industriais de elétrons são classificados como aceleradores de baixa, média e alta energia de acordo com a intensidade do feixe produzido.

Os principais componentes e subsistemas de um acelerador de elétrons são: fonte de alta tensão, tubo acelerador a vácuo, canhão de elétrons, sistema de rádio freqüência, câmara de irradiação, painel de controle, sistema de segurança, blindagem.

Os principais tipos de aceleradores de elétrons de baixa energia utilizados industrialmente são do tipo cortina ou varredura. Para energias de até $300 \mathrm{keV}$, os elétrons emitidos por um filamento longo (cátodo) são mantidos confinados em uma região do espaço, de forma a se obter uma cortina.

Em outro tipo de acelerador, os elétrons produzidos em uma fonte pontual, são focalizados e acelerados com um gradiente de potencial no centro de um tubo, formando assim um feixe cilíndrico de elétrons, que pode ser movimentado por um campo magnético produzido por uma bobina que envolve o tubo acelerador. Pode-se então obter uma varredura sobre a superfície de irradiação. 
Os principais tipos de aceleradores de elétrons disponíveis comercialmente são: acelerador de Van der Graaff: tem baixa potência, entre $0,4 \mathrm{MeV}$ e $4,0 \mathrm{MeV}$, com corrente de $1,0 \mathrm{~mA}$, aceleradores com transformador de núcleo isolado ("insulating core transformer"): operam até $0,5 \mathrm{MeV}$ com correntes altas, da ordem de centenas de $\mathrm{mA}$; aceleradores lineares por microondas (LINACS): possuem voltagem e potência elevadas, entre $10 \mathrm{~kW}$ e $100 \mathrm{~kW}$, aceleradores tipo Dynamitron: seguem o princípio dos aceleradores Cockcroft-Woltan (1,0MeV - 100mA; $1,5 \mathrm{MeV}-70 \mathrm{~mA} ; 3,0 \mathrm{MeV}-50 \mathrm{~mA} ; 4,5 \mathrm{MeV}$ $34 \mathrm{~mA}$ ), são apropriados para aplicações industriais e oferecem um custo por $\mathrm{kW}$ relativamente baixo.

\subsubsection{Princípio de funcionamento}

O acelerador de elétrons que usa a energia elétrica para gerar elétrons é composto de um filamento de tungstênio que ao ser aquecido fornece os elétrons. Este filamento que corresponde ao cátodo aquecido é mantido em uma região de potencial mais elevado. Estes elétrons são então acelerados por uma diferença de potencial aplicada entre o cátodo e o ânodo. $\mathrm{O}$ acelerador os focaliza na forma de um feixe linear, por campos magnéticos e são acelerados quase à velocidade da luz por meio de diferença de potencial. Assim os elétrons adquirem energia suficiente para atravessar a janela de saída que, em geral, é constituída de uma folha fina de titânio com espessura entre $20 \mu \mathrm{m}$ a $40 \mu \mathrm{m}$. Toda a região de aceleração dos elétrons deve ser mantida em alto vácuo (FERRO, 2003; SINGH \& SILVERMAN, 1992).

Os aceleradores de elétrons devem ser blindados para barrar a passagem dos raios $\mathrm{X}$ gerados pelo freamento dos elétrons ao penetrarem na matéria.

\subsubsection{Vantagens e desvantagens}

As principais vantagens dos aceleradores de elétrons são: taxas de doses altas, tempo de irradiação curto, intensidade de radiação alta, condução do material a ser exposto mais facilitado, maior rendimento da energia, licenciamento similar ao raio $\mathrm{X}$, sistema liga-desliga cessa emissão, menor tempo de irradiação - elevada taxa de dose da ordem de $\mathrm{kGy} / \mathrm{s}$. 
As principais desvantagens dos aceleradores de elétrons: necessita de operadores especializados, custo do equipamento, manutenção, baixo poder de penetração (irradiação de material com baixa espessura) (YAMASAKI, 1997).

\subsection{APLICAÇÃO DA RADIAÇÃO IONIZANTE EM COMPÓSITOS}

A aplicação da radiação ionizante em compósitos vem sendo desenvolvida recentemente. Os primeiros trabalhos encontrados envolvem resinas epóxi e vários tipos de fibras como de carbono ou poliamidas aromáticas. Iniciadores eram adicionados para facilitar a reticulação pela cura. Os materiais desenvolvidos tinham como objetivo aplicações no espaço aéreo, em grandes navios, outras aplicações incluem também a área automobilística.

Existem inúmeras vantagens ao utilizar a radiação ionizante que tenha como fonte de radiação feixe de elétrons. A cura a temperatura ambiente controla as dimensões e elimina o "stress" interno, o tempo de cura é curto e a resina é mais estável tornando mais durável. Além de vantagens ambientais pois a emissão de voláteis é muito baixa (CLOUGH, 2001).

\subsubsection{Aplicação da radiação ionizante em WPCs}

A radiação vem sendo aplicada para uma grande variedade de produtos naturais de baixo valor comercial a fim de acrescentar valor melhorando suas propriedades. Madeira, celulose, amido, algodão, lã e muitos outros têm sido utilizados para esses fins.

No caso dos compósitos madeira-polímero os primeiros trabalhos publicados desenvolviam pesquisas utilizando madeira impregnada utilizando monômeros, acrilatos estirenos, acetato vinílicos e subseqüentemente eram irradiados utilizando a radiação gama ou por feixe de elétrons. Estes produtos tinham boas propriedades como aumento da dureza, resistência mecânica, resistência a ruptura, resistência a umidade e a biodegradação. No mercado aparecem nos produtos como pisos poliméricos reforçados com fibras e painéis (CLOUGH, 2001). 


\section{COMPÓSITOS}

Um compósito polimérico é definido como uma combinação de dois ou mais materiais, cada qual permanecendo com suas características individuais em uma estrutura bifásica: uma fase contínua ou matriz representada pelo polímero e, a fase dispersa representada pelas cargas, reforçantes ou não (MASSON, 1998; CALLISTER, 2002).

Os componentes de um compósito determinam funções específicas, por exemplo, as fibras, não podem ser empregadas isoladamente, pois precisam de um meio para segurá-las. A matriz é a superfície final, determinando propriedades como resistência a agentes químicos, comportamento térmico e elétrico, aparência superficial e, a capacidade de transferência das tensões externas para a fase dispersa (DEKKER, 1992; PFAENDNER, 2001).

Em geral as cargas inertes alteram propriedades dos polímeros como exemplos maior estabilidade dimensional, menor retração de moldagem, menor dependência das propriedades com a temperatura, acabamento superficial inferior, menor resistência à tração, maior rigidez, maior dureza, maior densidade, maior HDT, menor fluência, menor custo. Já as cargas reforçantes que apresentam um custo superior, melhoram a resistência à tração e no caso das fibras tornam o produto anisotrópico (RABELLO, 2000).

As propriedades do compósito vão depender basicamente dos seguintes fatores: propriedade dos componentes individuais e composição, grau de iteração entre as fases, razão de aspecto e porosidade da carga e grau de mistura entre os componentes (RABELLO, 2000; ULLOA \& MAIORINO, 2003).

\subsection{CARGA}

Cargas são materiais sólidos, não solúveis, que são adicionados aos polímeros em quantidades suficientes para diminuir os custos ou alterar suas propriedades físicas. Para reduzir os custos de fabricação, em meio à crise do petróleo, na década de 60 e 70 iniciou-se a utilização de cargas minerais. No início, estas cargas foram usadas como enchimento, pois tinham baixo custo e viabilização econômica como aditivos de plásticos e 
borrachas, porém a necessidade despertou o interesse pelo uso técnico das cargas que passaram a alterar as propriedades dos materiais onde eram empregadas (RABELLO, 2000; MASSON, 1998).

As cargas minerais reforçantes proporcionam aumento na rigidez, dureza e algumas vezes o aumento na temperatura de deflexão térmica. As fibras, pela sua característica unidirecional, incrementam acentuadamente a maioria das propriedades mecânicas em determinadas direções.

Em termos práticos a diferenciação entre um material fibroso e um particulado é dada pela razão de aspecto ( $1 / \mathrm{d}$, em que 1 é o comprimento e d é o diâmetro).

1/d: razão de aspecto

$1 / \mathrm{d} \leq 1 \Rightarrow$ material particulado

$1 / \mathrm{d}>1 \Rightarrow$ material fibroso

As cargas podem ser classificadas de acordo com sua forma física. Tanto o material particulado quanto o material fibroso conferem à matriz polimérica propriedades mecânicas superiores às do material polimérico sem reforço. São vários os tipos de reforços e compreendem materiais orgânicos e inorgânicos.

\subsubsection{Carga fibrosa}

Possui uma elevada razão de aspecto (relação entre a maior e a menor dimensão de um corpo $=1 / \mathrm{d})$.

\subsubsection{Carga não fibrosa ou particulada}

A carga pode ser na forma de escamas ou de partículas mais ou menos anisométricas.

As fibras podem ser contínuas $(1 / \mathrm{d} \rightarrow \infty)$ ou curtas $(1 / \mathrm{d}<100)$. Ambos os reforços são envolvidos por uma matriz polimérica contínua. Os reforços particulados 
proporcionam reforços isotrópicos enquanto que os reforços fibrosos e laminados favorecem a reforços anisotrópicos.

As cargas podem ser todo o material sólido não solúvel no polímero, independente da forma e função que exerce podendo ser orgânica ou inorgânica, de origem natural ou sintética (RABELLO, 2000; MASSON, 1998).

\subsection{PROPRIEDADES DOS COMPÓSITOS INDIVIDUAIS E COMPOSIÇÃO}

O objetivo ao se adicionar uma carga ao polímero é obter propriedades intermediárias dos dois componentes, ou seja, uma mistura em que a propriedade $\mathrm{P}$ é dada por:

$$
\mathbf{P}=\mathbf{P}_{\mathrm{a}} \cdot \mathbf{V}_{\mathrm{a}}+\mathbf{P}_{\mathrm{b}} \cdot \mathbf{V}_{\mathrm{b}} \quad \text { limite superior }
$$

Em que, os índices a e b referem-se aos dois componentes e $\mathrm{V}$ é a fração volumétrica. Esta equação é verificada onde a adesão é perfeita. Em casos onde isso não ocorre à equação é a seguinte:

$$
\mathbf{P}=\frac{\mathbf{P}_{\mathbf{a}} \cdot \mathbf{P}_{\mathrm{b}}}{\mathbf{P}_{\mathbf{a}} \cdot \mathbf{V}_{\mathbf{a}}+\mathbf{P}_{\mathrm{b}} \cdot \mathbf{V}_{\mathrm{b}}}
$$

limite inferior

Sendo assim pela regra da mistura para um compósito pode ser considerada a equação 3:

$$
P_{r f}=P_{f} \cdot V_{f}+P_{r} \cdot\left(1-V_{f}\right)
$$

Em que:

$\mathrm{P}_{\mathrm{rf}}=$ propriedades reforçantes do plástico reforçado

$\mathrm{P}_{\mathrm{f}}=$ propriedades do material de reforço

$\mathrm{V}_{\mathrm{f}}=$ Fração volumétrica do reforço no compósito

$\mathrm{P}_{\mathrm{r}}=$ propriedade do plástico sem reforço 
Na Figura 2 são mostradas as curvas com os limites superior e inferior do módulo de elasticidade versus fração volumétrica da carga. O compósito deve se localizar entre os limites superior, equação 1 e limite inferior, equação 2.

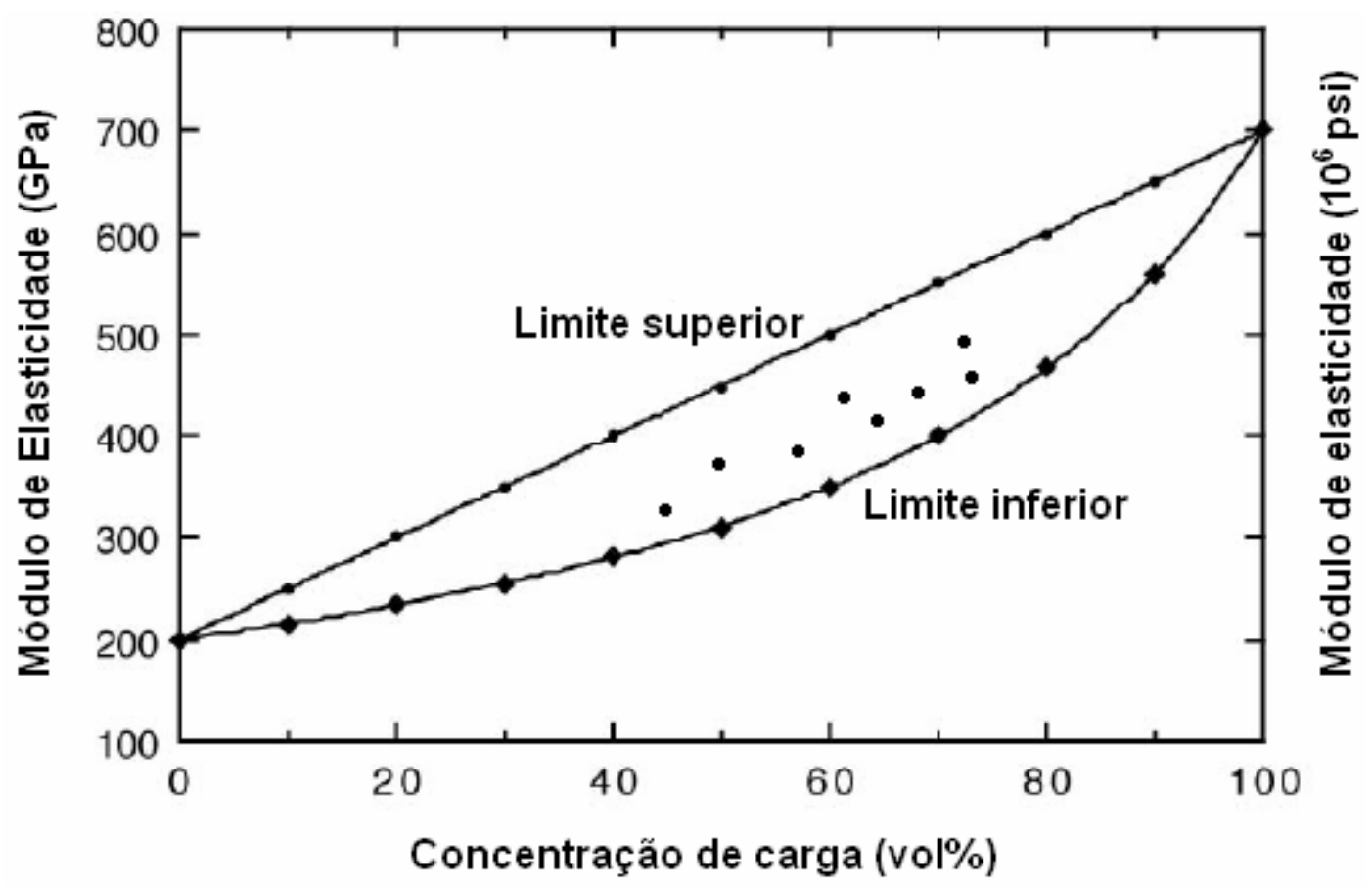

Figura 2 - Gráfico do módulo de elasticidade versus fração volumétrica da carga.

Existem muitos outros modelos além destes que envolvem fatores empíricos como o nível de adesão entre os componentes, a razão de aspecto ou o tamanho da partícula (ULLOA \&MAIORINO, 2003; RABELLO, 2000).

\subsection{GRAU DE INTERAÇÃO ENTRE AS FASES}

O grau de adesão entre as fases pode ser qualitativamente avaliado num compósito moldado pelos ensaios mecânicos. Se esta for superior à do polímero puro, significa que a matriz plástica transferiu parte das tensões para a parte dispersa (assumindo que este seja mais resistente que o polímero). Esta transferência ocorre pela interface que é a região de contato entre o polímero e a carga, é resultado da deformação elástica longitudinal entre a carga e a matriz e do contato por fricção entre os componentes. Existe um valor máximo de tensão de cisalhamento que pode ser transferido ao reforço, que 
depende de efeitos de fricção (MANO 1991; ULLOA \& MAIORINO, 2003; RABELLO, 2000).

Desse modo as propriedades mecânicas vão depender de uma boa adesão. A adesão está relacionada com as propriedades químicas das cargas, bem como as conformações moleculares e a constituição química da matriz. Caso não seja perfeita surgirão vazios na interface que provocarão a fragilização do material, observando-se uma superfície fraturada. Pela microscopia eletrônica de varredura é possível verificar a adesão de um compósito. Entre os constituintes de um compósito, os mecanismos de adesão são:

\subsubsection{Adsorção e molhamento}

Um molhamento eficiente da carga pelo polímero remove o ar incluso e cobre todas as protuberâncias. Esse mecanismo depende das tensões superficiais entre os constituintes em cargas hidrofílicas, a água na superfície da carga, impossibilita o molhamento, ou seja, a carga não pode estar úmida. A adsorção e molhamento também influem no arranjo das macromoléculas, alterando a temperatura vítrea e na cristalização atuando como nucleantes heterogêneos (ULLOA \& MAIORINO, 2003; RABELLO, 2000).

\subsubsection{Interdifusão}

É possível formar uma ligação entre duas superfícies poliméricas pela difusão nos compósitos isso ocorre quando as fibras são pré-cobertas com um polímero antes de serem incorporadas pela matriz. A resistência da ligação depende do grau de emaranhamento molecular gerado, que pode ser facilitado com o uso de solventes e plastificantes. 


\subsubsection{Atração eletrostática}

Ocorre quando duas superfícies possuem carga elétrica opostas, como na interação ácido-base e ligações iônicas. A resistência da ligação depende da densidade de cargas elétricas. Esta tem importância em alguns tipos de tratamentos superficiais da carga.

\subsubsection{Ligação química}

Ocorre quando se aplica agentes de acoplamento na superfície da carga, que servem de ponte entre o polímero e o reforço, como resultado de sua dupla funcionalidade. A resistência da interface depende do número e do tipo de ligações químicas presentes. É a forma mais significativa de adesão.

\subsubsection{Adesão mecânica}

É o resultado do preenchimento pelo polímero, nos entalhes da carga, que é na verdade rugosa, com cantos vivos, cavidades e outras irregularidades. A resistência desta ligação tende a ser baixa, a menos que haja um grande número de ângulos de reentrância na superfície da carga (ULLOA \& MAIORINO, 2003; RABELLO, 2000).

\subsubsection{Razão de aspecto e porosidade da carga}

Quanto maior a razão de aspecto mais eficiente é a distribuição de transferência de tensões, maior a probabilidade de a carga ser de reforço. A razão de aspecto depende da estrutura morfológica das partículas, a qual por sua vez, depende tanto da origem morfológica como do tipo de processo de cominuição. Assim sendo as cargas fibrosas seriam as mais eficientes, seguidas por escamas ou flocos e por último as partículas esféricas (ULLOA \& MAIORINO, 2003; RABELLO, 2000). 


\subsection{GRAU DE MISTURA ENTRE OS COMPONENTES}

Uma boa dispersão das partículas na matriz é uma das condições necessárias para se ter boas propriedades mecânicas do produto. Há uma tendência natural das cargas formarem agregados, impedindo o envolvimento completo pela matriz, o que gera concentração de tensões e conseqüente redução das propriedades mecânicas do material. A mistura deve ser realizada em equipamentos que promovam boa dispersão como extrusora de dupla rosca ou misturadores internos. Na etapa de mistura ocorre uma alteração na razão de aspecto de cargas fibrosas.

Três parâmetros são decisivos para um bom desempenho do material: a natureza da carga (se a carga é fibrosa ou particulada, orgânica ou inorgânica), se houver tratamentos superficiais na carga para melhorar a adesão entre carga e matriz e equipamento e condições de mistura (ULLOA \& MAIORINO, 2003; RABELLO, 2000). 


\section{POLIPROPILENO}

Desde a sua descoberta em 1954, o polipropileno se tornou uma das mais importantes resinas termoplásticas da atualidade, continuando ainda como a resina de maior crescimento.

\subsection{HISTÓRIA}

As primeiras tentativas de polimerizar o propileno usando processos de alta pressão deram origem a líquidos oleosos ou sólidos elásticos de pouco ou nenhum valor comercial. Este resultado era devido à formação de polímeros unicamente atáticos. No entanto, com a descoberta de catalisadores estereoespecíficos de polimerização, à base de cloreto de titânio e etil alumínio, foi possível obter polipropileno do tipo isotático, cristalinidade e de alta massa molar. Esses catalisadores são hoje denominados de catalisadores Ziegler-Natta.

Obteve esse nome pelos trabalhos realizados por Giulio Natta e Karl Ziegler. Giulio Nata na Itália em 1954, que pelo do processo estereoquímico desenvolveu a polimerização do polipropileno isotático. Essa forma de polipropileno tinha um nível de cristalinidade comparável ao polietileno de baixa densidade e exibindo boas propriedades mecânicas em uma larga faixa de temperaturas. Um processo similar foi usado por Karl Ziegler na Alemanha na polimerização de etileno. Esse processo emprega uma classe de catalisadores em geral um complexo organo-metálico de um cátion metálico dos grupos IIII da tabela periódica, como o trietil alumínio $\mathrm{Al}\left(\mathrm{C}_{2} \mathrm{H}_{5}\right)_{3}$, e um metal de transição dos grupos IV-VIII, como o tetracloreto de titânio $\left(\mathrm{TiCl}_{4}\right)$ (BNDES, 2007). 


\subsection{MATÉRIA-PRIMA}

A matéria-prima básica (monômero) é o propeno (ou propileno), que deve ter um alto nível de pureza (superior a 99,5\% e isento de água, oxigênio, dióxido de carbono, hidrogênio, enxofre e acetileno, que podem envenenar os catalisadores empregados).

A fonte predominante para a produção do propeno é o craqueamento da nafta, uma vez que o gás natural não apresenta vantagem competitiva. A desidrogenação do propano ou a recuperação do gás de refinaria são alternativas.

\subsection{ESTRUTURA DO POLIPROPILENO}

O polipropileno é linear, apolar produzido pela polimerização em cadeia do monômero em cadeia por meio de catalisadores específicos (SOARES, 1996).

O polipropileno possui um grupo metila, esse grupo restringe a rotação das cadeias originando um material mais resistente mecanicamente, mas menos flexível. Os grupos metila das cadeias também provocam um aumento da temperatura de transição vítrea, pelo que o propileno tem uma temperatura de amolecimento e uma temperatura de deflexão superior ao do polietileno. Com a utilização de catalisadores estereoespecíficos, sintetiza-se o polipropileno isotático, que tem uma temperatura de amolecimento no intervalo de 165 a $177^{\circ} \mathrm{C}$. Este material pode ser submetido a temperaturas de $120^{\circ} \mathrm{C} \mathrm{sem}$ se deformar.

A unidade estrutural do polipropileno é mostrada na Figura 3.

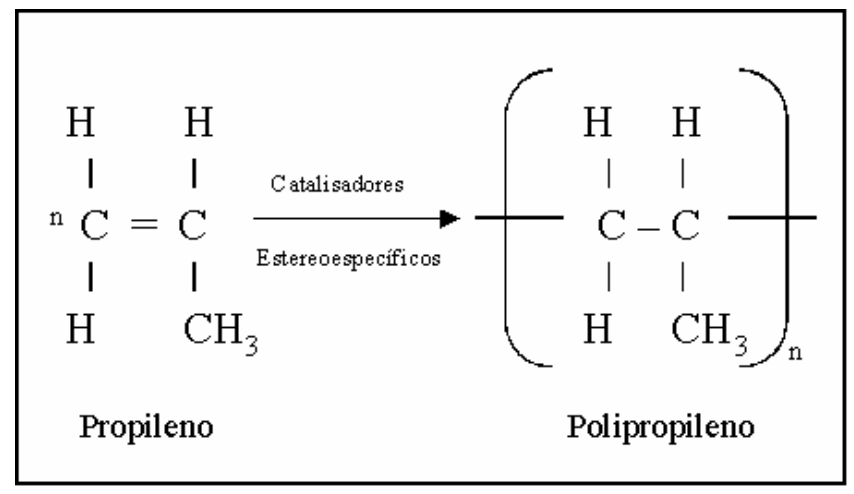

Figura 3 - Unidade estrutural do polipropileno

$\mathrm{Na}$ Figura 4 são mostradas as diferentes formas de estéreo-isômeros do polipropileno. 

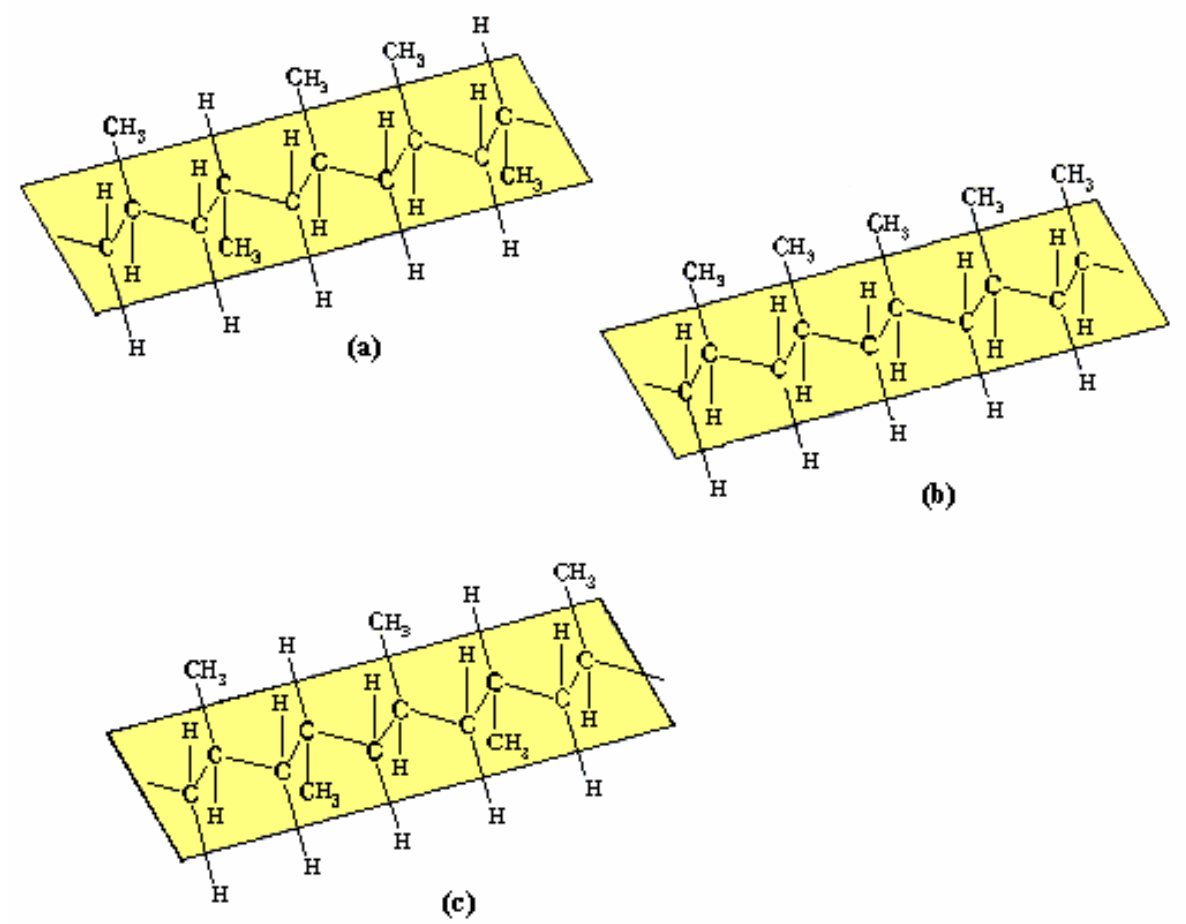

Figura 4 - Formas diferentes de estéreo-isômeros do polipropileno (a), (b) e (c).

(a) Isômero atático é aquele em que os grupos $\mathrm{CH}_{3}$ pendentes estão colocados aleatoriamente. (b) Isômero isotático é aquele em que os grupos $\mathrm{CH}_{3}$ pendentes estão todos do mesmo lado da cadeia principal de carbono. (c) Isômero sindiotático é aquele em que os grupos $\mathrm{CH}_{3}$ pendentes se encontram alternadamente num e noutro lado da cadeia principal de carbono.

\subsection{CARACTERÍSTICAS GERAIS}

Entre as características gerais serão abordados os pontos fortes do PP e as limitações para suas aplicações.

\subsubsection{Pontos fortes}

Os pontos fortes do PP são: boa resistência química, baixa absorção de umidade, boa resistência ao impacto, soldável e moldável, atóxico, baixo custo dentre os plásticos, bom isolante térmico, fácil usinagem, resistência ao atrito regular, boa estabilidade térmica, pode ser aditivado; alta resistência ao entalhe, ou seja à penetração de 
objetos afiados, opera até $115^{\circ} \mathrm{C}$, leveza $0,92 \mathrm{~g} / \mathrm{cm}^{3}$, sendo o mais leve dos plásticos, em revestimento até $90^{\circ} \mathrm{C}$ pode substituir o PVC, anti-aderente (ALBUQUERQUE, 2001).

\subsubsection{Limitações para aplicações}

As limitações do PP para aplicações são: baixa resistência mecânica, baixa resistência à abrasão, sensível à ação da radiação ultravioleta e de agentes oxidantes, resistência limitada à variação de temperaturas, com solicitação mecânica a ligação carbono mais hidrogênio se compromete, não é resistente à baixa temperatura (abaixo de $0^{\circ} \mathrm{C}$ ) (ALBUQUERQUE, 2001).

Exemplos de aplicações: tanques de produtos químicos, conexões e válvulas, tubulações de produtos químicos, mesa de corte para indústria de alimentos, aparelhos ortopédicos, engrenagem com pouco esforço mecânico, engrenagem para galvanoplastia, mesa para laboratório, cobertura para cabos de alta-tensão, separador de garrafas, estrelas e roscas sem-fim, molde para indústria de fibras, tambor rotativo para galvanoplastia, bombas de retornos para concentrados, placas de filtro de prensa, exaustores de hidrodecapagem, tubulação flutuante para barragem, trilhos de "redler's", dutos anticorrosivos entre outros (STEFFANI \& FLINKLER, 1999; MILES \& BRISTON, 1975).

O PP não tem características ideais para ser considerado como plástico de engenharia, pelas suas limitações (resistências mecânicas); sua grande característica é sua resistência química ao entalhe. Entre as poliolefinas, o polipropileno é sintético e rígido. Todas as indústrias que utilizam processos químicos são potencialmente consumidoras de polipropileno.

\subsection{PROPRIEDADES}

O polipropileno é uma resina de densidade baixa que oferece um bom equilíbrio de propriedades térmicas, químicas e elétricas, acompanhadas de resistência moderada. As propriedades de resistência podem ser significativamente aumentadas ou melhoradas pelo uso de reforços de fibras de vidro. A tenacidade é melhorada em graduações especiais de elevado massa molar modificadas com borrachas. 
As propriedades elétricas dos polipropilenos são afetadas em vários graus de temperatura de serviço. Com o aumento da temperatura, a constante dielétrica permanece razoavelmente constante; entretanto, a resistência ou o poder dielétrico aumenta, enquanto é reduzida a resistividade volumétrica.

Os polipropilenos apresentam resistência limitada ao calor; mas podem ser encontrados alguns com tipos de termoestabilizadores, podendo assim ser destinados a aplicações que exijam uso prolongado a temperaturas elevadas. Não são atacados pela maioria dos agentes químicos de natureza orgânica, porém, eles são atacados por compostos halogenados, por ácido nítrico fumegante e por outros agentes oxidantes ativos, além de serem também atacados por hidrocarbetos aromáticos e clorados, em temperaturas altas (ALBUQUERQUE, 2001).

\subsection{APLICAÇÕES}

Os polipropilenos não-reforçados são utilizados em aplicações de embalagens, tais como recipientes farmacêuticos e médicos, moldados por sopro, além dos destinados a alimentos. Os tipos em espuma são empregados em móveis e encostos de assentos de automóveis.

Tanto os tipos reforçados como os não-reforçados são aplicados em automóveis, aparelhos domésticos e elétricos. Por exemplo: carcaças de baterias, de lanterna, rotores e carcaças de ventoinhas, carcaças de ventiladores, forros de proteção, bombas domésticas, pás de ventiladores, e como suportes para peças elétricas condutoras de corrente, carretéis de bobinas, capas protetoras de cabos elétricos, jogos magnéticos de $\mathrm{TV}$, cartuchos para fusíveis e como isolantes, entre outras aplicações (ALBUQUERQUE, 2001). 


\section{PÓ DE MADEIRA}

Alguns aspectos gerais sobre madeira e pó de madeira serão abordados neste capítulo.

\subsection{MADEIRA}

A madeira é um material empregado pelo homem desde as épocas préhistóricas. Apesar do longo período de utilização, só na primeira metade do século XX foram estabelecidas teorias técnicas para a aplicação da madeira. E a partir da II Guerra Mundial, as pesquisas tecnológicas tiveram grande incremento (SOARES, 1996).

\subsection{A ESTRUTURA E COMPOSIÇÃO DA MADEIRA}

As propriedades químicas e físicas da madeira são determinadas pela sua constituição anatômica e pelas finas estruturas de suas paredes celulares (SOARES, 1996).

As madeiras consistem de matérias orgânicas, incluindo carbono, hidrogênio, oxigênio e certa quantidade de nitrogênio. Junto com os materiais orgânicos, a madeira contém substâncias minerais em pequenas quantidades (cerca de 0,2 a 1\%).

As propriedades físicas, químicas e mecânicas singulares da madeira tornaramna de emprego obrigatório em diversos campos. Utilizada desde sempre como combustível e na construção de moradias, móveis, embarcações e outros veículos, a madeira atende assim a três necessidades primordiais do homem: combustível, casa e transporte. Posteriormente ela se converteu também em matéria-prima para a indústria química, na produção de celulose e pastas hidráulicas, mecânicas, físico-químicas e químicas. 


\subsection{INDÚSTRIA MADEIREIRA}

A indústria da madeira abrange três grandes tipos de operações: beneficiamento, processamento e incorporação da madeira para diversos fins. No beneficiamento, realizam-se os processos de falquejamento (em que as toras são desbastadas), desdobramento (divisão em tábuas) e compensação (em que finas camadas lâminas - são superpostas e coladas). No processamento, a madeira é usada química ou físico-quimicamente como matéria-prima; na incorporação, fabricam-se peças e estruturas, material de embalagem ou de enchimento e mobiliário.

São nas operações de incorporação que se criam bens ou artefatos que utilizam as propriedades essencialmente mecânicas da madeira (dureza e maciez, densidade e leveza, elasticidade e rigidez, plasticidade): cabos de ferramentas, carretéis, roldanas, fôrmas trabalhadas, embalagens comuns e especiais, artigos de palha e cortiça, móveis de todo tipo com predomínio ou participação da madeira, composições arquitetônicas e decorativas, armações e outros sistemas de utilização composta (MASSON, 1998).

\subsection{PÓ DE MADEIRA}

Apesar do pó de madeira ser uma carga, neste trabalho ele será utilizado como um reforço particulado, por um processo de beneficiamento da serragem que se obtém do rejeito da indústria madeireira (MASSON, 1998).

Este material é de composição polimérica natural e pode ser facilmente encontrado: no descarregamento do pó por indústrias de móveis, do resíduo de madeira de demolição, de fontes de madeira reciclada pós-consumidor, fontes pós-limpas, árvores urbanas derrubadas entre outras.

Pesquisas demonstraram que quando adicionado o pó de madeira em polímeros termofixos principalmente os fenólicos foram conseguidas propriedades como aumento do módulo de Young, redução do peso específico, porém aumentando-se a absorção de água.

Em termoplásticos aumenta-se a rigidez do material que foi modificado e também a resistência química. Porém é observada a redução da sua resistência e da tenacidade isso ocorre principalmente no aumento da concentração de carga.

O pó de madeira industrializado possui tamanho de partículas que passam a peneira de 100 mesh e teor de umidade entre $6 \%$ a $8 \%$. Produz moldado de ótimas 
propriedades mecânicas e boa resistência à umidade. Devido à umidade o pó de madeira é um diluente e causador de bolhas e precisa passar por um processo de secagem como uma das operações de processamento.

\subsection{COMPÓSITOS PP/WF}

Como foi dito anteriormente o pó de madeira é facilmente encontrado como resíduo gerado nas indústrias madeireira. Este resíduo deixado não é de interesse industrial uma vez que por serem materiais de baixa densidade, exigem maior espaço para a estocagem, além de serem materiais altamente explosivos. Por isso atualmente, estudam-se esses resíduos como forma de reutilização destes materiais.

Atualmente os compósitos plástico-madeira já estão sendo utilizados na fabricação de uma série de produtos. As aplicações vão desde brinquedos até construções marinhas (YOUNGQUIST,1995, BRISTSH PLASTICS \& RUBBER, 2001, KOENIG \& SYPKENS, 2002).

Os compósitos plástico-madeira ou WPC ("wood plastic composites") começaram a ser produzidos na Europa e estão sendo fabricados nos Estados Unidos há décadas. Entretanto, o maior crescimento ocorreu a partir da última década (CLEMONS, 2002).

As primeiras pesquisas com o compósito plástico-madeira foram na década de 50 onde as indústrias automotivas começaram a adicionar pó de madeira ao polipropileno (PP) na fabricação de algumas partes internas dos carros. No final da década de 80 o compósito plástico-madeira começou a ser usado na fabricação de decks (KOENIG \& SYPKENS, 2002, YAMAJI \& BOUNDUELLE, 2004).

O compósito madeira-polímero apresenta vantagens sobre a madeira natural, tais como:

- Maior resistência à umidade e deterioração ambiental;

- Resistência a pragas e insetos;

- Podem ser extrusados em perfis com formatos diversificados;

- Apresentam melhor estabilidade dimensional;

- Resistência ao empenamento e trincas;

- Possuem menor custo de manutenção de rotina; 
- Maior durabilidade em ambientes agressivos como marinas e piscinas, impermeabilidade;

- São totalmente recicláveis e imitam em aspecto a madeira;

- Dispensam o uso de proteção superficial como tintas e vernizes, não requer manutenção regular (CORREA, 2003).

Outro fator importante é que, no trabalho com esse tipo de material, utilizam-se ferramentas convencionais de carpintaria, permitindo que a madeira plástica seja aplainada, serrada, aparafusada e pregada como a natural (CLIMENHAGE, 2003; GUADAGNINI, 2001).

A maioria de produtos de madeira plástica no mercado atual é feita a partir de polietilenos (PE) reciclados, sendo utilizado principalmente o polietileno de alta densidade (HDPE). Contudo, ela pode ser obtida também a partir de outras resinas como o polipropileno (PP), poliestireno (PS) e o poli(cloreto de vinila) (PVC) ou, até mesmo, de misturas de diferentes resíduos plásticos (LAMPO \& NOSKER, 1997).

Em algumas formulações de madeira plástica, são utilizados compósitos com cargas vegetais, tais como fibras naturais e serragem de madeira, ou ainda minerais como carbonato de cálcio, talco e fibras de vidro sintéticas. Essas cargas são utilizadas com o propósito de melhorar as propriedades físicas, térmicas e mecânicas dos produtos de madeira plástica e, assim, garantir um maior número de aplicações e melhores resultados (LAMPO \& NOSKER, 1997).

\subsection{PROCESSAMENTO}

Dentre os fatores que determinam a qualidade do produto de madeira plástica, destacam-se as propriedades do material a ser processado, a forma como o resíduo plástico chega à etapa de processamento, a presença de cargas e aditivos e a umidade do material. Esses requisitos conduzem à necessidade de extrusoras com características técnicas altamente específicas comparadas ao processamento de polímeros virgens (AMIM, 2006).

Madeiras plásticas do tipo WPC têm sido manufaturadas em extrusoras do tipo mono-rosca, dupla-rosca cônica e paralela, dupla-rosca contra-rotativas e co-rotativa e extrusoras em série (CAULFIELD et al., 2006). A configuração do processo é projetada especificamente para alimentar a fibra e o polímero, promover mistura suficiente a fim de dispersar a fibra de forma eficaz e uniforme no polímero e, finalmente, conformar a 
mistura na forma de perfis contínuos, com geometria desejada (CLIMENHAGE, 2003). Além da configuração da extrusora, as condições de processamento também são determinantes das características finais dos produtos de madeira plástica do tipo WPC.

Um fator limitante do processo de fabricação de WPC consiste na baixa temperatura de degradação do pó da madeira, em torno de $200^{\circ} \mathrm{C}$ a $220^{\circ} \mathrm{C}$. A exposição do resíduo de madeira a temperaturas acima dessa faixa libera compostos voláteis, provocando descoloração, aparecimento de odor e fragilização do compósito (ENGLISH et al., 2006). Isso tem restringido o uso de termoplásticos de baixa temperatura de processamento em WPC, tais como poliolefinas, plásticos estirênicos (PS, HIPS, ABS) e o PVC (CAULFIELD et al., 2006).

Ainda em relação à degradação da madeira, além do perfil de temperaturas adequado na extrusora, há que se estabelecer um grau de cisalhamento e um tempo de residência compatíveis para que se obtenha boa mistura e homogeneização do WPC e se evite a degradação excessiva da madeira no interior do equipamento quando sob temperatura, pressão e cisalhamento.

Outro fator que se constitui em uma dificuldade no processamento de WPC é o elevado teor de absorção de umidade da fibra de madeira. Portanto, uma secagem prévia do pó de madeira e uma boa degaseificação durante o processamento tornam-se essenciais para a produção de WPC (GUADAGNINI, 2001). Um dos fatores afetados mais diretamente pelo teor de umidade do reforço de madeira é a produtividade da linha de extrusão: quanto maiores os teores de umidade das partículas, menor a produtividade por conta do maior tempo de residência necessário para devolatilização do compósito (RODOLFO \& JOHN, 2006). Por outro lado, com uma maior permanência dentro da extrusora, o material torna-se mais suscetível à degradação devido à ação da temperatura e do cisalhamento.

A umidade e o tamanho granulométrico do pó da madeira também devem ser controlados de forma cuidadosa a fim de evitar descontinuidades de processo e peças com características inaceitáveis devido à presença de bolhas ou manchas superficiais (STARK, 2006).

Outro fator que requer um cuidado especial no processamento de WPC é a baixa densidade da fibra de madeira, que dificulta a sua entrada através das pequenas aberturas de alimentação, típicas de equipamentos transformadores de plásticos, levando a uma diminuição da velocidade de processamento (ENGLISH et al., 2006). 
Existe, atualmente, uma grande discussão entre os maiores fabricantes de equipamentos, tais como Bauzzano, Davis-Standard, Leistritz, Millacron Inc., Krupp Werner \& Pfleiderer entre outros, sobre a melhor configuração de máquina para processamento de compósitos termoplásticos com madeira (CORREA et al., 2003). Esses equipamentos podem ser classificados em quatro categorias distintas.

No processo que utiliza a madeira pré-seca e a mistura pré-homogeneizada ("Pre-dry"; "Pre-mix") são utilizados equipamentos em que a fibra de madeira é submetida a processos de pré-secagem em níveis de umidade inferiores a 1\% e alimentada em uma extrusora rosca-dupla contra-rotacional juntamente com o polímero, normalmente na forma de pó. A mistura polímero-madeira e aditivos é preparada em misturadores intensivos do tipo Henschel antes de ser alimentada na extrusora (CORREA et al., 2003; DOUGLAS \& DOUGLAS, 2003). A mistura pulverizada de madeira e polímero pode, então, ser alimentada em uma extrusora usando um dispositivo de alimentação Crammer. Devido à distribuição estreita de tempos de residência do material no sistema e às gerações limitadas da energia térmica são usados sistemas com dupla-rosca contra-rotacional, principalmente para a conversão do PVC, por sua instabilidade térmica (STASIEK, 1997).

O processo que utiliza a madeira pré-seca e a alimentação polímero-madeira em separado ("Pre-dry"; "Split Feed") propicia um melhor controle do tempo de residência da madeira durante o processamento (CORREA et al., 2003). Nesse caso, utilizam-se normalmente extrusoras dupla-rosca de grande capacidade, com portos laterais de alimentação, onde a fibra é misturada ao polímero fundido, passando por zonas de mistura distributiva e degaseificação da umidade residual.

Um terceiro processo utiliza primeiro a madeira úmida e, em seguida, a alimentação do polímero fundido ("Wood First"; "Melt Feed"). São necessárias duas extrusoras, que operam simultaneamente; uma extrusora primária, secando a farinha de madeira e uma outra menor, plastificando o polímero e os aditivos (CORREA et al., 2003). A empresa Davis-Standard dos EUA patenteou um equipamento dedicado ao processamento de compósitos termoplásticos com essas características, denominado Woodtruder ${ }^{\circledR}$ (JORGE, 2000). Essa extrusora equipada com dupla-rosca contra-rotante foi projetada para remover a umidade da fibra de madeira mesmo em altos níveis (umidade entre $1 \%$ e $8 \%$ ) (GUADAGNINI, 2001, JORGE, 2000). O processo inclui uma extrusora principal de dupla-rosca paralela contra-rotativa (L/D 28:1) e outra satélite para o polímero, a qual pode ser mono ou dupla-rosca, dependendo da resina empregada. A 
principal, seca e depois mistura a madeira ao polímero. A satélite funde o polímero e entrega-o fundido à madeira seca na extrusora principal.

O processamento que usa fibras de madeira em extrusora de roscas duplas paralelas é similar ao processamento de polímeros puros (JORGE, 2000). Apesar de se utilizarem alimentadores comuns para polímeros, neste caso, emprega-se um dosador gravimétrico a fim de suprir as fibras de madeira para a extrusora de dupla-rosca. A alimentação automaticamente ajustada pelo dosador gravimétrico enche os canais das roscas para aumentar a eficiência de alimentação e eliminar as variações de densidade das fibras de madeira. As roscas transportam as fibras para frente à medida que o calor do barril (canhão) e da rosca é transferido para o material. O calor transferido para as fibras de madeira não somente aquece a madeira, mas também a água contida nelas até o ponto de vapor, liberando a umidade.

No processo WoodTruder $\AA$, as fibras de madeira são submetidas a uma zona ou ponto de vazão (escape atmosférico - degasagem) para remoção da umidade, entrando na zona de alimentação contendo até $8 \%$ de umidade (GUADAGNINI, 2001, JORGE, 2000).

À proporção que a madeira é aquecida, a umidade na superfície evapora e escapa na degasagem.

A extrusora satélite processa o polímero até o ponto de fusão desejado. Isso é feito com desenho apropriado de rosca e ajuste da temperatura do canhão. A mistura entra na seção de compressão da extrusora principal para facilitar a fusão dos dois componentes.

Um ponto de degasagem está localizado após a zona de compressão para remoção de voláteis do polímero ou umidade residual das fibras de madeira. A mistura completamente seca e homogeneizada segue para outra seção a fim de aumentar a pressão do fluxo no cabeçote.

O último dos quatro processos usualmente empregados na produção de WPC utiliza primeiro a madeira úmida, mantendo sua alimentação separada do polímero e dos aditivos ("Wood First", "Split Feed") (CORREA et al., 2003). Nesse processo, a farinha de madeira pode ser alimentada ainda úmida na zona de alimentação e a mistura de resina e aditivos introduzida posteriormente no barril por meio de um alimentador lateral (CORREA et al., 2003, DOUGLAS \& DOUGLAS, 2003). Todavia, esse processo requer normalmente equipamentos com extrusoras muito longas (L/D 44 ou 48:1) e com zonas de degaseificação próximas à zona de alimentação para remover a umidade da madeira, o que 
nem sempre é possível. Muitos produtores têm obtido artefatos com conteúdo de madeira entre 50 a $60 \%$ em peso (DOUGLAS \& DOUGLAS, 2003).

Nos processos nos quais a extrusora é utilizada na secagem da farinha de madeira, pode haver problemas de consistência da massa fundida devido a alterações de umidade. Os custos associados a essa prática ainda têm sido objeto de discussões entre fabricantes de equipamentos e processadores. Dessa forma, a alternativa mais segura ainda tem sido a utilização de madeira pré-seca, adquirida dos fornecedores de farinha ou fibra de madeira (DOUGLAS \& DOUGLAS, 2003).

\subsection{APLICAÇÕES}

As aplicações da farinha de madeira em polímeros são inúmeras. Atualmente muitas indústrias possuem patentes sobre seus produtos uma delas é a empresa Araforros que possui a marca WoodCell ${ }^{\circledR}$ que produz forros de PVC/farinha de madeira. Na década de 70 a indústria automobilística tinha a marca Woodstock ${ }^{\circledR}$, a indústria americana produzia compósitos de polipropileno com farinha de madeira e dominou o mercado durantes três décadas. Esse compósito era extrusado e laminado em chapas para revestimento interno de portas e portas malas. Nas Figuras 5 a 14 são mostradas algumas aplicações destes compósitos.
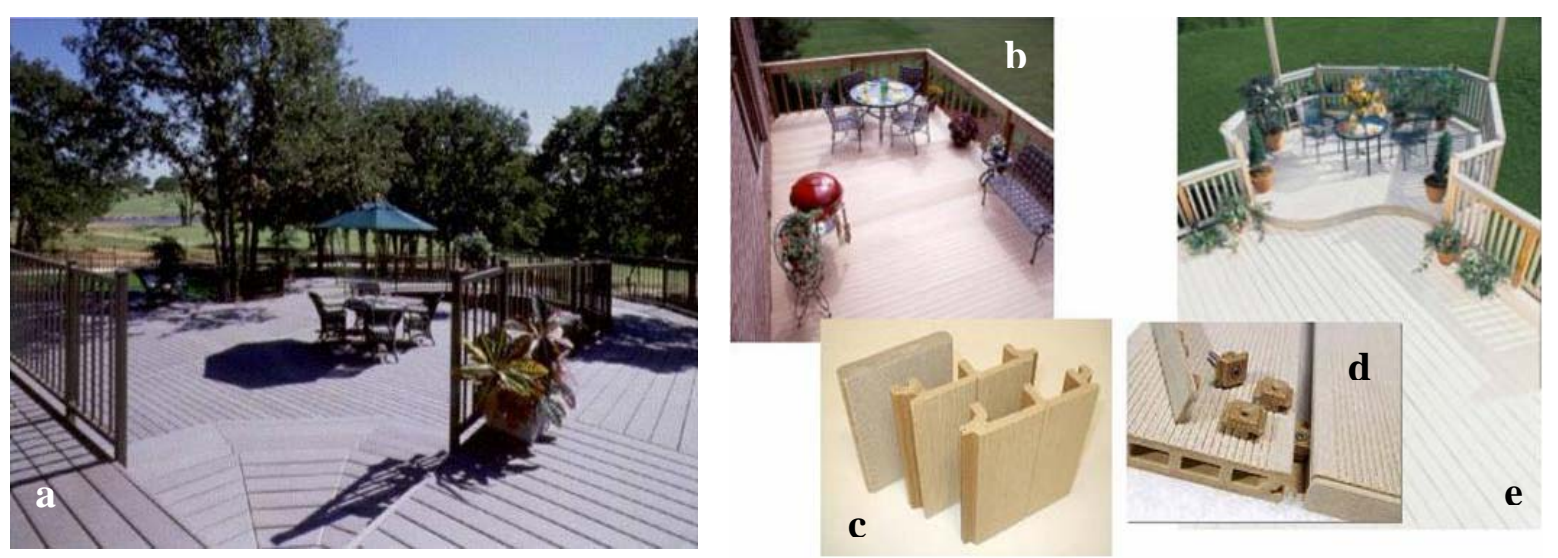

Figuras 5a, 5b, 5c, 5d e 5e - Ilustrações de aplicações do compósito em decks, em corrimão e em guarda corpo. 

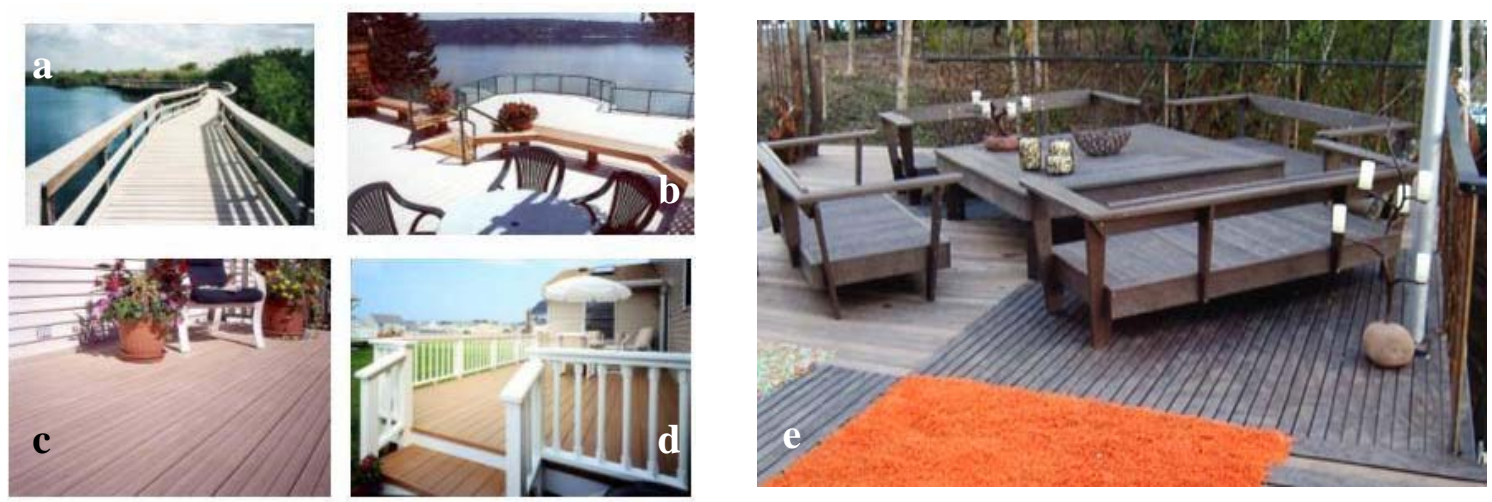

Figuras 6a, 6b, 6c, 6d e 6e - Ilustrações de outras aplicações do compósito em decks, em corrimão e em guarda corpo.

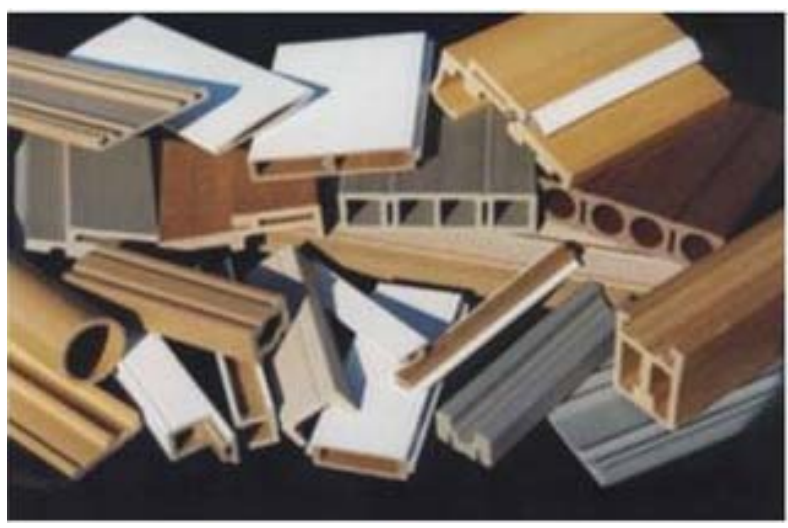

Figura 7 - Perfis diversos

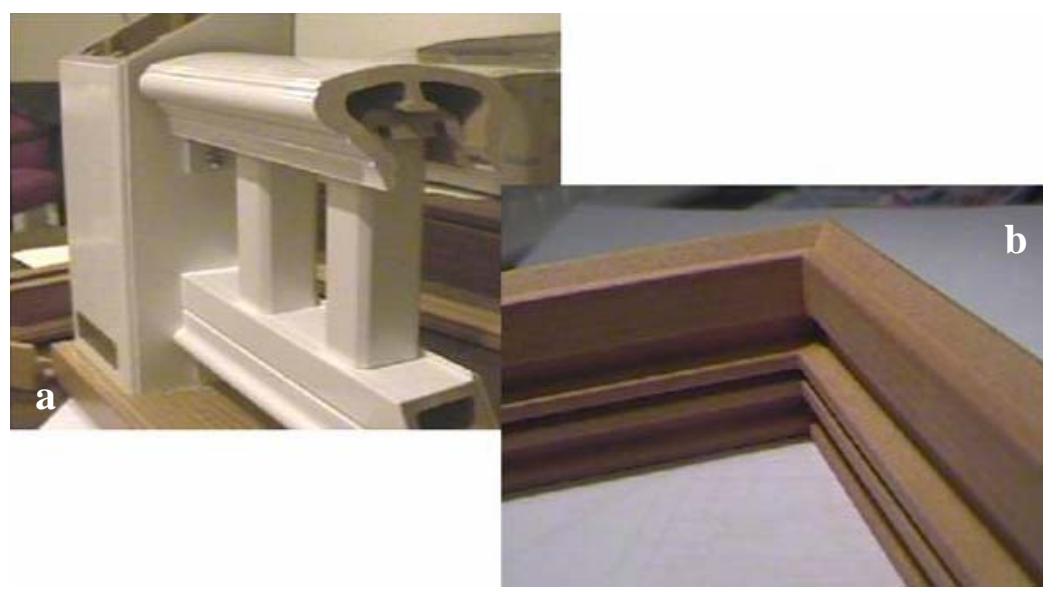

Figuras 9a, 9b - Perfis de acabamento como rodapés e batentes de portas.

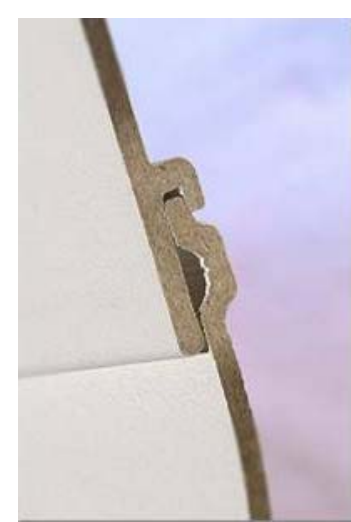

Figura 8 - Revestimento e "siding". 


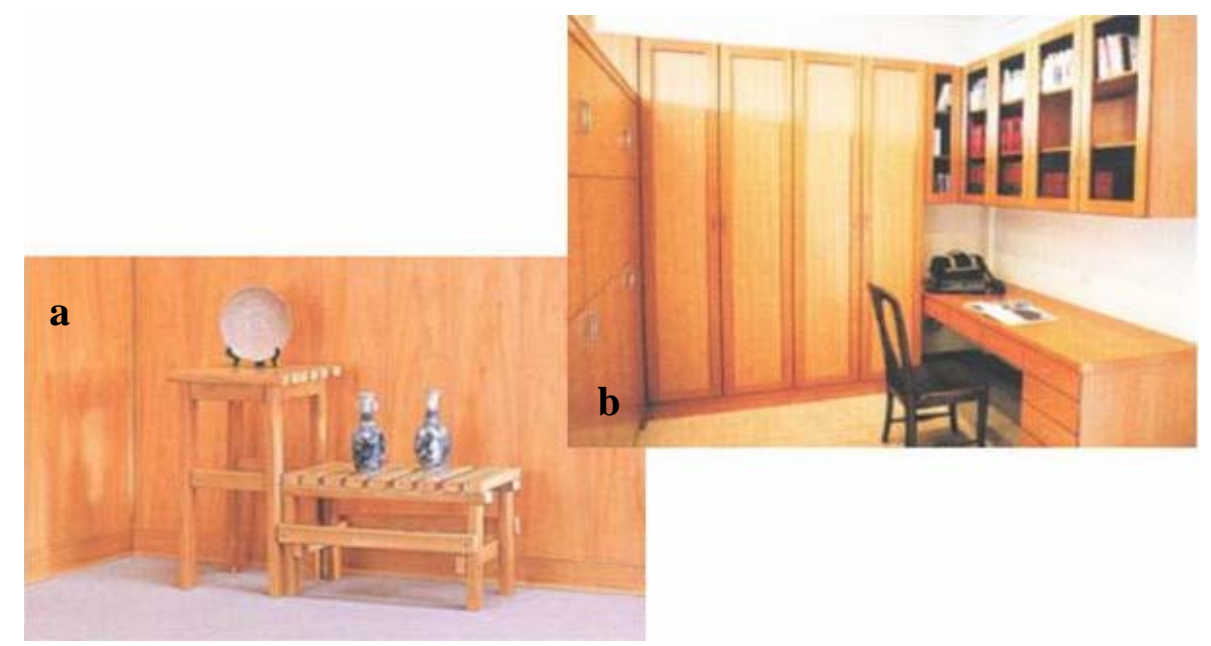

Figuras 10a, 10b - Chapas e perfis.

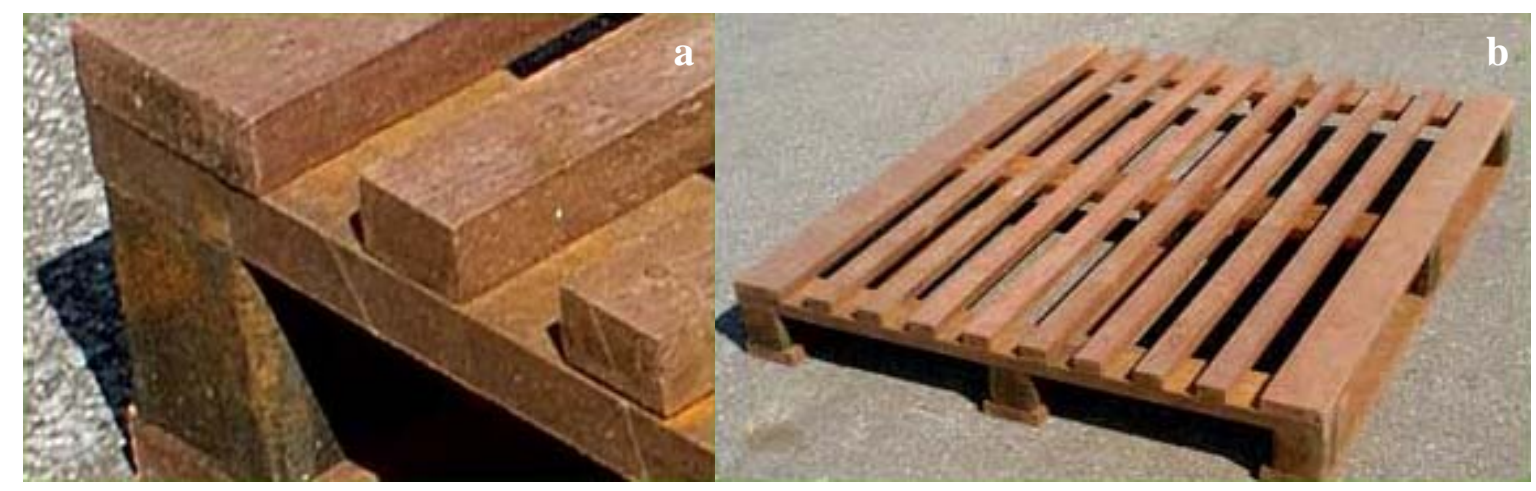

Figuras 11a, 11b - Pallets fabricados pela empresa Ecoblock.

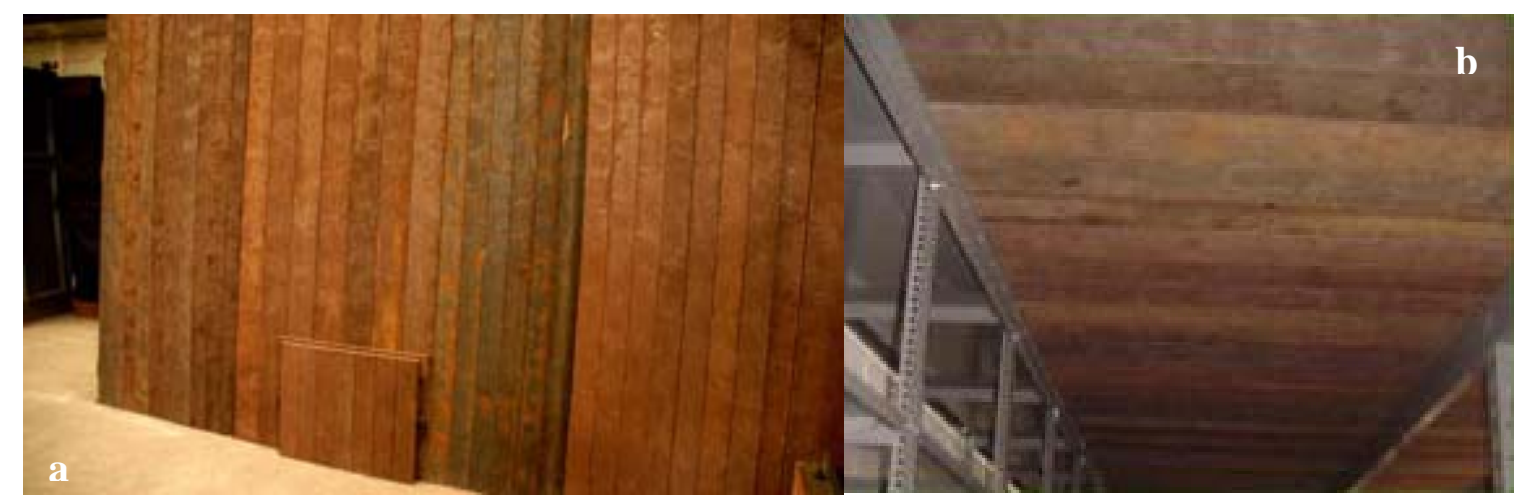

Figuras 12a, 12b - Marcos de porta e forros fabricados pela empresa Ecoblock. 


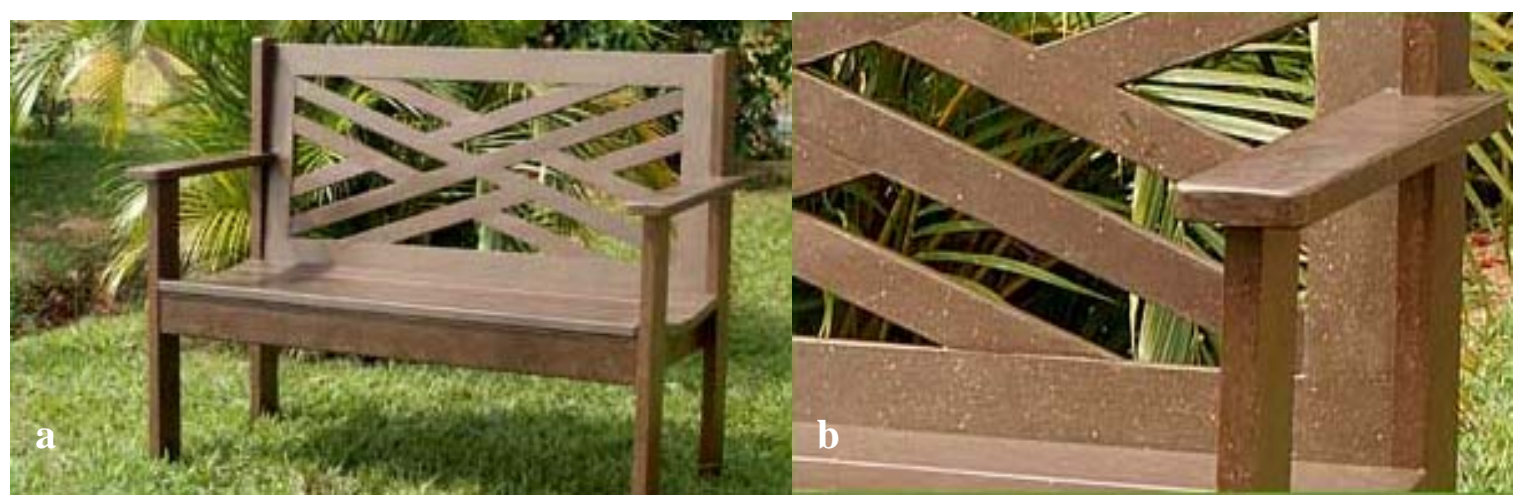

Figuras 13a, 13b -Bancos fabricados pela empresa Ecoblock.

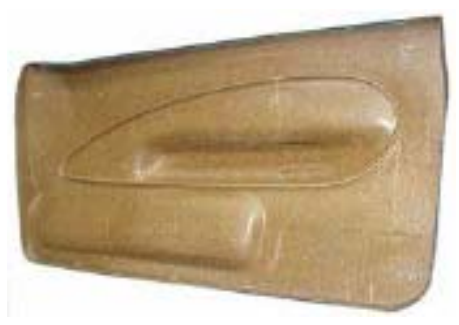

Figura 14 - Painéis para porta, 60\%PP e 40\% Lignocell.

\subsection{MERCADO E IMPORTÂNCIA}

O uso da madeira como carga reforçante em polímeros tornou-se importante para a economia mundial, em pouco tempo o mercado dos compósitos cresceu uma vez que ganhava ao ser comparada com a madeira, um material mais nobre e mais caro e que tem uma legislação que limita a queima indiscriminada de resíduos celulósicos nos EUA e na Europa. Tanto na Europa quanto nos EUA os compósitos apresentam crescimento no mercado como se pode observar na Figura 15.

Atualmente, o mercado de madeira plástica norte-americano, o maior do mundo, gira em torno de 5,2 bilhões de dólares por ano (CLIMENHAGE, 2003). Os compósitos com fibra de madeira (WPC) representam o segmento com o maior e mais rápido crescimento do mercado mundial da madeira plástica (CAULFIELD et al., 2005, CLIMENHAGE, 2003). Além da produção de decks, fabricantes norte-americanos estão introduzindo WPC em outros produtos, tais como cercas, janelas, bancos, telhas e lâminas para substituir a madeira compensada. Além desses empregos, existe um potencial para aplicação da madeira plástica em mobiliários residenciais como mesas, cadeiras, estantes, armários, entre outros. 
O polietileno é a matriz mais usada na América do Norte sendo utilizado em $70 \%$ dos compósitos, o PVC cerca de $18 \%$ e o polipropileno $11 \%$.

Nas Figuras 16, 17, 18, 19 e 20 são mostrados os mercados tanto nos EUA quanto na Europa.

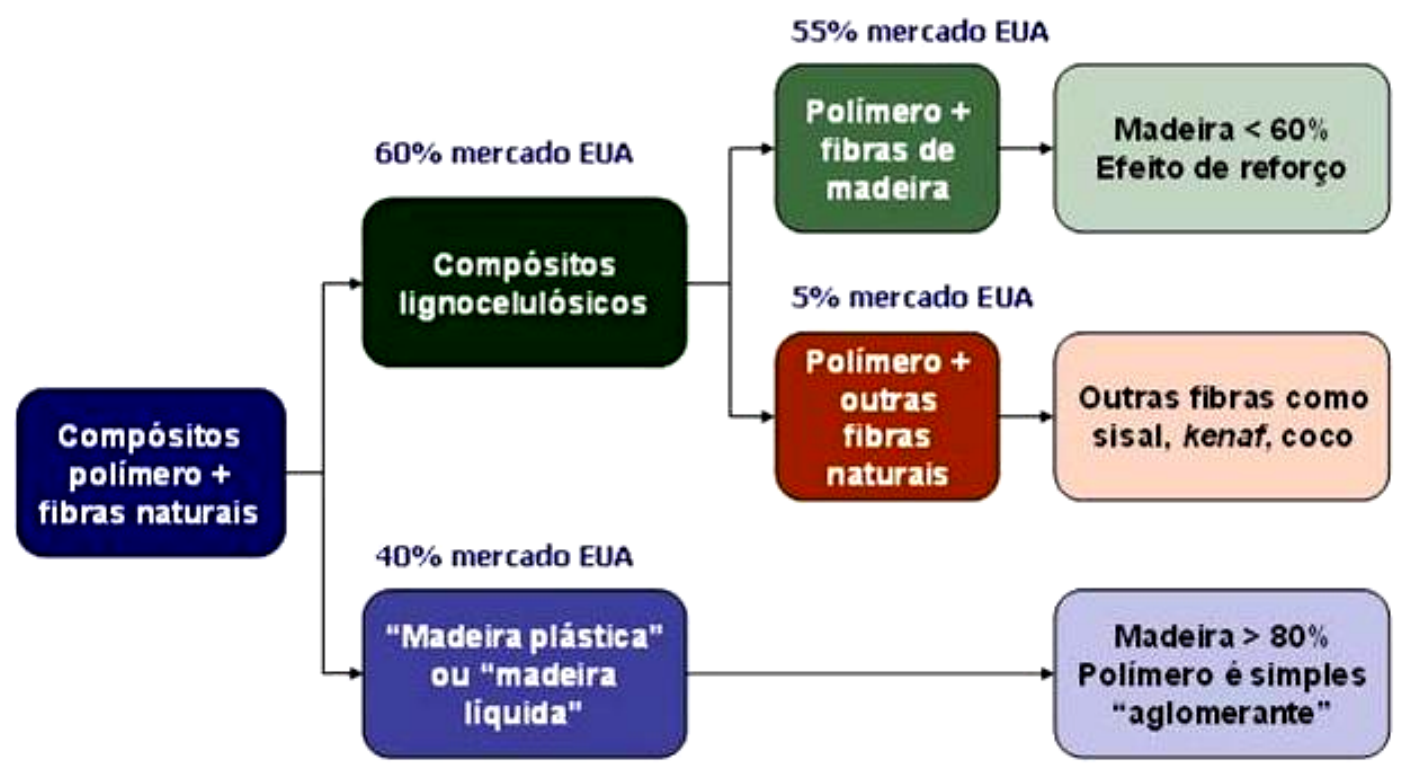

Figura 15 - Mercado dos compósitos polímero/madeira nos EUA.

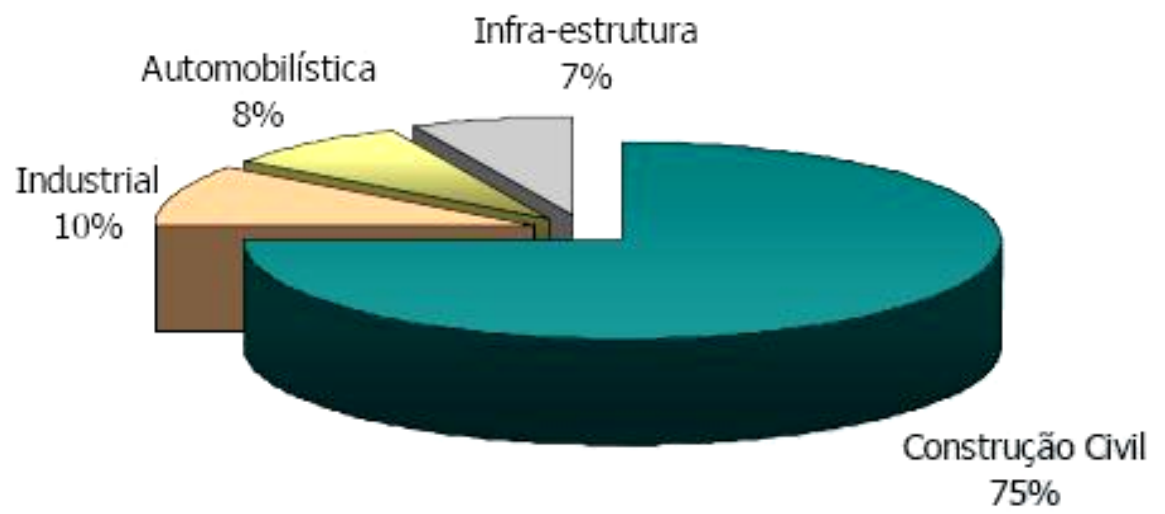

Figura 16 - Distribuição do mercado dos compósitos polímero/madeira nos EUA (2002). 


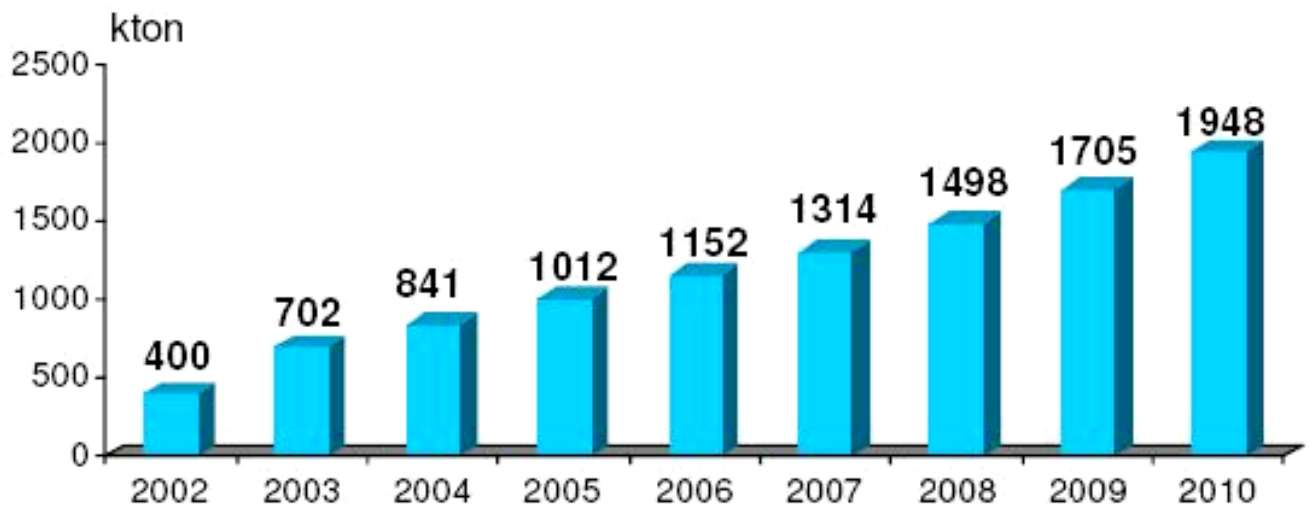

Figura 17 - Previsão da demanda dos compósitos polímero/madeira na América do Norte.

A previsão para a demanda até 2010 é que exista um crescimento de $14 \%$ a.a. Nos EUA as tendências de mercado apontam que:

- O PEAD principal resina utilizada no composto até 2010 devido a vantagem de preço

- Crescimento do PP no composto na aplicação de decks devido a sua característica de rigidez permitindo a fabricação de decks mais leves.

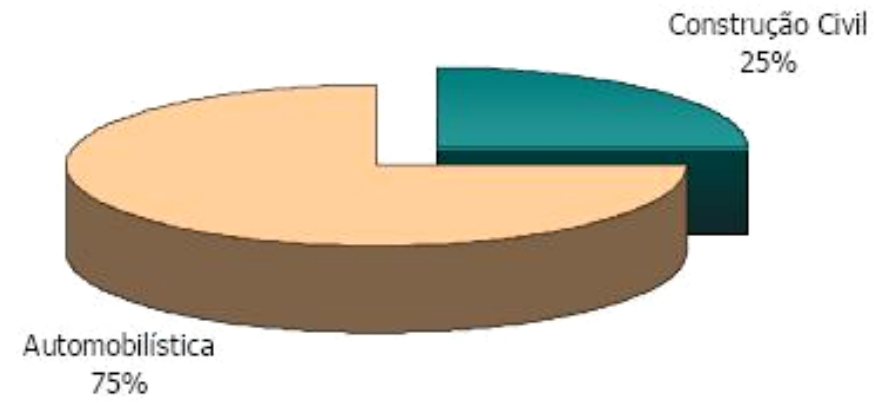

Figura 18 - Distribuição do mercado dos compósitos polímero/madeira na Europa.

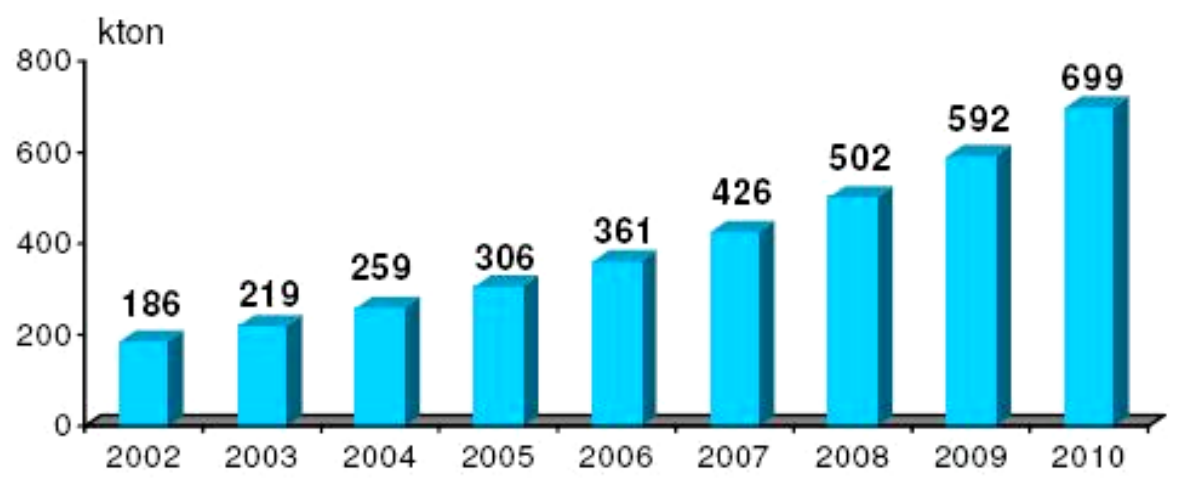

Figura 19 - Previsão da demanda dos compósitos polímero/madeira na Europa. 
A previsão para a demanda até 2010 é que exista um crescimento de $18 \%$ a.a. Na Europa os decks não são populares e as fibras naturais são mais usadas em compósitos do que a madeira conforme é mostrado na Figura 20.

- O PP é a resina mais utilizada no composto devido à disponibilidade e desempenho;

América do Norte

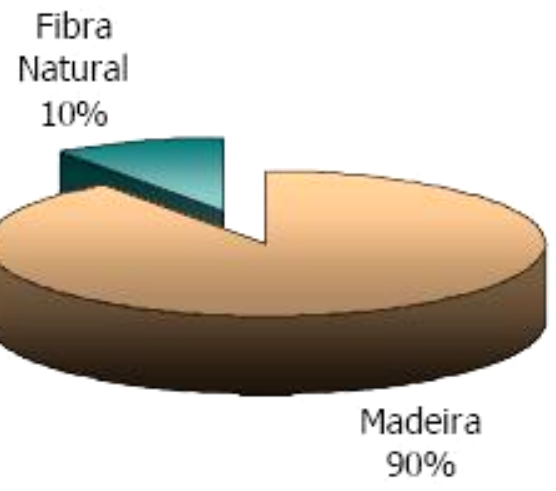

\section{Europa}

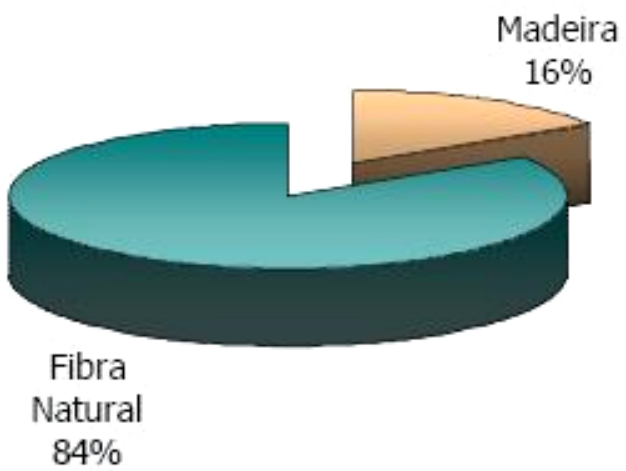

Figura 20 - Comparação entre a madeira e as fibras naturais na Europa e nos EUA. 


\section{TRATAMENTO SUPERFICIAL DAS CARGAS}

O tratamento superficial é uma alteração química realizada na superfície da carga ou um recobrimento do reforço, ambas alteram a superfície da carga permitindo um molhamento eficiente.

\subsection{AGENTES DE ACOPLAGEM}

Como foi dito anteriormente o agente de acoplagem promove a união química entre as fases ou altera a energia superficial da carga para permitir um molhamento eficiente, como no caso de polímeros apolares hidrofóbicos (como as poliolefinas) com cargas polares hidrofílicas (MANO, 1991).

A compatibilidade das características superficiais do reforço e da matriz pode ser conseguida pelas modificações superficiais do reforço. Essas modificações podem ser conseguidas pelos tratamentos superficiais específicos no reforço (RABELLO, 2000).

Existem dois tipos de tratamentos:

Alteração química da característica superficial do reforço: consiste em alterar a tensão superficial por meio de um processo controlado de oxidação, ocorrendo formação de grupos oxidados que aumentam a polaridade superficial, favorecendo uma maior interação com matrizes poliméricas polares.

Recobrimento do reforço: consiste em revestir superficialmente o reforço com uma camada fina de uma substância de característica bifuncional chamada de agente de acoplagem.

Os agentes de acoplagem são como pontes moleculares que atuam na interface entre dois substratos, usualmente uma carga inorgânica ou um reforço inorgânico e uma matriz polimérica orgânica, pode-se ainda dizer que o agente de acoplagem atua como ponte entre um substrato polar e o outro apolar.

Em compósitos não são encontradas substâncias que satisfaçam a bifuncionalidade necessária neste caso deve-se usar o tratamento de oxidação para 
aumentar o poder de molhabilidade em razão da similaridade química, favorecendo assim a possibilidade de ligação química entre o reforço e a matriz.

Os principais agentes de acoplagem são:

organo-silanos;

titanatos orgânicos;

zirconatos;

aluminatos;

zircoaluminatos.

Os mais utilizados comercialmente são os organos-silanos e os titanatos.

\subsection{TITANATOS}

Os titanatos (Figura 21) possuem grupos R'O que reagem com as hidroxilas na superfície da carga. O resto da molécula pode reagir com grupos carboxilas no polímero. $\mathrm{O}$ grupo X é fosfito ou fosfato, carboxila ou sulfona. O grupo R" é o que se liga ao termoplástico, podendo ser alifático ou aromático. O grupo $\mathrm{Y}$ se liga a termofixos, podendo ser amino, mercapto ou hidroxila. Os titanatos são bem menos eficientes do que os silanos, mas conferem propriedades de impacto maiores. Podem ser fornecidos como concentrados (em misturas de altas concentrações com o polímero) e são adicionados durante o processamento ou ao se fazer um molhamento na carga anterior à incorporação (GARCIA, 1999).

$$
\left(\mathrm{R}^{\prime} \mathrm{O}\right)_{\mathrm{m}} \longrightarrow \mathrm{Ti}-\left(\mathrm{O}-\mathrm{X}-\mathrm{R}{ }^{\prime \prime}-\mathrm{Y}\right)_{\mathrm{n}}
$$

Figura 21 - Grupos funcionais do Titanato.

Os agentes de acoplagem derivados do titânio, os titanatos, são os únicos que reagem com prótons livres existentes na superfície inorgânica resultando na formação de camadas orgânicas monomoleculares sobre a superfície do reforço.

A ausência de camadas poli moleculares na interface, cria um novo substrato com modificações na energia de superfície e na interação polimérica, resultando na redução da viscosidade em composições poliméricas carregadas ou não. 
Os titanatos incorporados em sistemas poliméricos, de um modo geral, promovem a adesão, melhoram a dispersão do material particulado e a reologia, melhoram a resistência ao impacto e as propriedades mecânicas, impedem a separação de fases e inibem a corrosão.

A reatividade dos titanatos é possível para diversos substratos, tais como materiais orgânicos e poliméricos, celulósicos, peróxidos, sulfato de bário, negro de fumo, nitratos e outros.

Tipos de titanatos:

Monoalcóxi;

Quelato;

Coordenado;

Quaternário;

Neoalcóxis;

Cicloheteoátomo.

\subsection{MECANISMO DE ACOPLAGEM}

A formação de uma matriz compatível e reativa de camadas monomoleculares sobre uma superfície inorgânica se dá de acordo com a Figura 22, onde MOH representa a superfície o reforço mineral e MO o mineral orgânico propriamente dito. As letras Y, R e $\mathrm{X}$ representam grupos funcionais orgânicos específicos que reagem ou compatibilizam-se com a matriz polimérica. A porção X representa grupos carboxilas, sulfônica, fenólico, entre outros. A porção R tem como função proporcionar compatibilidade com a matriz. $\mathrm{O}$ grupo $\mathrm{Y}$ representa grupos funcionais que podem reagir quimicamente com a matriz como, por exemplo, os grupos aminos e metacrílicos (GARCIA, 1999).

$$
(\mathbf{Y}-\mathbf{R}-\mathbf{X}-\mathbf{O})_{3}-\mathbf{T i}-\mathbf{O R}^{\prime}+\mathbf{M O H} \rightarrow(\mathbf{Y}-\mathbf{R}-\mathbf{X}-\mathbf{O})_{3}-\mathbf{T i}-\mathbf{O}-\mathbf{M}+\mathbf{R}^{\prime} \mathbf{O H}
$$

Figura 22- Fórmula geral dos agentes de acoplagem titanato e reação de tratamento superficial. 
Na Figura 23 é mostrado a esquerda, um aglomerado de partículas inorgânicas tendo como desvantagens água de hidratação e vazios de ar misturados com o veículo orgânico sem a presença de titanato, e a direita é mostrada essa aglomeração e a eliminação do ar e água, devido a presença do titanato, melhorando assim a dispersão, aumentando as propriedades mecânicas tais como envelhecimento e impacto, reduzindo a resistividade e proporcionando melhor resistência à corrosão.

$\mathrm{O}$ agente titanato tem sido preferencialmente aplicado a cargas reforçantes ou inertes, para matrizes termofixas e termoplásticas.

Novas modificações têm sido feitas a fim e tornar mais efetivas e menos dispendiosas as técnicas de tratamento superficial.

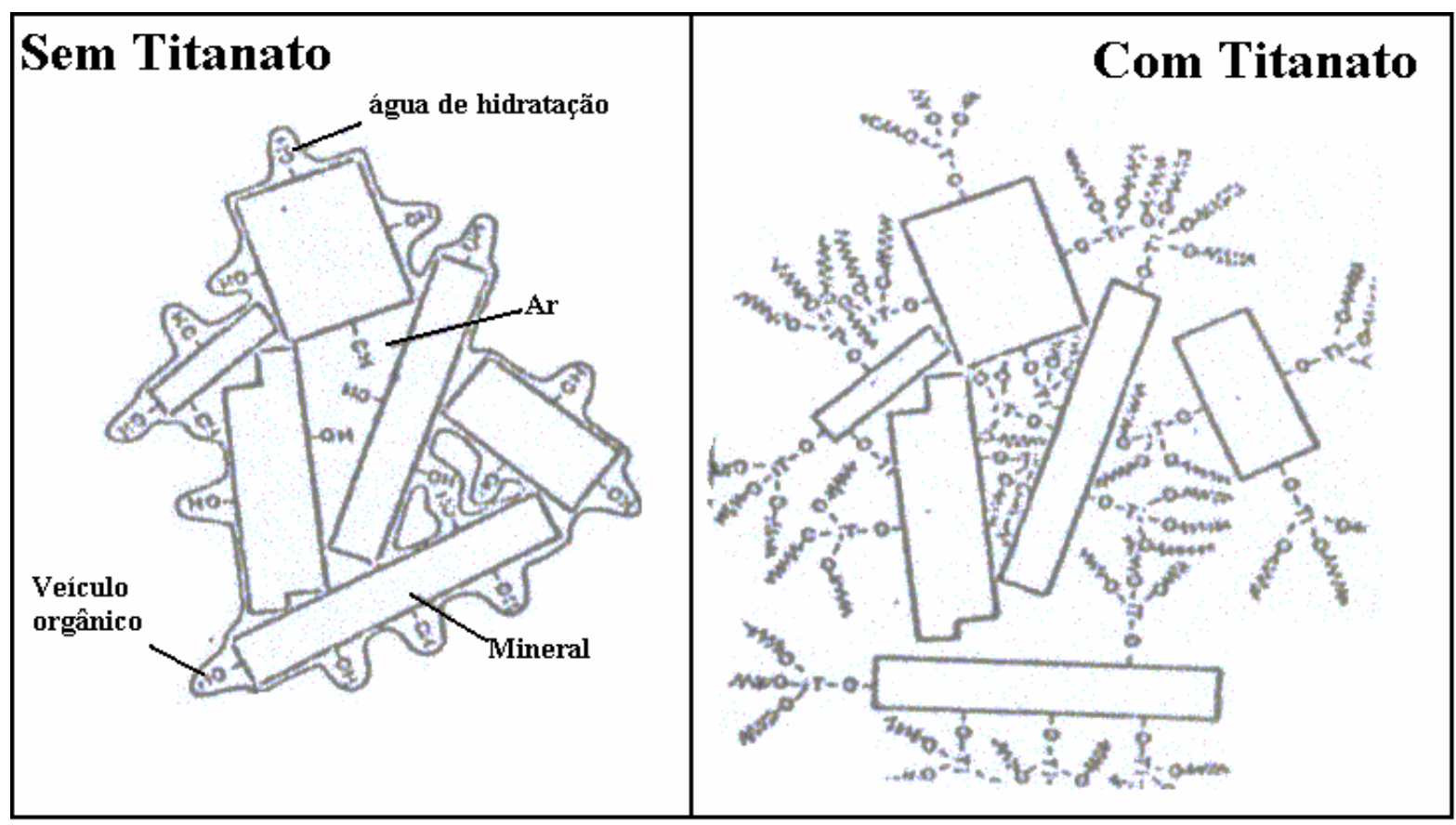

Figura 23 - Efeito da dispersão do agente de acoplagem no aglomerado inorgânico com o titanato monoalcóxi ou neoalcóxi na fase orgânica (GARCIA, 1999).

\subsection{TITANATO DE BÁRIO}

O Titanato de bário é muito utilizado para fabricação de componentes eletrônicos, pois possuem propriedades dielétricas. Estes materiais dielétricos ou materiais isolantes caracterizam-se por oferecerem uma considerável resistência à passagem de corrente, comparativamente ao valor intrínseco correspondente dos materiais condutores. 
O titanato de bário tem boas propriedades dielétricas a baixas temperaturas, porém quando aquecido a mais de $120^{\circ} \mathrm{C}$, essas propriedades pioram rapidamente.

O titanato de bário já foi utilizado como agente de acoplagem em trabalhos anteriores dando bons resultados (ULLOA \& MAIORINO, 2003).

\subsection{MONÔMERO REATIVO - DIACRILATO DE TRIPROPILENO GLICOL}

O TPDGA é um monômero reativo, muito utilizado na formulação de vernizes possui a função de solvente para diluir e reduzir a viscosidade do produto. Pertencendo ao grupo mais comum de monômeros reativos, é obtido por meio da esterificação do ácido acrílico com um poliálcool. Ao contrário dos oligômeros, de síntese mais cuidadosa, esses monômeros são fáceis de ser produzidos no Brasil, nas empresas equipadas com reatores para esterificação. Mas a maior parte em uso no País ainda provém de importação. O tripropileno glicol diacrilato é um monômero de baixa volatilidade, baixa viscosidade usado como radical livre de polimerização (FURTADO, 2004).

Sua unidade estrutural é mostrada na Figura 24.

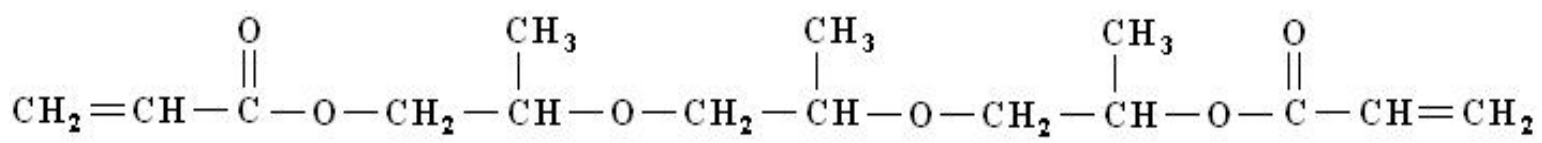

Figura 24 - Unidade estrutural do TPDGA. 


\section{MATERIAIS E MÉTODOS}

\subsection{MATERIAIS}

Os materiais utilizados no presente trabalho foram:

Polipropileno fornecido pela Polibrasil.

Pó de Madeira fornecido pela Pinhopó Madeira e Moagem Ltda.

Titanato de Bário fornecido pela indústria Certronic Ind. e Com. Ltda.

Diacrilato de tripropileno glicol fornecido pela Bandeirante Química Ltda.

\subsubsection{Pó de Madeira}

O pó de madeira (WF) usado neste trabalho foi obtido a partir da serragem industrializada e trituração de madeiras em especial o "Pinnus eliottis" chamado simplesmente de Pinus. A malha fornecida pela Pinhopó foi M-10050. As informações técnicas do WF são apresentadas na Tabela 1.

Tabela 1 - Informações técnicas do pó de madeira.

\begin{tabular}{cccccc}
\hline Fornecedor & $\begin{array}{c}\text { Denominação } \\
\text { técnica }\end{array}$ & Peneira & Densidade & Umidade \\
\hline \multirow{2}{*}{ Pó de Madeira } & $\begin{array}{c}\text { Pinhopó } \\
\text { Moagem de }\end{array}$ & $\begin{array}{c}\text { Farinha de } \\
\text { Madeira } \\
\text { Madeira Ltda }\end{array}$ & "mesh" 150 & $0,250 \mathrm{~g} / \mathrm{cm}^{3}$ & $8,5 \%$ \\
& & & & \\
\hline
\end{tabular}

Na Tabela 2 são apresentadas as características do pó de madeira. 
Tabela 2 - Características do pó de madeira.

\begin{tabular}{cccccccccc}
\hline Malha & M-40 & M-50 & M-60 & M-70 & M-80 & M-100 & M-140 & M-200 & Fundo \\
\hline Encontradas & 0,00 & 0,08 & 0,19 & 3,00 & 2,70 & 17,58 & 28,07 & 18,89 & 29,49 \\
\hline
\end{tabular}

Esta farinha de madeira é muito utilizada pelas indústrias como carga para redução de custos e para melhorar as condições físicas dos produtos finais, nos segmentos de plásticos, de fundição (macharia e moldes), de cerâmica refratária e de tintas. É utilizada também como material acústico, em explosivos, eletrodos e ainda como abrasivo suave para limpeza e polimento de peças.

\subsubsection{Polipropileno}

O polipropileno utilizado neste trabalho foi do tipo SM 6100, fabricado pela Polibrasil S.A Indústria e Comércio, as propriedades físicas do polipropileno são apresentadas na Tabela 3.

Tabela 3 - Propriedades físicas do polipropileno.

Polipropileno do Tipo Prolen SM 6100

\begin{tabular}{|c|c|c|c|}
\hline Propriedades & Unidades & Norma ASTM & Valores \\
\hline Índice de fluidez & $\mathrm{g} / 10 \mathrm{~min}$ & $\mathrm{D} 1238\left(230^{\circ} \mathrm{C} / 2,16 \mathrm{Kg}\right)$ & 9,0 a 14,0 \\
\hline Densidade & $\mathrm{g} / \mathrm{cm}^{3}$ & D-792 & 0,905 \\
\hline Módulo de Flexão & $\mathrm{MPa}$ & D790 (método I/A) & 13000 \\
\hline Temperatura de amolecimento Vicat & ${ }^{\circ} \mathrm{C}$ & D1525 & 152,0 \\
\hline Resistência à tração & $\mathrm{MPa}$ & $\mathrm{D} 638(50 \mathrm{~mm} / \mathrm{min})$ & 34 \\
\hline Dureza Shore D & - & D2240 (1 s) & 70 \\
\hline Impacto IZOD $\left({ }^{\circ} \mathrm{C}\right)$ & \multirow[b]{3}{*}{$\mathrm{J} / \mathrm{m}$} & \multirow[b]{3}{*}{ D256 } & \\
\hline 23 & & & 25 \\
\hline-25 & & & - \\
\hline Temperatura de deflexão ao calor & \multirow[b]{3}{*}{${ }^{\circ} \mathrm{C}$} & \multirow[b]{3}{*}{ D648 } & \\
\hline $0,45 \mathrm{MPa}$ & & & 105,0 \\
\hline $1,8 \mathrm{MPa}$ & & & 57,0 \\
\hline
\end{tabular}




\subsubsection{Titanato de Bário}

$\mathrm{O}$ agente de acoplagem titanato de bário utilizado foi fornecido pela indústria Certronic Ind. e Com. Ltda. Na Tabela 4 são apresentadas as características do titanato de bário tipo A.

Tabela 4 - Características do titanato de bário tipo A.

\begin{tabular}{lcccc}
\hline \multicolumn{4}{c}{ Características } \\
\hline \multicolumn{1}{c}{ Propriedades } & Dados & Mínimo & Máximo & Unidades \\
\hline Umidade & 0,08 & - & 0,20 & $\%$ \\
Superfície de contado & 3,45 & 2,20 & 4,00 & $\mathrm{~m}^{2} / \mathrm{g}$ \\
Densidade em massa & 1,40 & 1,40 & 1,80 & $\mathrm{~g} / \mathrm{cm}^{3}$ \\
Mesh & 325 & - & - & $\#$ \\
Resíduo na malha & 0,001 & - & 0,10 & $\%$ \\
Magnétco & ok & - & 0,0005 & $\%$ \\
\hline
\end{tabular}

$\mathrm{Na}$ Tabela 5 são apresentadas as propriedades químicas do titanato de bário tipo A.

Tabela 5 - Propriedades químicas do titanato de bário tipo A.

\begin{tabular}{|c|c|c|c|c|}
\hline \multicolumn{5}{|c|}{ Propriedades Químicas } \\
\hline Fórmula & Dados & Mínimo & Máximo & Unidades \\
\hline $\mathrm{BaTiO}_{3}($ Pureza $)$ & 99,22 & 99,20 & - & $\%$ \\
\hline $\mathrm{BaO} / \mathrm{TiO}_{2}$ & 0,99 & 0,99 & 1,01 & $\%$ \\
\hline $\mathrm{BaO}$ (livre) & 1,00 & - & 1,00 & $\%$ \\
\hline $\mathrm{Al}_{2} \mathrm{O}_{3}$ & 0,06 & - & 0,10 & $\%$ \\
\hline $\mathrm{SiO}_{2}$ & 0,01 & - & 0,05 & $\%$ \\
\hline $\mathrm{SrO}$ & 0,10 & - & 0,80 & $\%$ \\
\hline $\mathrm{Na}_{2} \mathrm{O}+\mathrm{K}_{2} \mathrm{O}$ & 0,03 & - & 0,05 & $\%$ \\
\hline Perdas na queima $\left(@ 1000^{\circ} \mathrm{C}\right)$ & 0,42 & - & 0,5 & $\%$ \\
\hline
\end{tabular}




\subsubsection{Diacrilato de Tripropileno Glicol}

O diacrilato de tripropileno glicol foi fornecido pela Bandeirante Química Ltda. As características do TPDGA são apresentadas na Tabela 6.

Tabela 6 - Características do diacrilato de tripropileno glicol

\begin{tabular}{llc}
\hline & Propriedades químicas & \\
\hline Ensaio & Especificação & Unidades \\
\hline Densidade Específica DMA 48 & 1,0310 - 1,0450 & \\
HQ HPLC & Máx. 10,00 & $\mathrm{ppm}$ \\
MEHQ HPLC & $150,00-200,00$ & $\mathrm{ppm}$ \\
Peróxido I2 LIB & Máx. 50,00 & $\mathrm{ppm}$ \\
Acidez AA & Máx. 0,0200 & $\%$ \\
Água & 0,2000 & $\%$ \\
Poli MEOH 1=Passa & $1,00-1,00$ & \\
Viscosidade BKFD 25C & $10,00-20,00$ & $\%$ \\
Pureza CG, & $79,00-100,00$ & $\%$ \\
Solvente CG & Máx. 0,1000 & $\mathrm{~g} / \mathrm{mol}$ \\
Claridade 1=CL 2=HZ 3=CD & $1,00-1,00$ & \\
Cor, APHA & Máx. 150,00 & \\
Índice de Refração & 1,4485 & \\
$\mathrm{~T}_{\mathrm{g}}$ & 62 & \\
Massa Molar & 300 & \\
\hline
\end{tabular}

É um líquido claro de baixa volatilidade, de baixa viscosidade e rápida reatividade.

O diacrilato de tripropileno glicol possui como propriedades:

- Molhabilidade;

- Resistência à água e química;

- Flexibilidade, 
- Adesão;

- Dureza e resistência à abrasão;

- Resistência ao impacto.

Possui diversas aplicações:

- Adesivos: fitas;

- Revestimentos: vidro, metal, papel, plástico, assoalho PVC, madeira;

- Tintas de impressão: flexo e roto gravura, lito, "offset", "screen".

\subsection{TÉCNICA DE PREPARAÇÃO DAS AMOSTRAS}

Os materiais citados no item 7.1 foram misturados em calandra, triturados obtendo-se um produto em pellets possível de ser injetado. $\mathrm{Na}$ injetora foram produzidos os corpos-de-provas de acordo com as normas específicas de cada ensaio. Nas Figuras 25 a 28 são mostrados os materiais usados neste trabalho.

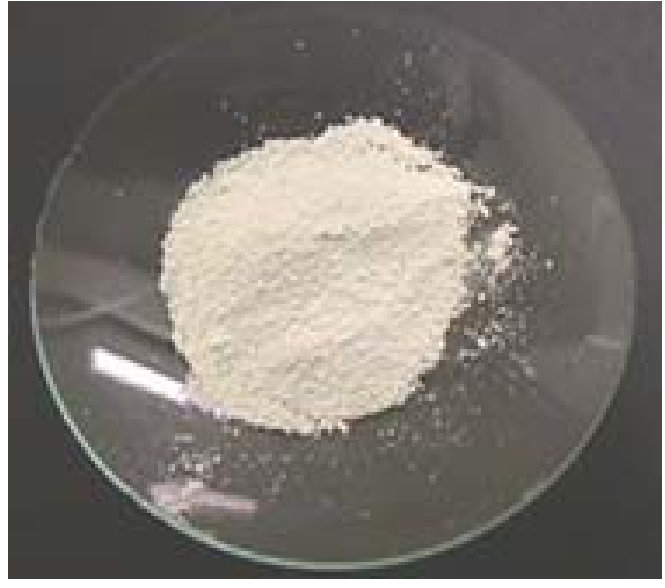

Figura 25 - Titanato de Bário

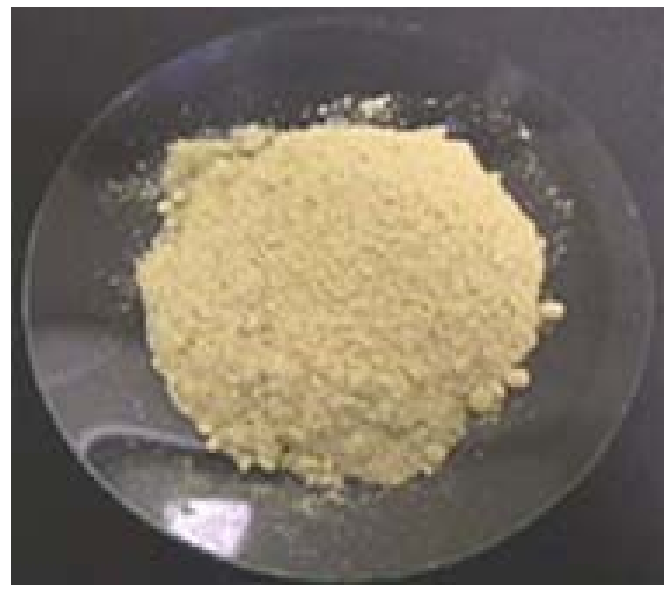

Figura 26 - Pó de Madeira (WF) 


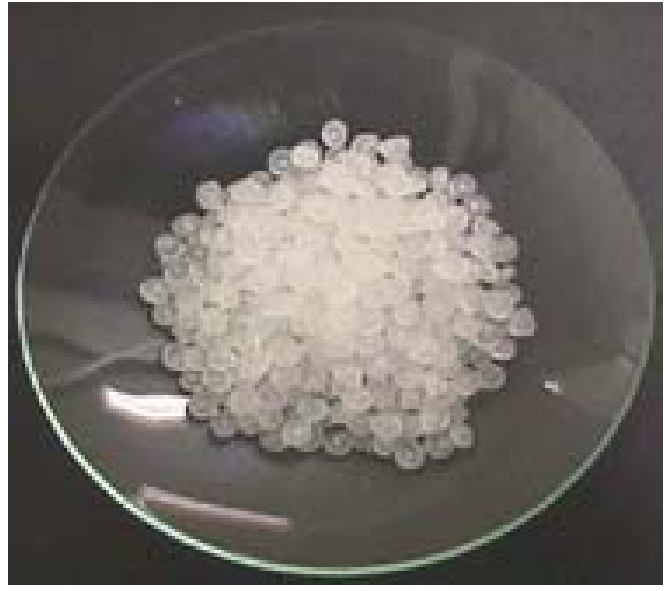

Figura 27 - Polipropileno (PP).

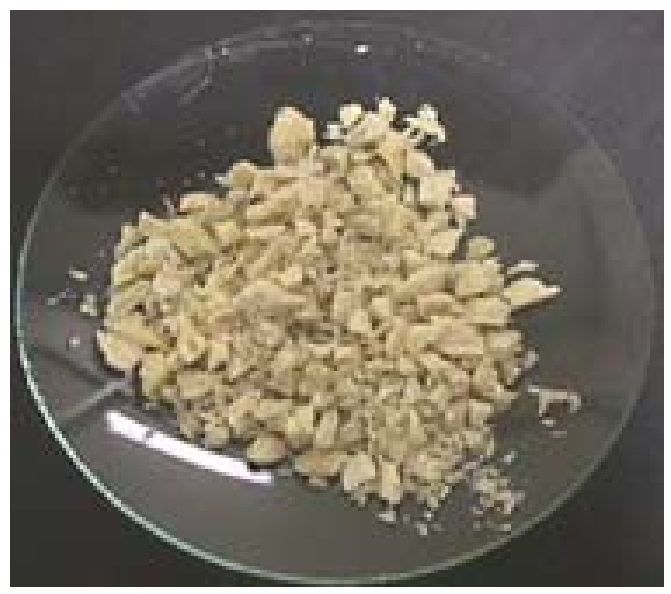

Figura 28 - Compósito WF/PP.

Na Tabela 7 são apresentados os materiais constituintes do compósito e sua composição.

Tabela 7 - Composição em peso dos materiais constituintes do compósito.

\begin{tabular}{lcccc}
\hline \multicolumn{1}{c}{ Amostras } & Polipropileno & Pó de madeira & TiBa & TPDGA \\
\hline $10 \% \mathrm{WF} / \mathrm{PP}$ & $90 \%$ & $10 \%$ & $0 \%$ & $0 \%$ \\
$10 \% \mathrm{WF}+\mathrm{TiBa} / \mathrm{PP}$ & $90 \%$ & $10 \%$ & $1 \%$ & $0 \%$ \\
$10 \% \mathrm{WF}+\mathrm{TiBa}+\mathrm{TPDGA} / \mathrm{PP}$ & $90 \%$ & $10 \%$ & $1 \%$ & $1 \%$ \\
$15 \% \mathrm{WF} / \mathrm{PP}$ & $85 \%$ & $15 \%$ & $0 \%$ & $0 \%$ \\
$15 \% \mathrm{WF}+\mathrm{TiBa} / \mathrm{PP}$ & $85 \%$ & $15 \%$ & $1 \%$ & $0 \%$ \\
$15 \% \mathrm{WF}+\mathrm{TiBa}+\mathrm{TPDGA} / \mathrm{PP}$ & $85 \%$ & $15 \%$ & $1 \%$ & $1 \%$ \\
$20 \% \mathrm{WF} / \mathrm{PP}$ & $80 \%$ & $20 \%$ & $0 \%$ & $0 \%$ \\
$20 \% \mathrm{WF}+\mathrm{TiBa} / \mathrm{PP}$ & $80 \%$ & $20 \%$ & $1 \%$ & $0 \%$ \\
$20 \% \mathrm{WF}+\mathrm{TiBa}+\mathrm{TPDGA} / \mathrm{PP}$ & $80 \%$ & $20 \%$ & $1 \%$ & $1 \%$ \\
\hline
\end{tabular}

\subsection{TRATAMENTO DA CARGA PÓ DE MADEIRA COM O AGENTE DE ACOPLAGEM}

O procedimento consiste em misturar o agente de acoplagem a 2\% numa solução de água em etanol que teve seu $\mathrm{pH}$ acertado entre 4,5 e 5,5 com o uso de ácido acético. 
A solução foi homogeneizada por agitação mecânica durante dois minutos, para posteriormente ser adicionada a uma quantidade de carga tal que a porcentagem em massa do agente de acoplagem em relação à carga fique em torno de $1 \%$. A mistura ficou em repouso por 5 minutos, e em seguida efetuou-se a lavagem da carga com etanol para posterior secagem em estufa durante 1 hora a $110^{\circ} \mathrm{C}$. Nos casos das amostras com TPDGA este foi adicionado na solução contendo titanato com pó de madeira.

Depois de seca a carga será levada para a etapa de mistura e homogeneização na calandra.

Para o tratamento da carga com o TPDGA juntamente com o TiBa o procedimento utilizado foi o mesmo porém a porcentagem do monômero e do agente de acoplagem deve ficar em torno de $1 \%$ cada um na solução preparada.

\subsection{MISTURA DOS MATERIAIS NA CALANDRA}

A mistura dos materiais ocorreu em uma calandra, modelo C 400-3. A calandra é um equipamento que consiste essencialmente de dois rolos cuja função é converter um polímero (termoplástico ou elastômero), altamente viscoso, em filme ou laminado, esse processamento leva o nome de calandragem. A calandra utilizada é mostrada na Figura 29.

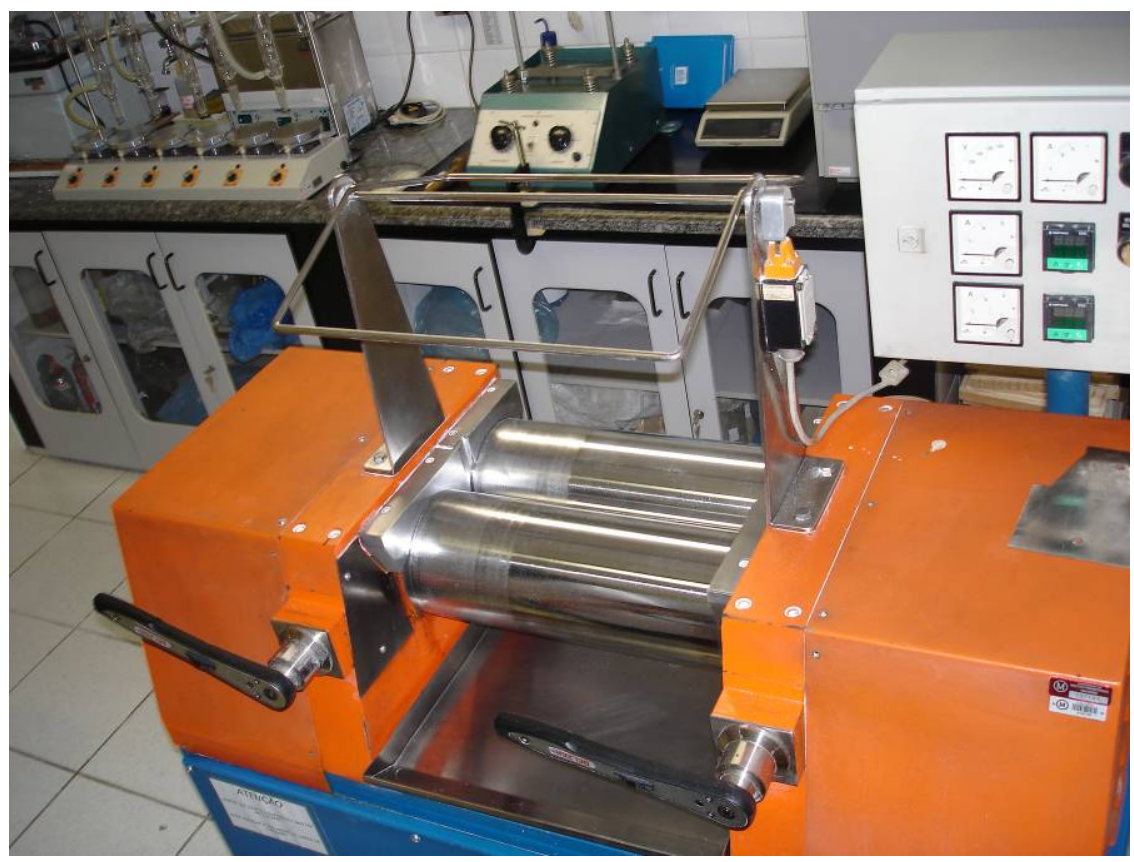

Figura 29 - Calandra, modelo C 400-3 da Universidade Presbiteriana Mackenzie.

As amostras foram calandradas a uma temperatura de aproximadamente $180^{\circ} \mathrm{C}$. 


\subsection{INJEÇÃO DAS AMOSTRAS}

As amostras depois de misturadas foram injetadas utilizando o equipamento modelo Primax 65R, Figura 30. A resina alimenta um cilindro aquecido, onde no seu interior há uma rosca que gira empurrando o material para a parte dianteira da injetora passando pelas zonas de aquecimento e plastificando para então sob certa pressão forçar a resina para dentro do molde.

Foram utilizadas as seguintes temperaturas:

$\mathrm{Z}_{1}=175^{\circ} \mathrm{C} ; \mathrm{Z}_{2}=180^{\circ} \mathrm{C} ; \mathrm{Z}_{3}=190^{\circ} \mathrm{C} ; \mathrm{Bico} \mathrm{Z}_{4}=205^{\circ} \mathrm{C}$

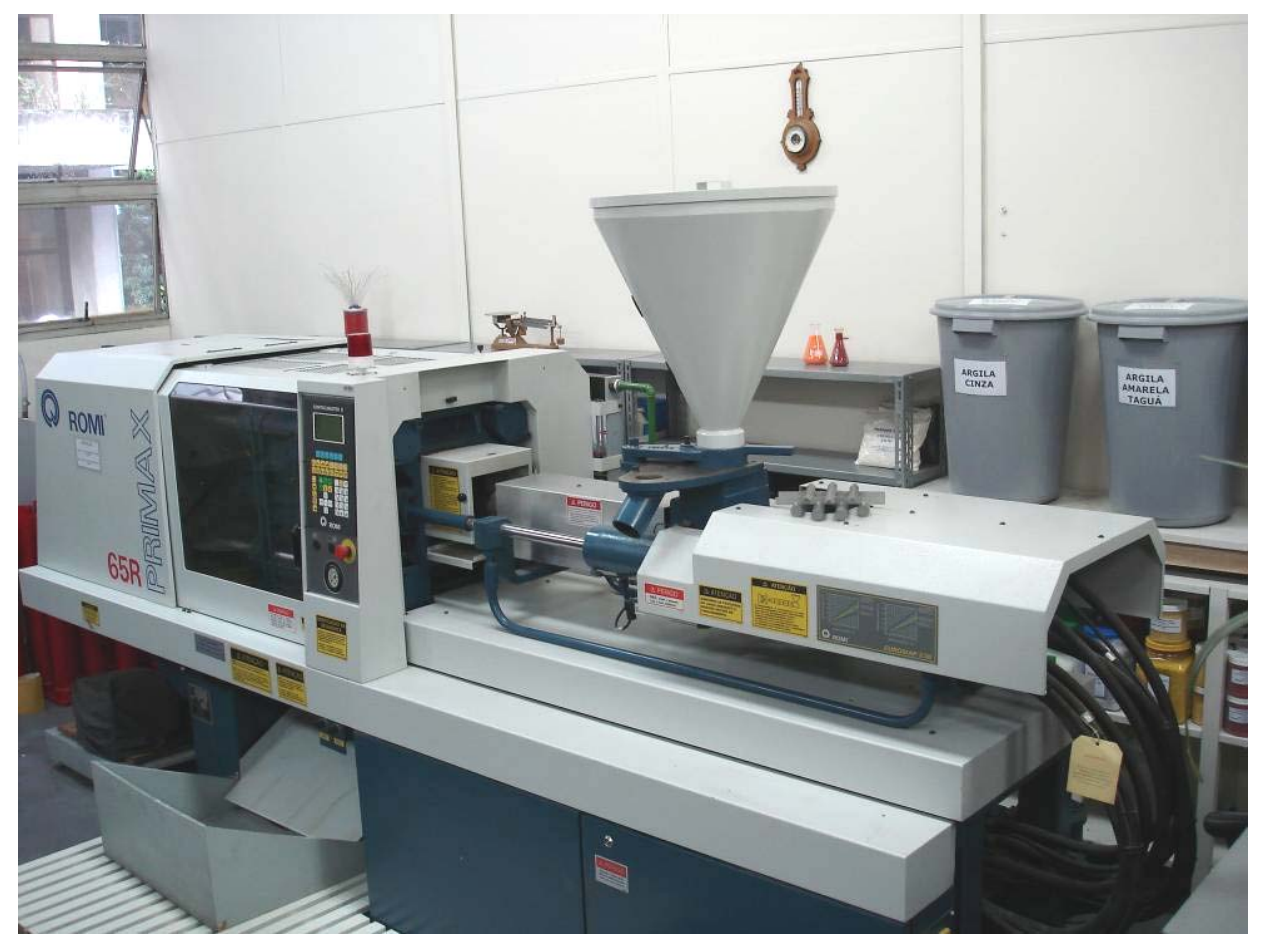

Figura 30 - Injetora modelo Primax 65R da Universidade Presbiteriana Mackenzie.

\subsection{IRRADIAÇÃO DAS AMOSTRAS}

Para irradiação das amostras foi utilizado o acelerador de elétrons do CTRIPEN, Dynamitron JOB 188, Figura 31 que possui as seguintes características:

- Energia dos elétrons entre 0,5 e 1,5MeV;

- Corrente de $0,3 \mathrm{~mA}$ a $25 \mathrm{~mA}$; 
- Doses de radiação utilizadas $10 \mathrm{kGy}$ e $20 \mathrm{kGy}$. Nos ensaios de tração além dessas doses foram utilizadas também $15 \mathrm{kGy}$ e $25 \mathrm{kGy}$.

- Área de irradiação - diâmetro do feixe $2,5 \mathrm{~cm}$ a $10 \mathrm{~cm}$ da janela, a largura da varredura é ajustável entre 60 e $120 \mathrm{~cm}$.

Possui ainda um sistema com bomba a vácuo e uma bandeja com suporte para as amostras serem irradiadas.

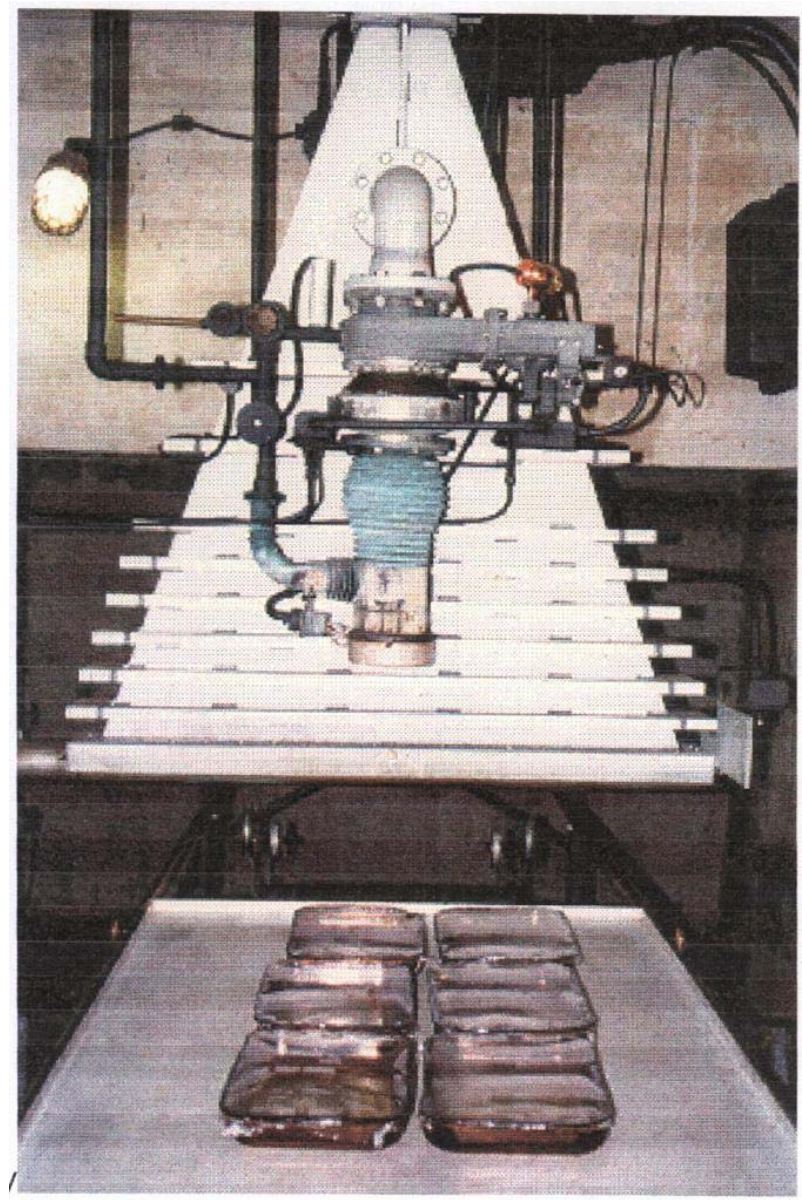

Figura 31 - Acelerador de elétrons do CTR-IPEN, Dynamitron JOB 188.

\subsection{ENSAIO REOLÓGICO}

Foi realizado o ensaio de índice de fluidez para as amostras de compósito WF/PP nas condições descritas a continuação. 


\subsection{1 Índice de Fluidez (IF)}

O ensaio do índice de fluidez para materiais termoplásticos obedeceu à norma ASTM D-1238, condição L, que fixa as condições técnicas exigidas para a medição do índice de fluidez.

A unidade mais usual do índice de fluidez é g/10min, isto é, a quantidade de massa, medida em gramas, extrudada em 10 minutos.

$\mathrm{O}$ instrumento utilizado para a determinação do índice de fluidez foi $\mathrm{o}$ Extrusion Plastometer, modelo MP993a, que opera em temperatura determinada. Consiste de um cilindro de aço, fixado na posição vertical e adequadamente isolado para temperaturas de até $300^{\circ} \mathrm{C}$.

O comprimento do cilindro deve estar entre 115 e 180mm e o diâmetro interno ao longo de todo comprimento medindo entre 9.500 e $10.000 \mathrm{~mm}$ com uma tolerância de \pm $0,025 \mathrm{~mm}$. A base do cilindro deve ser termicamente isolada, de tal forma que a área exposta seja inferior a $400 \mathrm{~mm}$ sendo recomendável que o material usado seja isolado com politetrafluoroetileno, com uma espessura em torno de $3 \mathrm{~mm}$, para evitar aderência. A superfície interna do cilindro deve ser convenientemente endurecida e não inferior a 500 Vickers de dureza (HV).

O pistão de aço deve ter um comprimento útil que seja no mínimo tão longo quanto o cilindro, com uma cabeça de comprimento $\mathrm{L}=(6,35 \pm 0,10) \mathrm{mm}$.

$\mathrm{O}$ diâmetro da cabeça do pistão deve ser inferior ao diâmetro interno do cilindro em $(0,075 \pm 0.015) \mathrm{mm}$. A borda inferior da cabeça do pistão deve ter um raio de $0,4 \mathrm{~mm}$ e a superior deve ter suas bordas cortantes removidas. Acima da cabeça, o pistão deve ter o seu diâmetro reduzido para cerca de $9 \mathrm{~mm}$. Um pino pode ser inserido na extremidade superior do pistão a fim de suportar a carga removível e o pistão deve ser termicamente isolado da carga. O pistão deve ser marcado com dois traços anulares de referência, indicadores do comprimento do cilindro dentro do qual todos os cortes úteis do extrudado devem ser considerados separados de $30 \mathrm{~mm}$ e posicionados de tal forma que o traço superior fique alinhado com o topo do cilindro, quando a distância entre a borda inferior da cabeça do pistão e o topo da matriz for de $20 \mathrm{~mm}$.

O sistema de aquecimento e controle de temperatura deve ser tal que a temperatura selecionada do material do cilindro possa ser mantida de $\pm 0,5^{\circ} \mathrm{C}$. 
O termômetro de mercúrio ou outro dispositivo para medir a temperatura deve ser localizado tão próximo quanto possível do orifício do cilindro e a $15 \mathrm{~mm}$ de sua base, possibilitando medições de temperatura com incerteza de $\pm 0,1^{\circ} \mathrm{C}$.

A carga removível no topo do pistão consiste num conjunto de pesos que podem ser ajustados de modo que a massa combinada da carga e pistão será calculada conforme a Equação 4, com uma tolerância de $\pm 0,5 \%$ g.

$$
\mathrm{IF}_{(\mathrm{T}, \mathrm{M})}=\frac{\mathrm{s} . \mathrm{m}}{\mathrm{t}}
$$

Sendo:

$\mathrm{T}=$ temperatura do ensaio;

$\mathrm{M}=$ carga nominal em quilogramas;

$\mathrm{s}=$ tempo de referência em segundos, tempo escolhido onde os intervalos de tempo de corte são reportados;

$\mathrm{m}=$ massa média em gramas da amostra;

$\mathrm{t}=$ intervalo de tempo em segundos, no qual as amostras foram recolhidas.

O ensaio realizado seguindo a norma ASTM D-1238, condição L, determina a temperatura $\mathrm{T}=203^{\circ} \mathrm{C}$ e carga de $2160 \mathrm{~kg}$, sendo que o material estava na forma de grânulos. O instrumento utilizado para a determinação do índice de fluidez é o Extrusion Plastometer, modelo MP993a do Departamento de Engenharia de Materiais, da Escola de Engenharia da UPM, como mostrado na Figura 32.

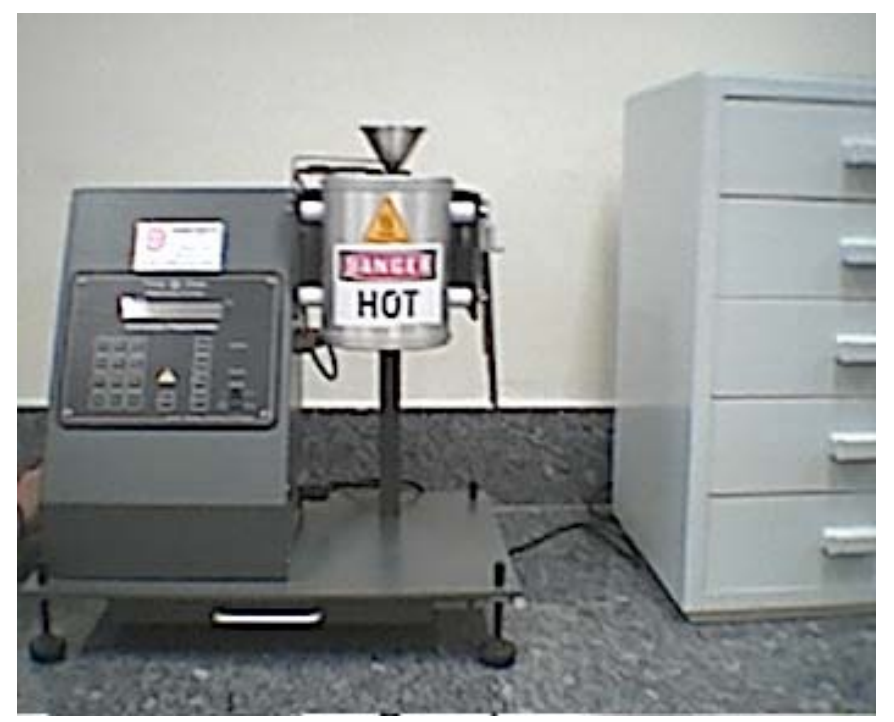

Figura 32 - "Extrusion Plastometer" da Universidade Mackenzie. 


\subsection{ENSAIOS MECÂNICOS}

Foram realizados os ensaios de resistência à tração, resistência ao impacto e dureza para as amostras de WF/PP nas condições descritas nos itens a continuação.

\subsubsection{Resistência à tração}

O ensaio é descrito pela norma ASTM D638 que determina a máxima tensão que um material pode suportar antes de romper, ocorrendo a deformação. É a força máxima requerida pela área da secção transversal. O equipamento utilizado foi uma máquina universal de ensaios Instron modelo 5567 este ensaio foi realizado no Centro de Tecnologia das Radiações (CTR). - IPEN (Instituto de Pesquisas Energéticas e Nucleares).

O módulo de elasticidade é uma indicação da rigidez de um material, sendo determinado a partir do digrama tensão versus deformação. A máquina de ensaios Universal utilizada é similar a mostrada na Figura 33.

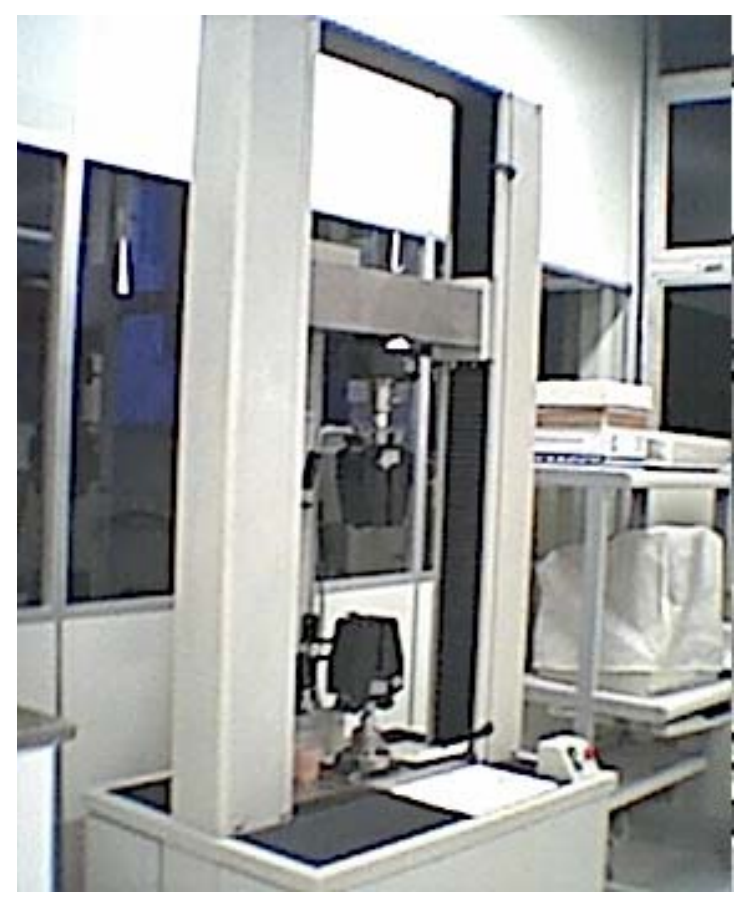

Figura 33 - Máquina de ensaios Universal

Neste ensaio, 5 corpos-de-prova de cada composição, na forma de gravatas tipo 1 de acordo com a norma foram submetidos à tração até a ruptura, em equipamento Instron 
5567, com célula de carga de $1 \mathrm{kN}$, velocidade do travessão de $50 \mathrm{~mm} / \mathrm{min}$ e L0 de $15 \mathrm{~mm}$, a temperatura ambiente. A norma recomenda um condicionamento dos corpos de prova à $(23 \pm 2)^{\circ} \mathrm{C}$ e $(50 \pm 5) \%$ de umidade relativa, no mínimo 40 horas antes do ensaio. A tensão de tração na ruptura é a relação entre a força de ruptura e a área da secção transversal original, como na equação 5:

$$
\sigma_{\mathrm{tr}}=\underline{\mathrm{F}_{\mathrm{r}}}
$$

Sendo:

$\sigma_{\mathrm{tr}}=$ tensão na ruptura sob tração;

$\mathrm{F}_{\mathrm{r}}=$ força de ruptura na tração;

$\mathrm{A}_{0}=$ área da secção transversal inicial do corpo-de-prova.

\subsubsection{Resistência ao Impacto}

A resistência ao impacto é aquela necessária para o rompimento do material. É descrita pela norma ASTM D256, e depende da geometria do corpo-de-prova, da presença de falhas e das condições do ensaio. Existem materiais com pouca resistência ao impacto (frágeis) e materiais com grande resistência (dúcteis) como os materiais cerâmicos e os metais.

A energia requerida para quebrar o corpo-de-prova é a soma das energias necessárias para deformá-lo, iniciar sua fratura, para propagar sua fratura, através de sua seção transversal, e a energia para alcançar sua destruição final. O equipamento utilizado para o ensaio de impacto Charpy, foi o Plastics Impact Tests modelo 892, do Departamento de Engenharia de Materiais, da Escola de Engenharia da UPM, como mostrado na Figura 34. 


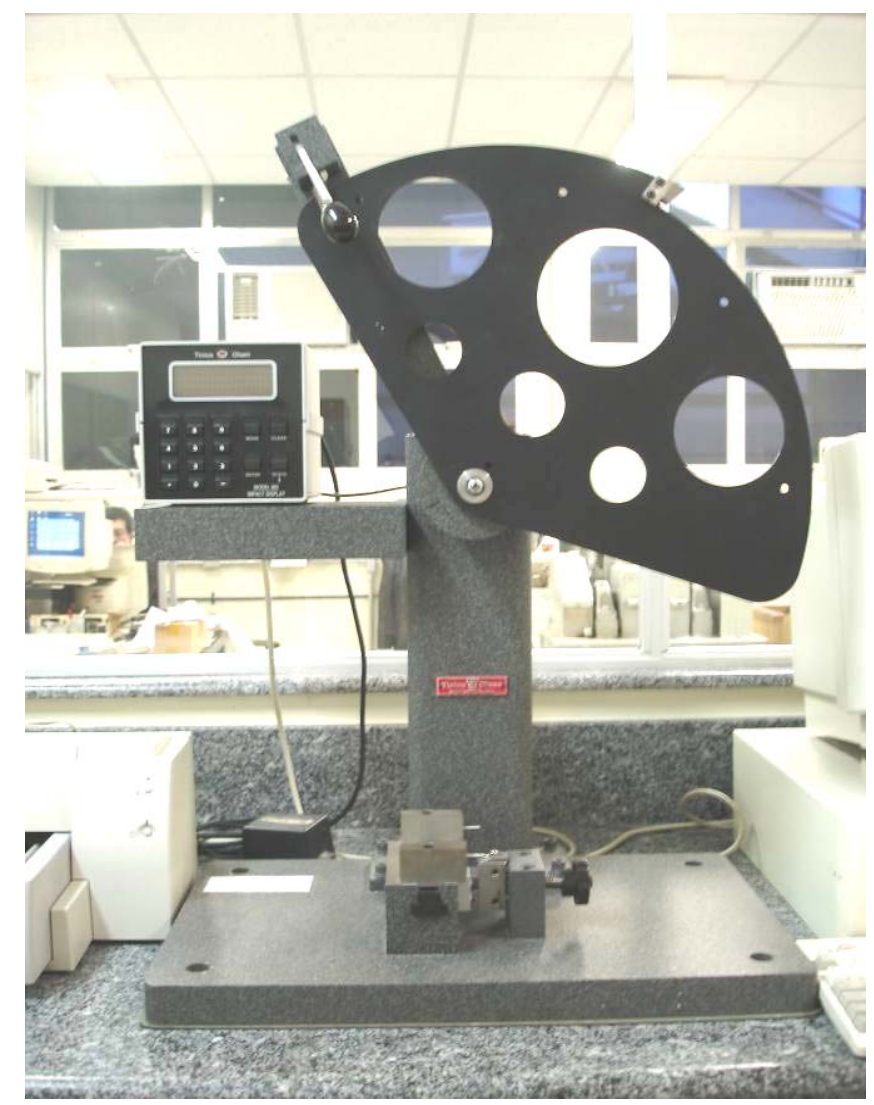

Figura 34 - Máquina de ensaios de impacto Charpy, modelo 892 da Universidade Mackenzie.

\subsubsection{Dureza}

O ensaio de dureza consiste em medir a resistência à penetração dos materiais, utilizando um instrumento chamado de durômetro. O princípio do método é a medida do esforço de um determinado penetrador, aplicado sobre um material em condições determinadas. A dureza por penetração é inversamente proporcional à penetração e depende do módulo de elasticidade e das propriedades viscoelásticas do produto.

O durômetro do tipo Shore A é utilizado para materiais mais flexíveis e o durômetro do tipo Shore $\mathrm{D}$ para materiais mais rígidos.

O corpo-de-prova deve ter pelo menos $5 \mathrm{~mm}$ de espessura para a determinação da dureza Shore A e pelo menos $3 \mathrm{~mm}$ para a determinação da dureza Shore D. A superfície do corpo-de-prova deve ser plana, colocado sobre uma superfície que permita à base de pressão tomar apoio sobre o corpo-de-prova de acordo com a norma ASTM D785.

A cristalinidade e as ligações cruzadas são fatores que aumentam a dureza de um material. O equipamento utilizado para o ensaio de dureza Shore D foi o durômetro 
Analógico Pacifc Transducer Corp. modelo 2301, do Departamento de Engenharia de Materiais, da Escola de Engenharia da UPM, como mostrado na Figura 35.

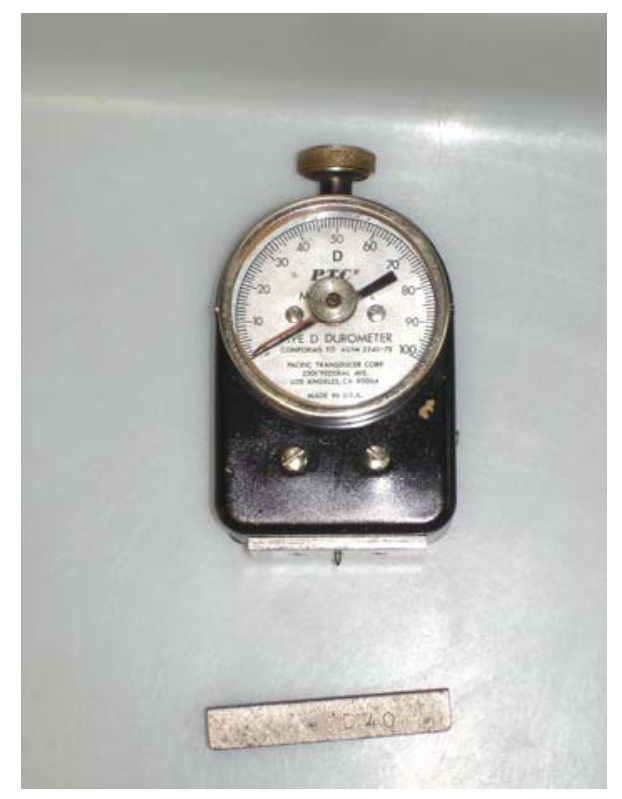

Figura 35 - Durômetro Analógico Pacifc Transducer Corp. 2301.

\subsection{ENSAIOS TÉRMICOS}

Foram realizados os ensaios de temperatura de deflexão térmica e de temperatura de amolecimento Vicat para as amostras de WF/PP nas condições descritas nos itens 7.9.1 e 7.92.

\subsubsection{Temperatura de Deflexão térmica (HDT)}

A temperatura de deflexão térmica é aquela na qual se observa um decréscimo pronunciado das propriedades mecânicas de um corpo-de-prova, quanto mais alta a temperatura maior a resistência do material. É determinada em graus Celsius pela norma ASTM D648.

O teste mede o efeito da temperatura a uma tensão em uma área definida e a temperatura é então levada a uma taxa constante. A amostra a ser ensaiada é aquecida num banho de óleo de silicone. 
A carga atua no material durante $5 \mathrm{~min}$. para que se tenha a estabilização dos efeitos da fluência. Após esse tempo tem início o ensaio cujo banho começa a ser aquecido a uma temperatura de $25^{\circ} \mathrm{C}$, e eleva-se a uma taxa de aquecimento de $5{ }^{\circ} \mathrm{C} / \mathrm{min}$.

A deflexão no corpo-de-prova é registrada, e a temperatura na qual o corpo-deprova atinge uma deflexão de $0,25 \mathrm{~mm}$ é a temperatura de deflexão térmica do material ensaiado.

Os ensaios podem ser de longa ou curta duração, os de longa duração dependem das propriedades químicas dos polímeros, isto é, da resistência à degradação térmica e à oxidação dos polímeros. Já os de curta duração vão depender das propriedades físicas como temperatura de transição vítrea, cristalinidade, ponto de fusão e o reforço contido.

O equipamento utilizado para o ensaio de temperatura de deflexão ao calor foi o Tinus Olsen modelo HD-94/398, do Departamento de Engenharia de Materiais, da Escola de Engenharia da UPM, como mostrado na Figura 36.

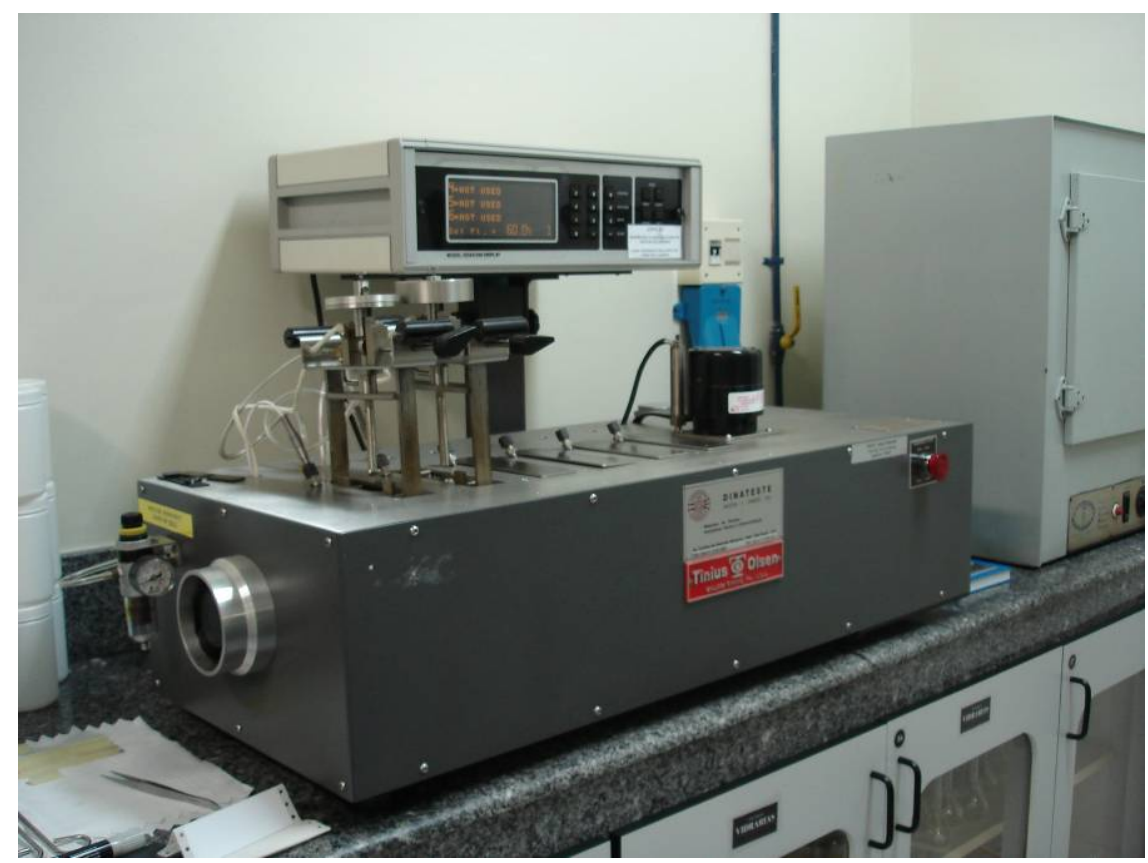

Figura 36 - Equipamento utilizado para o ensaio de temperatura de deflexão ao calor e ponto de amolecimento Vicat. 


\subsubsection{Temperatura de amolecimento Vicat}

É aplicado apenas em materiais termoplásticos pela norma ASTM D1525. Consiste de um banho de óleo de silicone, tendo controle sensível da temperatura e contendo um penetrador na forma de agulha fina, montado de forma a permitir o registro do grau de penetração por meio de um apalpador de precisão. No procedimento deste ensaio, a agulha, cuja a área mede $1 \mathrm{~mm}^{2}$, atua como uma carga de $1 \mathrm{~kg}$ sobre a amostra, sendo que a temperatura do óleo de silicone aumenta a uma taxa de $50{ }^{\circ} \mathrm{C} / \mathrm{h}$ ou $120{ }^{\circ} \mathrm{C} / \mathrm{h}$. A temperatura na qual a agulha penetrar $1 \mathrm{~mm}$ é defina como temperatura de amolecimento Vicat.

O equipamento utilizado para o ensaio de temperatura de amolecimento Vicat foi o Tinus Olsen modelo HD-94/398, do Departamento de Engenharia de Materiais, da Escola de Engenharia da UPM, como mostrado na Figura 36. 


\section{RESULTADOS E DISCUSSÃO}

Foram realizados diversos ensaios com o objetivo de caracterizar os compostos obtidos e comparar as suas propriedades nas seguintes composições:

- PP (puro) e PP (puro) irradiado nas doses de 10kGy e 20kGy;

- 10\%WF/PP não irradiado (90\% polipropileno reforçado com $10 \%$ de pó de madeira) e irradiado nas doses de $10 \mathrm{kGy}$ e $20 \mathrm{kGy}$.

- $10 \% \mathrm{WF}+\mathrm{TiBa} / \mathrm{PP}$ não irradiado (90\% polipropileno reforçado com $10 \%$ de pó de madeira tratada com titanato de bário) e irradiado nas doses de $10 \mathrm{kGy}$ e 20kGy.

- 10\%WF+TiBa+TPDGA/PP não irradiado (90\% polipropileno reforçado com $10 \%$ de pó de madeira tratada com titanato de bário e diacrilato de tripropileno glicol ) e irradiado nas doses de $10 \mathrm{kGy}$ e $20 \mathrm{kGy}$.

Também se preparou o mesmo número de amostras para as composições de $15 \% \mathrm{WF} / \mathrm{PP}$ e $20 \% \mathrm{WF} / \mathrm{PP}$.

Para o ensaio de resistência à tração as amostras foram irradiadas também com doses de radiação de $15 \mathrm{kGy}$ e $20 \mathrm{kGy}$.

\subsection{ENSAIOS DE ÍNDICE DE FLUIDEZ}

A caracterização reológica dos compostos não irradiados foi feita por meio de ensaios de índice de fluidez

O índice de fluidez foi determinado para as seguintes composições de PP:

- PP (puro);

$-10 \% \mathrm{WF} / \mathrm{PP}$,

- 10\%WF+TiBa/PP,

$-10 \% \mathrm{WF}+\mathrm{TiBa}+\mathrm{TPDGA} / \mathrm{PP}$,

$-15 \% \mathrm{WF} / \mathrm{PP}$,

$-15 \% \mathrm{WF}+\mathrm{TiBa} / \mathrm{PP}$,

- 15\%WF+TiBa+TPDGA/PP,

$-20 \% \mathrm{WF} / \mathrm{PP}$, 
$-20 \% \mathrm{WF}+\mathrm{TiBa} / \mathrm{PP}$,

- 20\%WF+TiBa+TPDGA/PP.

Nas Tabelas 8, 9 e 10 são apresentadas os resultados para o ensaio de índice de fluidez para as composições de PP; 10\%WF/PP, 10\%WF+TiBa/PP, $10 \% \mathrm{WF}+\mathrm{TiBa}+\mathrm{TPDGA} / \mathrm{PP} ; 15 \% \mathrm{WF} / \mathrm{PP}, 15 \% \mathrm{WF}+\mathrm{TiBa} / \mathrm{PP}, 15 \% \mathrm{WF}+\mathrm{TiBa}+\mathrm{TPDGA} / \mathrm{PP}$; 20\%WF/PP, 20\%WF+TiBa/PP, 20\%WF+TiBa+TPDGA/PP.

Tabela 8 - Índice de fluidez (g/10min) das amostras de PP (puro) e de diferentes composições de PP com $10 \%$ de pó de madeira.

\begin{tabular}{c|cccc}
\hline Amostras & PP (Puro) & $10 \% \mathrm{WF} / \mathrm{PP}$ & $\begin{array}{c}10 \% \mathrm{WF}+\mathrm{TiBa} / \\
\text { PP }\end{array}$ & $\begin{array}{c}10 \% \mathrm{WF}+\mathrm{TiBa}+ \\
\mathrm{TPDGA} / \mathrm{PP}\end{array}$ \\
\hline 1 & 0,190 & 0,168 & 0,166 & 0,188 \\
2 & 0,201 & 0,170 & 0,180 & 0,192 \\
3 & 0,199 & 0,170 & 0,164 & 0,200 \\
4 & 0,197 & 0,168 & 0,180 & 0,203 \\
5 & 0,196 & 0,168 & 0,162 & 0,214 \\
6 & 0,198 & 0,170 & 0,152 & 0,190 \\
\hline Média & 0,197 & 0,169 & 0,167 & 0,198 \\
Fluidez & 11,81 & 10,14 & 10,04 & 11,87 \\
Desvio Padrão & 0,004 & 0,001 & 0,011 & 0,010 \\
\hline
\end{tabular}

Tabela 9 - Índice de fluidez (g/10min) das amostras de PP (puro) e de diferentes composições de PP com $15 \%$ de pó de madeira.

\begin{tabular}{c|cccc}
\hline Amostras & PP (Puro) & $15 \% \mathrm{WF} / \mathrm{PP}$ & $\begin{array}{c}15 \% \mathrm{WF}+\mathrm{TiBa} / \\
\mathrm{PP}\end{array}$ & $\begin{array}{c}15 \% \mathrm{WF}+\mathrm{TiBa}+ \\
\mathrm{TPDGA} / \mathrm{PP}\end{array}$ \\
\hline 1 & 0,190 & 0,153 & 0,167 & 0,167 \\
2 & 0,201 & 0,163 & 0,173 & 0,177 \\
3 & 0,199 & 0,158 & 0,144 & 0,180 \\
4 & 0,197 & 0,159 & 0,156 & 0,189 \\
5 & 0,196 & 0,141 & 0,149 & 0,192 \\
6 & 0,198 & 0,164 & 0,176 & 0,186 \\
\hline Média & 0,197 & 0,156 & 0,161 & 0,182 \\
Fluidez & 11,81 & 9,38 & 9,65 & 10,91 \\
Desvio Padrão & 0,004 & 0,008 & 0,013 & 0,009 \\
\hline
\end{tabular}


Tabela 10 - Índice de fluidez (g/10min) das amostras de PP (puro) e de diferentes composições de PP com $20 \%$ de pó de madeira.

\begin{tabular}{c|cccc}
\hline Amostras & PP (Puro) & $20 \% \mathrm{WF} / \mathrm{PP}$ & $\begin{array}{c}20 \% \mathrm{WF}+\mathrm{TiBa} / \\
\text { PP }\end{array}$ & $\begin{array}{c}20 \% \mathrm{WF}+\mathrm{TiBa}+ \\
\text { TPDGA } / \mathrm{PP}\end{array}$ \\
\hline 1 & 0,190 & 0,130 & 0,124 & 0,164 \\
2 & 0,201 & 0,131 & 0,125 & 0,165 \\
3 & 0,199 & 0,124 & 0,126 & 0,174 \\
5 & 0,197 & 0,128 & 0,126 & 0,159 \\
6 & 0,196 & 0,128 & 0,124 & 0,164 \\
Média & 0,198 & 0,121 & 0,126 & 0,190 \\
Fluidez & 0,197 & 0,127 & 0,125 & 0,169 \\
Desvio Padrão & 11,81 & 7,62 & 7,51 & 10,161 \\
\hline
\end{tabular}

Na Figura 37 são mostrados os resultados dos ensaios de índice de fluidez para as diferentes composições de PP estudadas.

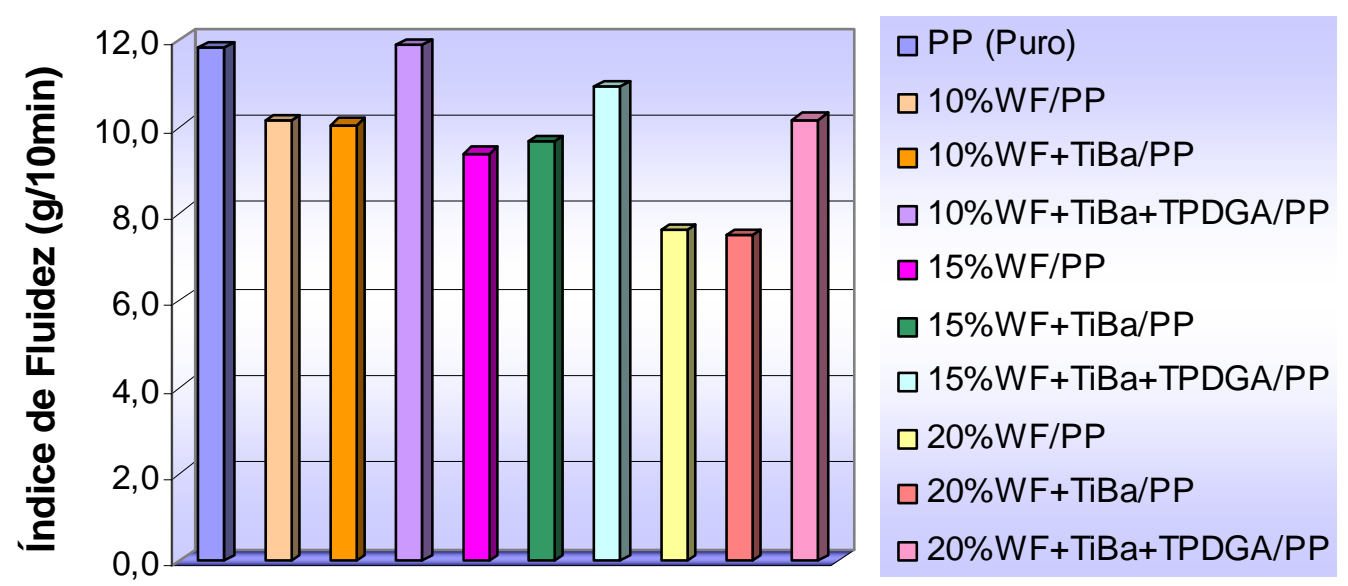

Figura 37 - Índice de fluidez para as diferentes composições de PP estudadas.

De acordo com os resultados apresentados nas Tabelas 8, 9 e 10 e mostrados na Figura 37 observou-se que:

Houve uma redução do índice de fluidez em todas as amostras comparadas com o PP (puro) com exceção da amostra com 10\%WF+TiBa+TPDGA/PP.

Os resultados mostraram que nas amostras WF/PP houve uma redução no índice de fluidez em relação ao PP (puro) de: 
$14,14 \%$ na amostra de $10 \% \mathrm{WF} / \mathrm{PP}$;

$20,58 \%$ na amostra de $15 \% \mathrm{WF} / \mathrm{PP}$;

$35,48 \%$ na amostra de $20 \% \mathrm{WF} / \mathrm{PP}$.

Nas amostras com adição de titanato houve uma redução em relação ao PP (puro) de:

$$
\begin{aligned}
& 14,99 \% \text { na amostra de } 10 \% \mathrm{WF}+\mathrm{TiBa} / \mathrm{PP} \\
& 18,29 \% \text { na amostra de } 15 \% \mathrm{WF}+\mathrm{TiBa} / \mathrm{PP} \\
& 36,41 \% \text { na amostra de } 20 \% \mathrm{WF}+\mathrm{TiBa} / \mathrm{PP}
\end{aligned}
$$

Esta redução ocorreu, pois a adição de reforço geralmente reduz o índice de fluidez dos compósitos poliméricos. A presença de partículas na matriz restringe a mobilidade das macromoléculas, dificultando o fluxo do polímero fundido e conseqüentemente aumentando sua viscosidade.

Nas amostras com o monômero TPDGA apresentaram valores próximos ao do PP (puro).

A amostra de 10\%WF+TiBa+TPDGA/PP apresentou valor de $0,51 \%$ acima do valor do PP (puro).

A amostra de 15\%WF+TiBa+TPDGA/PP apresentou um decréscimo de 7,62\% em relação ao PP (puro).

A amostra de 20\%WF+TiBa+TPDGA/PP apresentou uma redução de 13,96\% em relação ao PP (puro).

$\mathrm{O}$ tratamento superficial de $\mathrm{WF}+\mathrm{TiBa}$ proporcionou maior adesão entre o reforço e matriz polimérica reduzindo o índice de fluidez.

Os resultados das amostras com tratamento superficial de WF+TiBa+TPDGA apresentaram esses resultados pois o TPGDA agiu como aditivo plastificante tornando as amostras mais fáceis de se processar aumentando a mobilidade entre as macromoléculas. 


\subsection{ENSAIOS DE RESISTÊNCIA À TRAÇÃO}

A resistência à tração foi determinada para as seguintes composições de PP:

- PP (puro);

$-10 \% \mathrm{WF} / \mathrm{PP}$,

$-10 \% \mathrm{WF}+\mathrm{TiBa} / \mathrm{PP}$,

- 10\%WF+TiBa+TPDGA/PP,

$-15 \% \mathrm{WF} / \mathrm{PP}$,

$-15 \% \mathrm{WF}+\mathrm{TiBa} / \mathrm{PP}$,

- 15\%WF+TiBa+TPDGA/PP,

$-20 \% \mathrm{WF} / \mathrm{PP}$,

$-20 \% \mathrm{WF}+\mathrm{TiBa} / \mathrm{PP}$,

$-20 \% \mathrm{WF}+\mathrm{TiBa}+\mathrm{TPDGA} / \mathrm{PP}$.

Também foram determinadas a resistência à tração para todas as composições citadas anteriormente submetidas a doses de radiação de $10 \mathrm{kGy}, 15 \mathrm{kGy}, 20 \mathrm{kGy}$ e $25 \mathrm{kGy}$.

Nas Tabelas 11, 12, 13, 14, 16, 17, 18, 20, 21 e 22 são apresentados os resultados para a propriedade de resistência à tração das amostras irradiadas e não irradiadas do PP (puro) e das diferentes composições de PP com 10\%WF, 15\%WF e $20 \% \mathrm{WF}$.

Tabela 11 - Resistência à tração $(\mathrm{MPa})$ do $\mathrm{PP}$ (puro) das amostras irradiadas e não irradiadas.

\begin{tabular}{c|ccccc}
\hline Amostras & PP (Puro) & $\begin{array}{c}\text { PP (Puro) } \\
10 \mathrm{kGy}\end{array}$ & $\begin{array}{c}\text { PP (Puro) } \\
15 \mathrm{kGy}\end{array}$ & $\begin{array}{c}\text { PP (Puro) } \\
20 \mathrm{kGy}\end{array}$ & $\begin{array}{c}\text { PP (Puro) } \\
25 \mathrm{kGy}\end{array}$ \\
\hline 1 & 15,62 & 25,52 & 12,71 & 22,92 & 26,89 \\
2 & 18,02 & 16,76 & 21,00 & 12,15 & 25,84 \\
3 & 12,91 & 10,41 & 11,49 & 19,57 & 24,26 \\
4 & 24,98 & 17,57 & 25,62 & 19,92 & 23,31 \\
5 & 12,81 & 17,41 & 20,89 & 21,16 & - \\
\hline Média & 16,87 & 17,53 & 18,34 & 19,14 & 25,08 \\
Desvio Padrão & 5,02 & 5,37 & 6,02 & 4,12 & 1,60 \\
\hline
\end{tabular}


Na Figura 38 são mostrados os resultados de resistência à tração para as diferentes composições das PP irradiadas e não irradiadas.

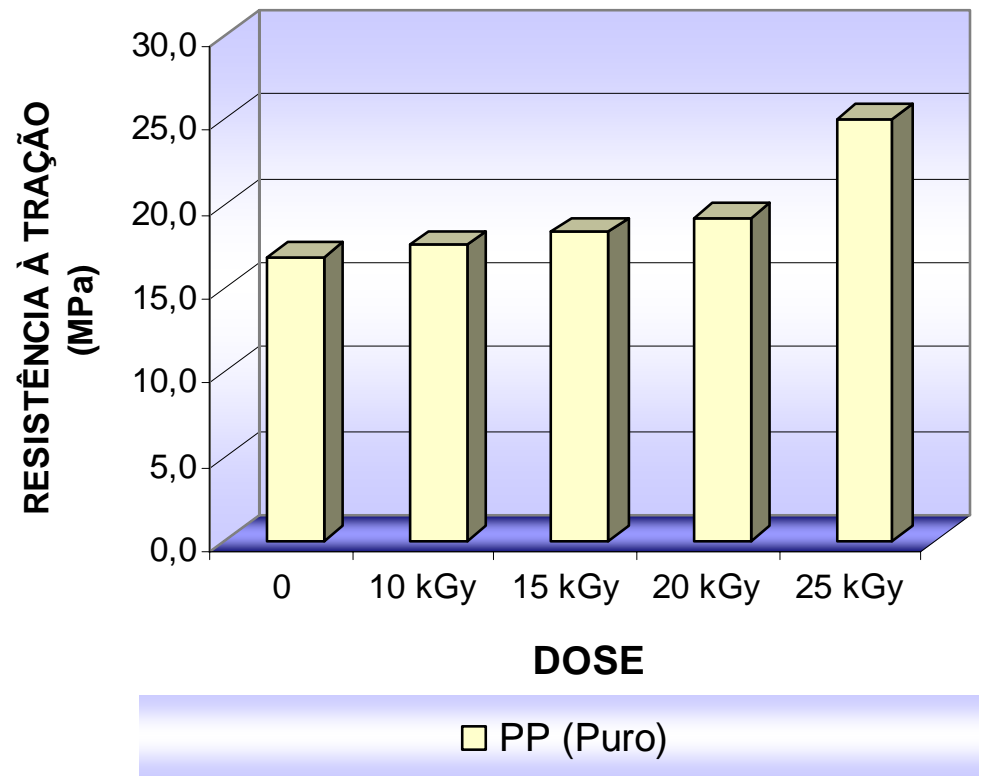

Figura 38 - Resultados do ensaio de resistência à tração das amostras de PP irradiadas e não irradiadas.

Os resultados apresentados na Tabela 11 mostraram que nas amostras de PP, quando comparados ao PP sem dose de radiação, observou-se um aumento da resistência à tração conforme o aumento da dose de radiação, este aumento foi de:

$$
\begin{aligned}
& 3,95 \% \text { na amostra PP com } 10 \mathrm{kGy} \text {; } \\
& \text { 8,64\% na amostra PP com } 15 \mathrm{kGy} \text {; } \\
& \text { 13,49\% na amostra PP com } 20 \mathrm{kGy} \text {; } \\
& \text { 48,65\% na amostra PP com } 25 \mathrm{kGy} \text {. }
\end{aligned}
$$

O acréscimo da resistência à tração conforme o aumento das doses de radiação ocorreu porque houve reticulação no PP. 
Tabela 12 - Resistência à tração $(\mathrm{MPa})$ das amostras com 10\%WF/PP irradiadas e não irradiadas.

\begin{tabular}{c|cccccc}
\hline \multirow{2}{*}{ Amostras } & PP (Puro) & $10 \% \mathrm{WF} / \mathrm{PP}$ & $\begin{array}{c}10 \% \mathrm{WF} / \mathrm{PP} \\
10 \mathrm{kGy}\end{array}$ & $\begin{array}{c}10 \% \mathrm{WF} / \mathrm{PP} \\
15 \mathrm{kGy}\end{array}$ & $\begin{array}{c}10 \% \mathrm{WF} / \mathrm{PP} \\
20 \mathrm{kGy}\end{array}$ & $\begin{array}{c}10 \% \mathrm{WF} / \mathrm{PP} \\
25 \mathrm{kGy}\end{array}$ \\
\hline 1 & 15,62 & 27,90 & 28,42 & 29,05 & 29,46 & 30,46 \\
2 & 18,02 & 32,85 & 27,66 & 30,51 & 28,08 & 29,26 \\
3 & 12,91 & 29,15 & 29,10 & 24,98 & 28,45 & 30,29 \\
4 & 24,98 & 28,60 & 29,30 & 27,50 & 29,65 & 31,47 \\
5 & 12,81 & 27,91 & 28,34 & 29,57 & 30,34 & 30,57 \\
\hline Média & 16,87 & 29,28 & 28,56 & 28,32 & 29,20 & 30,41 \\
Desvio Padrão & 5,02 & 2,06 & 0,66 & 2,16 & 0,92 & 0,79 \\
\hline
\end{tabular}

Tabela 13 - Resistência à tração $(\mathrm{MPa})$ das amostras com $10 \% \mathrm{WF}+\mathrm{TiBa} / \mathrm{PP}$ irradiadas e não irradiadas.

\begin{tabular}{c|cccccc}
\hline \multirow{3}{*}{ Amostras } & PP & $10 \% \mathrm{WF}+$ & $\begin{array}{c}10 \% \mathrm{WF}+ \\
\mathrm{TiBa} / \mathrm{PP}\end{array}$ & $\begin{array}{c}10 \% \mathrm{WF}+ \\
\mathrm{TiBa} / \mathrm{PP}\end{array}$ & $\begin{array}{c}10 \% \mathrm{WF}+ \\
\mathrm{TiBa} / \mathrm{PP}\end{array}$ & $\begin{array}{c}10 \% \mathrm{WF}+ \\
\text { TiBa/ PP }\end{array}$ \\
& & & $10 \mathrm{kGy}$ & $15 \mathrm{kGy}$ & $20 \mathrm{kGy}$ & $25 \mathrm{kGy}$ \\
\hline 1 & 15,62 & 26,53 & 26,88 & 25,95 & 26,72 & 26,96 \\
2 & 18,02 & 27,53 & 28,40 & 26,45 & 27,50 & 25,37 \\
3 & 12,91 & 27,64 & 25,01 & 25,80 & 27,45 & 25,80 \\
4 & 24,98 & 27,42 & 26,77 & 27,28 & 27,69 & 25,16 \\
5 & 12,81 & 27,00 & 27,82 & 27,61 & 28,24 & 27,62 \\
\hline Média & 16,87 & 27,22 & 26,98 & 26,62 & 27,52 & 26,18 \\
Desvio Padrão & 5,02 & 0,46 & 1,29 & 0,80 & 0,55 & 1,06 \\
\hline
\end{tabular}


Tabela 14 - Resistência à tração $(\mathrm{MPa})$ das amostras com 10\%WF+TiBa+TPDGA/PP irradiadas e não irradiadas.

\begin{tabular}{|c|c|c|c|c|c|c|}
\hline Amostras & $\begin{array}{c}\text { PP } \\
\text { (Puro) }\end{array}$ & $\begin{array}{c}10 \% \mathrm{WF}+ \\
\mathrm{TiBa}+ \\
\text { TPGDA/ } \\
\text { PP }\end{array}$ & $\begin{array}{c}10 \% \mathrm{WF}+ \\
\text { TiBa+ } \\
\text { TPGDA/ } \\
\text { PP 10kGy }\end{array}$ & $\begin{array}{c}10 \% \mathrm{WF}+ \\
\mathrm{TiBa}+ \\
\text { TPGDA/ } \\
\text { PP } 15 \mathrm{kGy}\end{array}$ & $\begin{array}{c}10 \% \mathrm{WF}+ \\
\mathrm{TiBa}+ \\
\text { TPDGA/ } \\
\text { PP20 kGy }\end{array}$ & $\begin{array}{c}10 \% \mathrm{WF}+ \\
\mathrm{TiBa}+ \\
\text { TPDGA/ } \\
\text { PP } 25 \mathrm{kGy}\end{array}$ \\
\hline 1 & 15,62 & 28,23 & 26,33 & 27,83 & 26,49 & 28,99 \\
\hline 2 & 18,02 & 27,45 & 27,75 & 27,32 & 26,96 & 27,66 \\
\hline 3 & 12,91 & 28,71 & 25,63 & 25,86 & 27,09 & 28,88 \\
\hline 4 & 24,98 & 28,23 & 26,47 & 27,83 & 28,65 & 29,03 \\
\hline 5 & 12,81 & 28,47 & 25,65 & 26,76 & - & 29,27 \\
\hline Média & 16,87 & 28,22 & 26,37 & 27,12 & 27,30 & 28,77 \\
\hline Desvio Padrão & 5,02 & 0,47 & 0,86 & 0,83 & 0,94 & 0,63 \\
\hline
\end{tabular}

Na Figura 39 são mostrados os resultados dos ensaios de resistência à tração do PP (puro) e das diferentes composições de PP com 10\%WF irradiadas e não irradiadas.

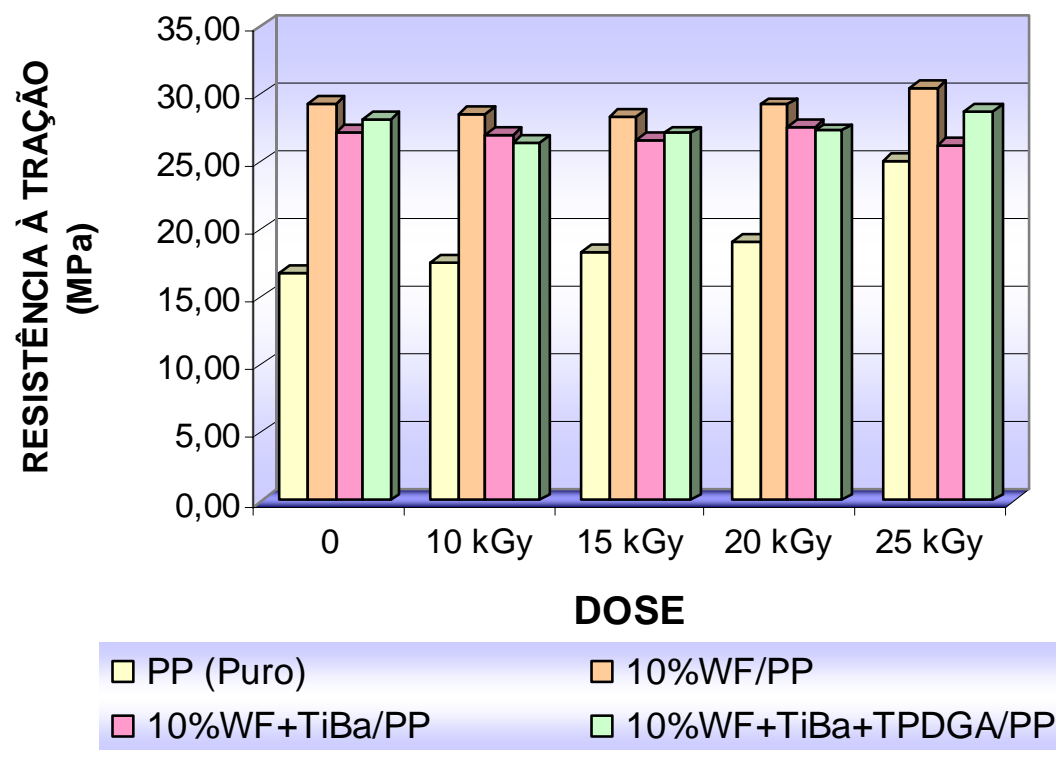

Figura 39 - Resistência à tração das amostras das de PP (puro) e de diferentes composições de PP com 10\%WF irradiadas e não irradiadas.

Analisando os resultados apresentados nas Tabelas 12, 13 e 14 e mostrado na Figura 39, observou-se que:

As amostras com 10\%WF apresentaram um acréscimo nos resultados de resistência à tração em relação ao PP (puro) não irradiado. 
Na Tabela 15 são apresentados os resultados da porcentagem de aumento da resistência à tração para as diferentes composições com 10\%WF submetidas a diferentes doses em comparação ao PP (puro) não irradiado.

Tabela 15 - Porcentagem de aumento da resistência à tração para as diferentes composições com $10 \% \mathrm{WF}$ submetidas a diferentes doses de radiação em relação ao PP (puro) não irradiado.

\begin{tabular}{cccc}
\hline $\begin{array}{c}\text { Doses } \\
\mathrm{kGy}\end{array}$ & $10 \% \mathrm{WF} / \mathrm{PP}$ & $10 \% \mathrm{WF}+\mathrm{TiBa} / \mathrm{PP}$ & $\begin{array}{c}10 \% \mathrm{WF}+\mathrm{TiBa}+ \\
\mathrm{TPDGA} / \mathrm{PP}\end{array}$ \\
\hline 0 & $73,59 \%$ & $61,39 \%$ & $67,29 \%$ \\
10 & $69,34 \%$ & $59,92 \%$ & $56,31 \%$ \\
15 & $67,90 \%$ & $57,80 \%$ & $60,78 \%$ \\
20 & $73,08 \%$ & $63,15 \%$ & $61,83 \%$ \\
25 & $80,28 \%$ & $55,22 \%$ & $70,54 \%$ \\
\hline
\end{tabular}

Ao comparar as amostras de 10\%WF com a amostra de PP (puro) não irradiado observou-se que as amostras que apresentaram melhores resultados foram:

As amostras com 10\%WF/PP com dose e sem dose de radiação.

A amostra com 10\%WF+TiBa+TPDGA/PP irradiada a 25kGy.

Ocorreu reticulação nas amostras irradiadas em relação ao PP não irradiado.

$\mathrm{O} \mathrm{TiBa}$ proporcionou maior homogeneidade aos resultados das amostras constituindo assim em um acréscimo na resistência à tração das amostras irradiadas e não irradiadas.

Tabela 16 - Resistência à tração (MPa) das amostras com 15\%WF/PP irradiadas e não irradiadas.

\begin{tabular}{c|cccccc}
\hline \multirow{2}{*}{ Amostras } & PP & $15 \% \mathrm{WF} / \mathrm{PP}$ & $15 \% \mathrm{WF} / \mathrm{PP}$ & $15 \% \mathrm{WF} / \mathrm{PP}$ & $15 \% \mathrm{WF} / \mathrm{PP}$ & $15 \% \mathrm{WF} / \mathrm{PP}$ \\
& (Puro) & & $10 \mathrm{kGy}$ & $15 \mathrm{kGy}$ & $20 \mathrm{kGy}$ & $25 \mathrm{kGy}$ \\
\hline 1 & 15,62 & 29,43 & 25,95 & 28,44 & 29,92 & 30,39 \\
2 & 18,02 & 29,62 & 25,59 & 28,00 & 27,48 & 28,20 \\
3 & 12,91 & 29,55 & 26,84 & 28,31 & 29,83 & 27,88 \\
4 & 24,98 & 33,62 & 25,60 & 27,44 & 29,26 & 29,30 \\
5 & 12,81 & 29,43 & 27,02 & 26,76 & 27,81 & 30,34 \\
\hline Média & 16,87 & 30,33 & 26,20 & 27,79 & 28,86 & 29,22 \\
Desvio Padrão & 5,02 & 1,84 & 0,68 & 0,69 & 1,14 & 1,17 \\
\hline
\end{tabular}


Tabela 17 - Resistência à tração $(\mathrm{MPa})$ das amostras com 15\%WF+TiBa/PP irradiadas e não irradiadas.

\begin{tabular}{|c|c|c|c|c|c|c|}
\hline Amostras & $\begin{array}{c}\text { PP } \\
\text { (Puro) }\end{array}$ & $\begin{array}{c}15 \% \mathrm{WF}+ \\
\mathrm{TiBa} / \mathrm{PP}\end{array}$ & $\begin{array}{c}15 \% \mathrm{WF}+ \\
\mathrm{TiBa} / \mathrm{PP} \\
10 \mathrm{kGy}\end{array}$ & $\begin{array}{c}15 \% \mathrm{WF}+ \\
\mathrm{TiBa} / \mathrm{PP} \\
15 \mathrm{kGy}\end{array}$ & $\begin{array}{c}15 \% \mathrm{WF}+ \\
\mathrm{TiBa} / \mathrm{PP} \\
20 \mathrm{kGy}\end{array}$ & $\begin{array}{c}15 \% \mathrm{WF}+ \\
\mathrm{TiBa} / \mathrm{PP} \\
25 \mathrm{kGy}\end{array}$ \\
\hline 1 & 15,62 & 27,51 & 27,85 & 24,98 & 27,88 & 26,94 \\
\hline 2 & 18,02 & 28,32 & 28,07 & 24,07 & 26,71 & 28,93 \\
\hline 3 & 12,91 & 26,63 & 25,88 & 26,57 & 28,23 & 27,25 \\
\hline 4 & 24,98 & 28,09 & 27,60 & 27,95 & 27,10 & - \\
\hline 5 & 12,81 & 27,70 & 27,90 & 27,22 & 27,84 & - \\
\hline Média & 16,87 & 27,65 & 27,46 & 26,16 & 27,55 & 27,71 \\
\hline Desvio Padrão & 5,02 & 0,65 & 0,90 & 1,60 & 0,63 & 1,07 \\
\hline
\end{tabular}

Tabela 18 - Resistência à tração $(\mathrm{MPa})$ das amostras com 15\%WF+TiBa+TPDGA/PP irradiadas e não irradiadas.

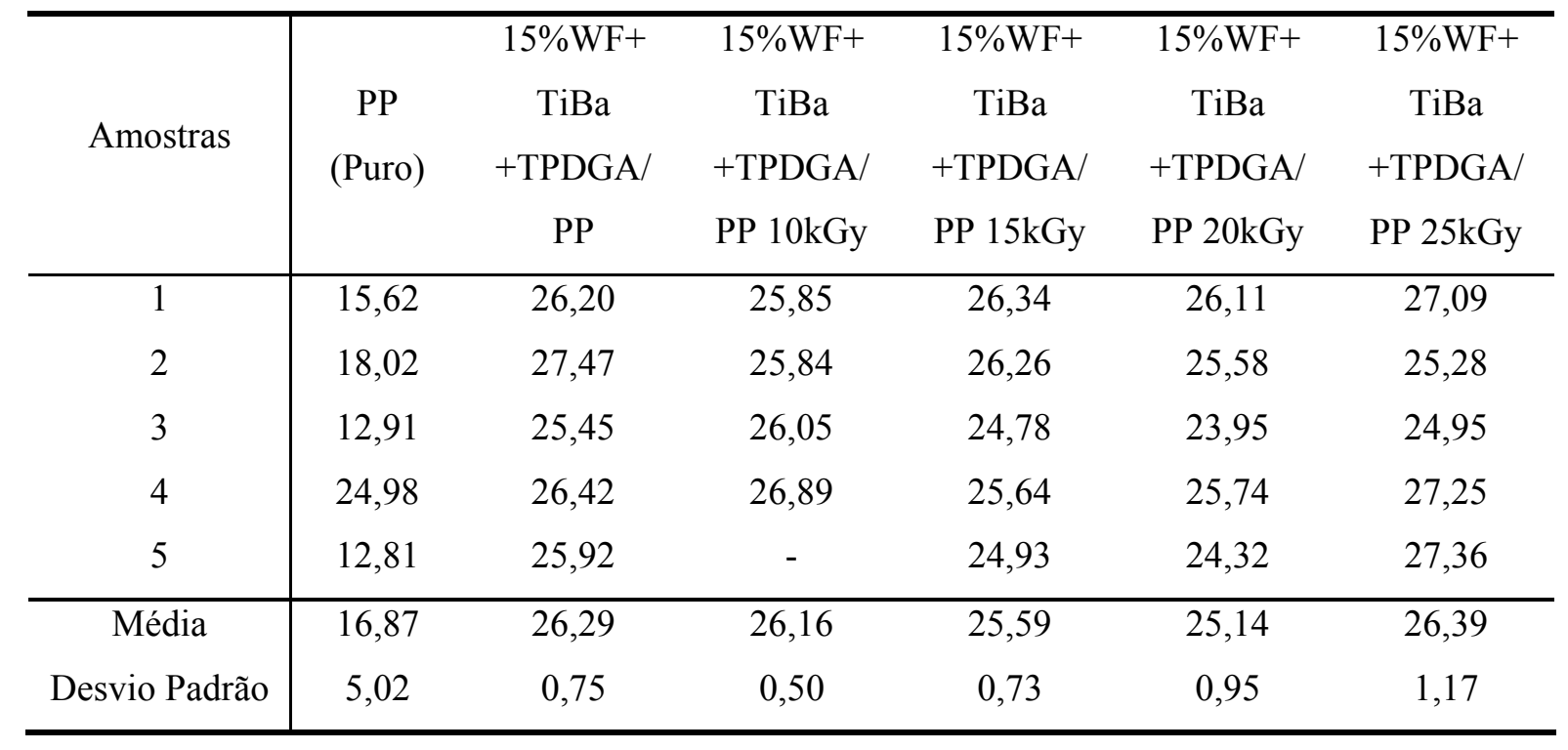

Na Figura 40 são mostrados os resultados dos ensaios de resistência à tração do PP (puro) e de diferentes composições de PP com 15\%WF irradiadas e não irradiadas. 


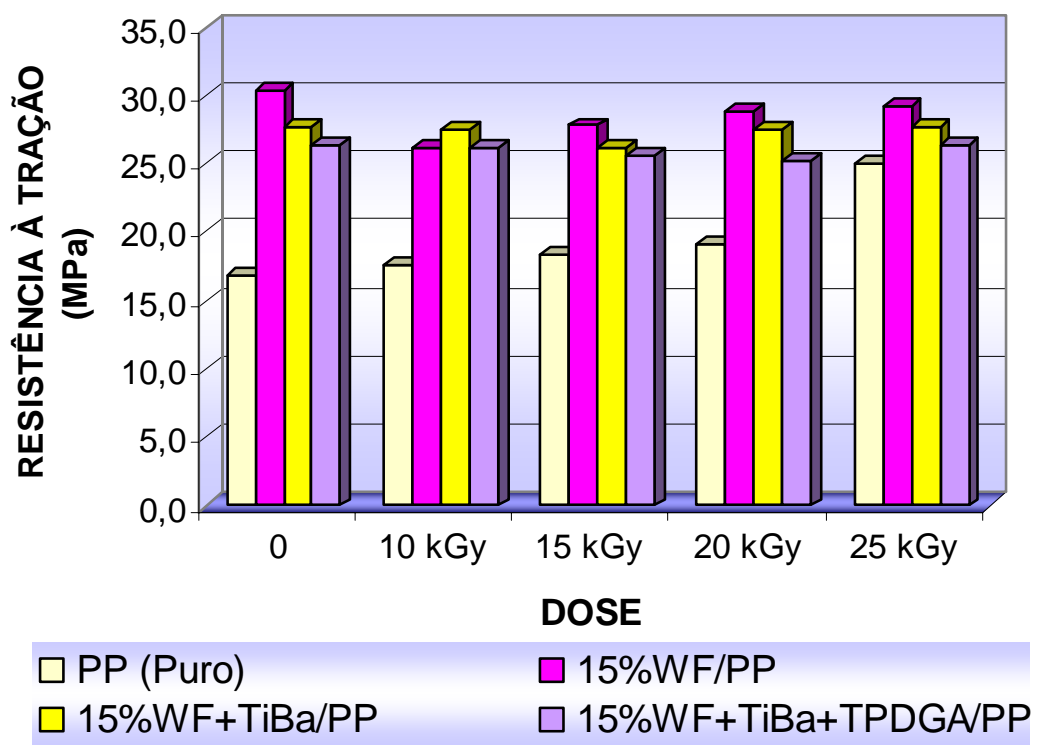

Figura 40 - Resistência à tração das amostras de PP (puro) e de diferentes composições de PP com 15\%WF irradiadas e não irradiadas.

Analisando os resultados apresentados nas Tabelas 16,17 e 18 e mostrados na Figuras 40 observou-se que:

Ocorreu um aumento da resistência à tração em todas as amostras em relação ao PP (puro) não irradiado

Na Tabela 19 são apresentados os resultados da porcentagem de aumento da resistência à tração para as diferentes composições com 15\%WF submetidas a diferentes doses em comparação ao PP (puro) não irradiado.

Tabela 19 - Porcentagem de aumento da resistência à tração para as diferentes composições com $15 \% \mathrm{WF}$ submetidas a diferentes doses de radiação em relação ao PP (puro) não irradiado.

\begin{tabular}{cccc}
\hline $\begin{array}{c}\text { Doses } \\
\mathrm{kGy}\end{array}$ & $15 \% \mathrm{WF} / \mathrm{PP}$ & $15 \% \mathrm{WF}+\mathrm{TiBa} / \mathrm{PP}$ & $\begin{array}{c}15 \% \mathrm{WF}+\mathrm{TiBa}+ \\
\mathrm{TPDGA} / \mathrm{PP}\end{array}$ \\
\hline 0 & $79,81 \%$ & $63,92 \%$ & $55,87 \%$ \\
10 & $55,32 \%$ & $62,79 \%$ & $55,07 \%$ \\
15 & $64,75 \%$ & $55,07 \%$ & $51,71 \%$ \\
20 & $71,09 \%$ & $63,34 \%$ & $49,04 \%$ \\
25 & $73,24 \%$ & $64,26 \%$ & $56,43 \%$ \\
\hline
\end{tabular}


Ao comparar as amostras de $15 \% \mathrm{WF}$ com a amostra de PP (puro) não irradiado observou-se que:

As amostras com 15\%WF/PP com dose e sem dose de radiação apresentaram melhores resultados.

O acréscimo apresentados pelas amostras irradiadas foi devido à reticulação do PP.

Tabela 20 - Resistência à tração $(\mathrm{MPa})$ das amostras com 20\%WF/PP irradiadas e não irradiadas.

\begin{tabular}{c|cccccc}
\hline \multirow{2}{*}{ Amostras } & PP & $20 \% \mathrm{WF} / \mathrm{PP}$ & $20 \% \mathrm{WF} / \mathrm{PP}$ & $20 \% \mathrm{WF} / \mathrm{PP}$ & $20 \% \mathrm{WF} / \mathrm{PP}$ & $20 \% \mathrm{WF} / \mathrm{PP}$ \\
& (Puro) & & $10 \mathrm{kGy}$ & $15 \mathrm{kGy}$ & $20 \mathrm{kGy}$ & $25 \mathrm{kGy}$ \\
\hline 1 & 15,62 & 27,36 & 28,46 & 29,31 & 28,05 & 30,85 \\
2 & 18,02 & 25,75 & 28,75 & 27,72 & 29,74 & 30,82 \\
3 & 12,91 & 25,68 & 29,35 & 30,97 & 31,26 & 30,13 \\
4 & 24,98 & 26,29 & 30,39 & 29,00 & 31,48 & 30,79 \\
5 & 12,81 & 24,45 & 28,69 & 29,55 & 29,40 & 29,67 \\
\hline Média & 16,87 & 25,91 & 29,13 & 29,31 & 29,99 & 30,45 \\
Desvio Padrão & 5,02 & 1,06 & 0,78 & 1,17 & 1,41 & 0,53 \\
\hline
\end{tabular}

Tabela 21 - Resistência à tração $(\mathrm{MPa})$ das amostras com 20\%WF+TiBa/PP irradiadas e não irradiadas.

\begin{tabular}{c|cccccc}
\hline \multirow{3}{*}{ Amostras } & PP & $20 \% \mathrm{WF}+$ & $\begin{array}{c}20 \% \mathrm{WF}+ \\
\mathrm{TiBa} / \mathrm{PP}\end{array}$ & $\begin{array}{c}20 \% \mathrm{WF}+ \\
\mathrm{TiBa} / \mathrm{PP}\end{array}$ & $\begin{array}{c}20 \% \mathrm{WF}+ \\
\mathrm{TiBa} / \mathrm{PP}\end{array}$ & $\begin{array}{c}20 \% \mathrm{WF}+ \\
\text { TiBa/PP }\end{array}$ \\
& (Puro) & $\mathrm{TiBa} / \mathrm{PP}$ & $10 \mathrm{kGy}$ & $15 \mathrm{kGy}$ & $20 \mathrm{kGy}$ & $25 \mathrm{kGy}$ \\
\hline 1 & 15,62 & 28,92 & 28,16 & 29,83 & 31,41 & 29,56 \\
2 & 18,02 & 28,22 & 30,60 & 28,67 & 31,62 & 31,18 \\
3 & 12,91 & 31,60 & 29,64 & 28,48 & 29,18 & 28,55 \\
4 & 24,98 & 28,16 & 28,18 & 27,87 & 29,73 & 29,96 \\
5 & 12,81 & 30,25 & 27,98 & 28,93 & 29,44 & 28,84 \\
\hline Média & 16,87 & 29,43 & 28,91 & 28,76 & 30,28 & 29,62 \\
Desvio Padrão & 5,02 & 1,48 & 1,16 & 0,72 & 1,15 & 1,04 \\
\hline
\end{tabular}


Tabela 22 - Resistência à tração $(\mathrm{MPa})$ das amostras com 20\%WF+TiBa+TPDGA/PP irradiadas e não irradiadas.

\begin{tabular}{|c|c|c|c|c|c|c|}
\hline Amostras & $\begin{array}{c}\text { PP } \\
\text { (Puro) }\end{array}$ & $\begin{array}{c}20 \% \mathrm{WF}+ \\
\text { TiBa+ } \\
\text { TPDGA/ } \\
\text { PP }\end{array}$ & $\begin{array}{c}20 \% \mathrm{WF}+ \\
\text { TiBa+ } \\
\text { TPDGA/ } \\
\text { PP 10kGy }\end{array}$ & $\begin{array}{c}20 \% \mathrm{WF}+ \\
\text { TiBa+ } \\
\text { TPDGA/ } \\
\text { PP } 15 \mathrm{kGy}\end{array}$ & $\begin{array}{c}20 \% \mathrm{WF}+ \\
\text { TiBa+ } \\
\text { TPDGA/ } \\
\text { PP 20kGy }\end{array}$ & $\begin{array}{c}20 \% \mathrm{WF}+ \\
\mathrm{TiBa}+ \\
\text { TPDGA/ } \\
\text { PP } 25 \mathrm{kGy}\end{array}$ \\
\hline 1 & 15,62 & 29,16 & 25,25 & 26,43 & 23,54 & 28,45 \\
\hline 2 & 18,02 & 26,27 & 26,37 & 26,33 & 26,27 & 27,05 \\
\hline 3 & 12,91 & 27,87 & 27,18 & 26,09 & 26,31 & 24,92 \\
\hline 4 & 24,98 & 29,25 & 26,90 & 26,29 & 25,95 & 27,17 \\
\hline 5 & 12,81 & 26,35 & - & 24,69 & 24,58 & - \\
\hline Média & 16,87 & 27,78 & 26,43 & 25,97 & 25,33 & 26,90 \\
\hline Desvio Padrão & 5,02 & 1,45 & 0,85 & 0,72 & 1,22 & 1,46 \\
\hline
\end{tabular}

Na Figura 41 são mostrados os resultados dos ensaios de resistência à tração do PP (puro) e de diferentes composições de PP com 20\%WF irradiadas e não irradiadas.
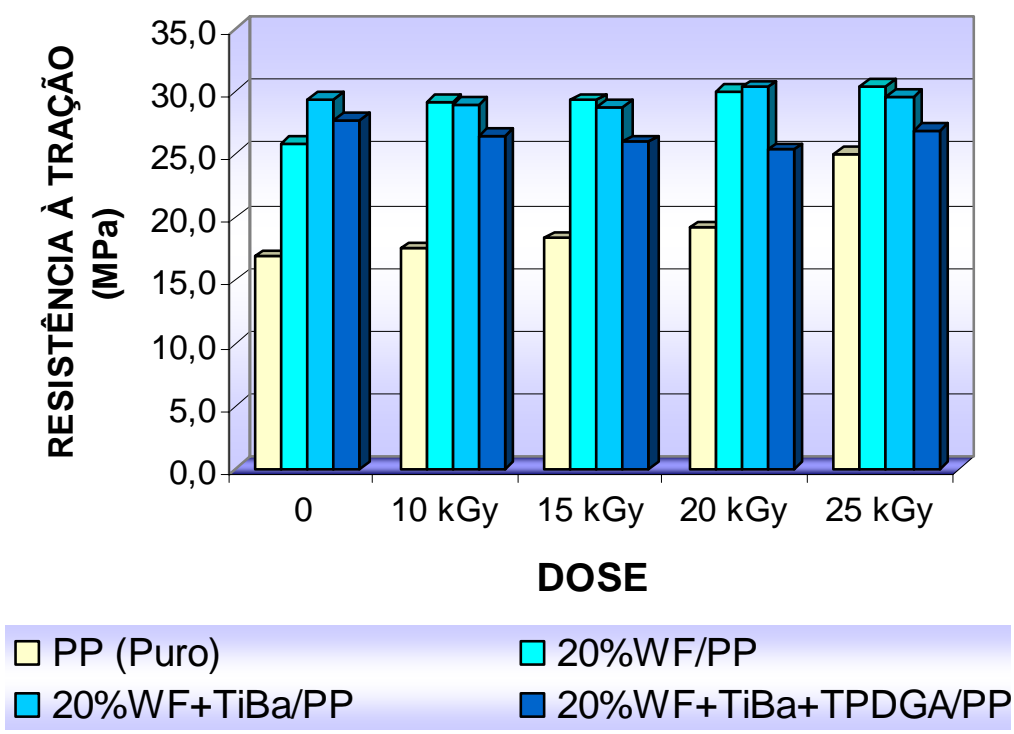

Figura 41 - Resistência à tração das amostras de PP (puro) e de diferentes composições de PP com 20\%WF irradiadas e não irradiadas em relação ao PP.

Analisando os resultados apresentados nas Tabelas 20,21, 22 e mostrado na Figura 41, observou-se que:

Ocorreu um aumento da resistência à tração em todas as amostras em relação ao PP (puro) não irradiado 
Na Tabela 23 são apresentados os resultados da porcentagem de aumento da resistência à tração para as diferentes composições com $20 \%$ WF submetidas a diferentes doses em comparação ao PP (puro) não irradiado.

Tabela 23 - Porcentagem de aumento da resistência à tração para as diferentes composições com $20 \% \mathrm{WF}$ submetidas a diferentes doses de radiação em relação ao PP (puro) não irradiado.

\begin{tabular}{cccc}
\hline $\begin{array}{c}\text { Doses } \\
\mathrm{kGy}\end{array}$ & $20 \% \mathrm{WF} / \mathrm{PP}$ & $20 \% \mathrm{WF}+\mathrm{TiBa} / \mathrm{PP}$ & $\begin{array}{c}20 \% \mathrm{WF}+\mathrm{TiBa}+ \\
\mathrm{TPDGA} / \mathrm{PP}\end{array}$ \\
\hline 0 & $53,58 \%$ & $74,47 \%$ & $64,69 \%$ \\
10 & $72,68 \%$ & $71,40 \%$ & $56,66 \%$ \\
15 & $73,76 \%$ & $70,48 \%$ & $53,94 \%$ \\
20 & $77,77 \%$ & $79,49 \%$ & $50,17 \%$ \\
25 & $80,53 \%$ & $75,59 \%$ & $59,46 \%$ \\
\hline
\end{tabular}

Ao comparar as amostras de $20 \% \mathrm{WF}$ com a amostra de PP (puro) não irradiado observou-se que:

As amostras com 20\%WF/PP e 20\%WF+TiBa/PP foram as que apresentaram melhores resultados principalmente as amostras irradiadas a 20kGy e $25 \mathrm{kGy}$.

$\mathrm{O}$ acréscimo na resistência à tração foi devido à reticulação ocorrida nas amostras 20\%WF irradiadas.

Como conclusão desses resultados de resistência à tração pode se dizer que:

As amostras WF/PP apresentaram resultados semelhantes e às vezes superiores às amostras com aditivos TiBa e TPDGA tanto para amostras irradiadas quanto para amostras não irradiadas.

O TiBa proporcionou maior homogeneidade aos resultados das amostras. Esta homogeneidade foi observada principalmente nas amostras com 10\%WF.

O resultados obtidos do ensaio de resistência a tração indicaram que a amostra de melhor desempenho foi a de $20 \% \mathrm{WF}$ e que o TiBa proporcionou um acréscimo nos resultados de resistência a tração para as amostras de $20 \% \mathrm{WF}+\mathrm{TiBa} / \mathrm{PP}$ tanto para amostras irradiadas quanto não irradiadas.

Ao comparar o resultado de resistência à tração do PP (puro) com 10kGy e as amostras de compósitos irradiadas nesta mesma dose observou-se um acréscimo na resistência à tração das amostras de compósito em comparação com a amostra de PP. 
Porém ao fazer a mesma comparação do PP (puro) com doses maiores observou-se que a diferença da resistência à tração diminui entre o PP (puro) e os compósitos com o aumento da dose de radiação isto pode ser observado nas Figuras 43, 44 e 45.

Assim pode-se dizer que a doses maiores de radiação os compósitos sofreram oxidação e perderam propriedades mecânicas isso porque a madeira se oxida com a radiação.

\subsection{ENSAIOS DE RESISTÊNCIA AO IMPACTO}

Foram realizados ensaio de impacto com entalhe para os seguintes compostos:

- PP (puro);

- 10\%WF/PP,

$-10 \% \mathrm{WF}+\mathrm{TiBa} / \mathrm{PP}$,

$-10 \% \mathrm{WF}+\mathrm{TiBa}+\mathrm{TPDGA} / \mathrm{PP}$,

- 15\%WF/PP,

$-15 \% \mathrm{WF}+\mathrm{TiBa} / \mathrm{PP}$,

$-15 \% \mathrm{WF}+\mathrm{TiBa}+\mathrm{TPDGA} / \mathrm{PP}$,

$-20 \% \mathrm{WF} / \mathrm{PP}$,

$-20 \% \mathrm{WF}+\mathrm{TiBa} / \mathrm{PP}$,

$-20 \% \mathrm{WF}+\mathrm{TiBa}+\mathrm{TPDGA} / \mathrm{PP}$.

Também foram determinadas a resistência ao impacto para todas estas composições citadas anteriormente submetidas a doses de radiação de 10kGy e 20kGy.

Nas Tabelas 24, 25, 26, 27, 29, 30, 31, 33, 34 e 35 são apresentados os resultados para a propriedade de resistência ao impacto das amostras irradiadas e não irradiadas de PP (puro) e das diferentes composições de PP com 10\%WF, 15\%WF e $20 \% \mathrm{WF}$. 
Tabela 24 - Resistência ao impacto $(\mathrm{J} / \mathrm{m})$ das amostras de PP irradiadas e não irradiadas.

\begin{tabular}{c|ccc}
\hline Amostras & PP (Puro) & PP (Puro) 10kGy & PP (Puro) 20kGy \\
\hline 1 & 32,60 & 26,30 & 19,37 \\
2 & 35,10 & 23,40 & 16,32 \\
3 & 33,00 & 25,20 & 17,92 \\
4 & 34,40 & 23,50 & 19,85 \\
\hline Média & 33,78 & 24,60 & 18,37 \\
Desvio Padrão & 1,17 & 1,40 & 1,59 \\
\hline
\end{tabular}

Na Figura 42 são mostrados os gráficos dos resultados de resistência ao impacto das amostras de PP irradiadas e não irradiadas.

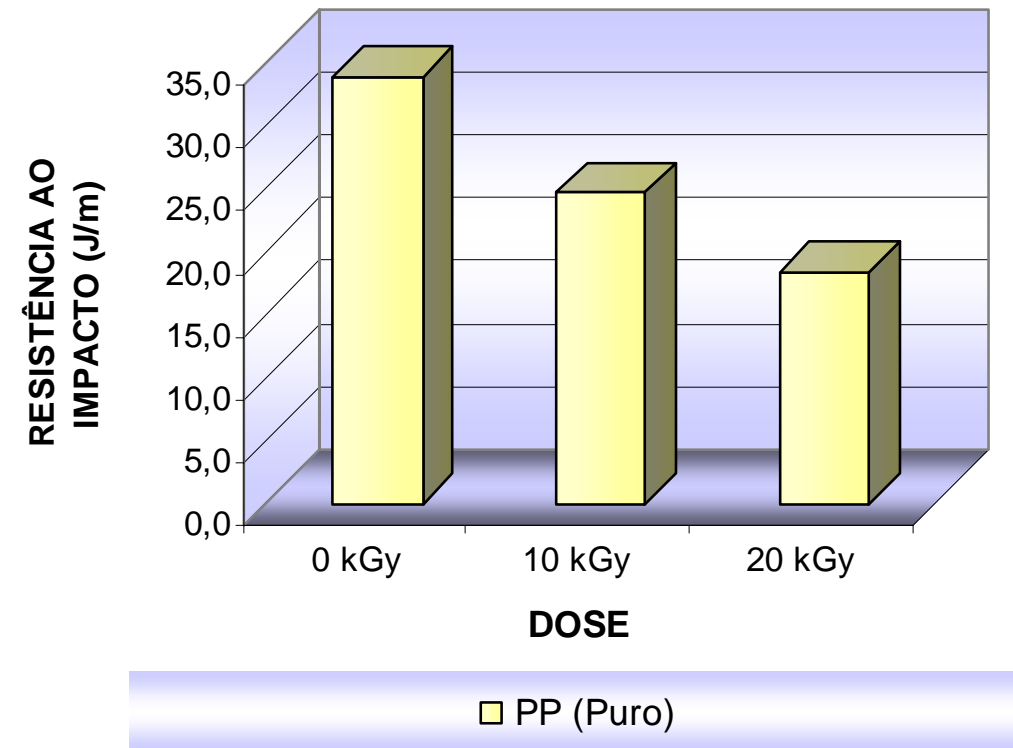

Figura 42 - Resistência ao impacto das amostras de PP irradiadas e não irradiadas.

Analisando os resultados apresentados na Tabela 24 e mostrado na Figura 42 a medida que aumentou-se a dose de radiação observou-se que a resistência ao impacto diminuiu indicando que a rigidez do material aumentou tornando-se mais frágil, em razão da reticulação do $\mathrm{PP}$.

O decréscimo do PP irradiado em relação ao PP não irradiado foi de:

$27,18 \%$ no PP irradiado a $10 \mathrm{kGy}$;

$54,38 \%$ no PP irradiado a $20 \mathrm{kGy}$. 
Tabela 25 - Resistência ao impacto $(\mathrm{J} / \mathrm{m})$ das amostras de 10\%WF/PP irradiadas e não irradiadas

\begin{tabular}{c|cccc}
\hline Amostras & PP (Puro) & $10 \% \mathrm{WF} / \mathrm{PP}$ & $\begin{array}{c}10 \% \mathrm{WF} / \mathrm{PP} \\
10 \mathrm{kGy}\end{array}$ & $\begin{array}{c}10 \% \mathrm{WF} / \mathrm{PP} \\
20 \mathrm{kGy}\end{array}$ \\
\hline 1 & 32,60 & 26,30 & 25,10 & 15,99 \\
2 & 35,10 & 29,30 & 22,50 & 16,12 \\
3 & 33,00 & 27,60 & 22,50 & 16,92 \\
4 & 34,40 & 26,60 & 24,80 & 19,20 \\
Média & 33,78 & 27,45 & 23,73 & 17,06 \\
\hline Desvio Padrão & 1,17 & 1,35 & 1,42 & 1,49 \\
\hline
\end{tabular}

Tabela 26 - Resistência ao impacto $(\mathrm{J} / \mathrm{m})$ das amostras de 10\%WF+TiBa/PP irradiadas e não irradiadas

\begin{tabular}{c|cccc}
\hline Amostras & PP (Puro) & $\begin{array}{c}10 \% \mathrm{WF}+\mathrm{TiBa} / \\
\text { PP }\end{array}$ & $\begin{array}{c}10 \% \mathrm{WF}+\mathrm{TiBa} / \\
\text { PP } 10 \mathrm{kGy}\end{array}$ & $\begin{array}{c}10 \% \mathrm{WF}+\mathrm{TiBa} / \\
\text { PP 20kGy }\end{array}$ \\
\hline 1 & 32,60 & 29,50 & 21,60 & 17,61 \\
2 & 35,10 & 27,60 & 24,10 & 17,62 \\
3 & 33,00 & 29,60 & 24,60 & 18,85 \\
4 & 34,40 & 28,50 & 23,00 & 16,85 \\
\hline Média & 33,78 & 28,80 & 23,33 & 17,73 \\
Desvio Padrão & 1,17 & 0,94 & 1,33 & 0,83 \\
\hline
\end{tabular}

Tabela 27 - Resistência ao impacto $(\mathrm{J} / \mathrm{m})$ das amostras de 10\%WF+TiBa+TPDGA/PP irradiadas e não irradiadas.

\begin{tabular}{c|cccc}
\hline \multirow{2}{*}{ Amostras } & PP (Puro) & $\begin{array}{c}10 \% \mathrm{WF}+\mathrm{TiBa}+ \\
\text { TPGDA/PP }\end{array}$ & $\begin{array}{c}10 \% \mathrm{WF}+\mathrm{TiBa}+ \\
\text { TPGDA/PP } \\
10 \mathrm{kGy}\end{array}$ & $\begin{array}{c}10 \% \mathrm{WF}+\mathrm{TiBa}+ \\
\text { TPDGA/PP } \\
20 \mathrm{kGy}\end{array}$ \\
\hline 1 & 32,60 & 31,10 & 29,30 & 18,85 \\
2 & 35,10 & 32,90 & 28,80 & 19,20 \\
4 & 33,00 & 30,00 & 28,10 & 17,62 \\
\hline Média & 34,40 & 29,30 & 27,30 & 19,66 \\
\hline Desvio Padrão & 33,78 & 30,83 & 28,38 & 18,83 \\
\hline
\end{tabular}


$\mathrm{Na}$ Figura 43 são mostrados os gráficos dos resultados de resistência ao impacto das amostras de PP (puro) e de diferentes composições de PP com 10\%WF irradiadas e não irradiadas.

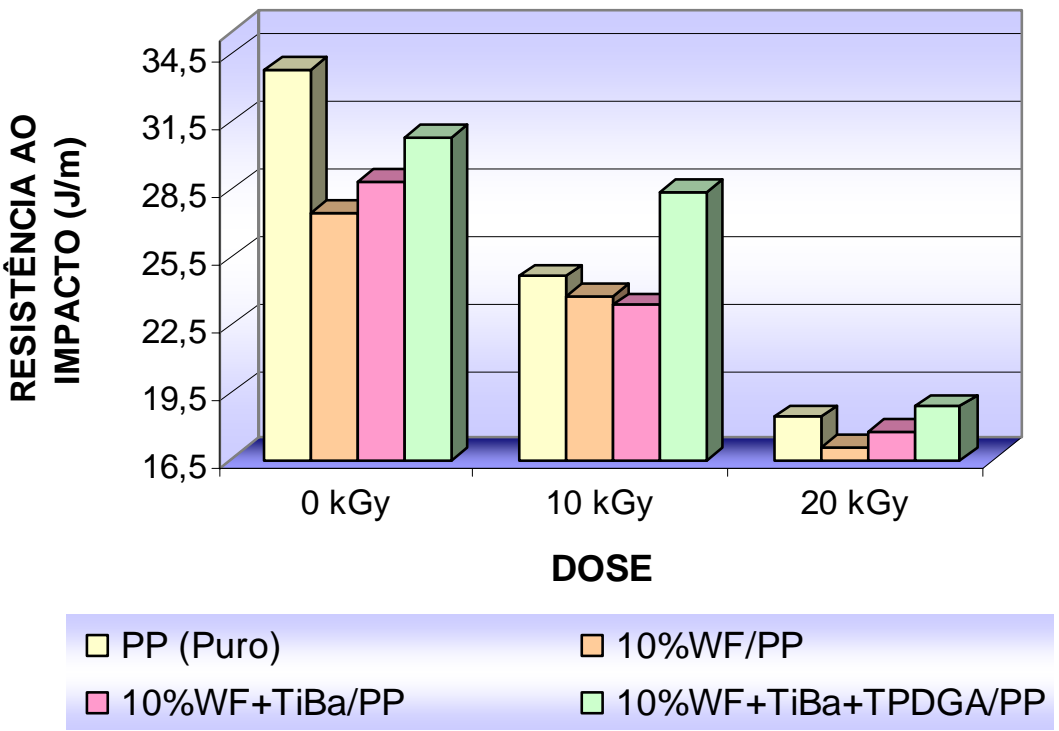

Figura 43 - Resistência ao impacto das amostras de PP (puro) e de diferentes composições de PP com 10\%WF irradiadas e não irradiadas.

Analisando os resultados apresentados nas Tabelas 25, 26, 27 e mostrado na Figura 43 à medida que se aumentou a dose de radiação observou-se que a resistência ao impacto diminuiu indicando que a rigidez do material aumentou tornando-se mais frágil, em razão da reticulação do PP.

$\mathrm{Na}$ Tabela 28 são apresentados os resultados da porcentagem de decréscimo da resistência ao impacto para as diferentes composições com $10 \% \mathrm{WF}$ submetidas a diferentes doses em comparação ao PP (puro) não irradiado. 
Tabela 28 - Porcentagem de decréscimo da resistência ao impacto para as diferentes composições com $10 \% \mathrm{WF}$ submetidas a diferentes doses de radiação em relação ao PP (puro) não irradiado.

\begin{tabular}{cccc}
\hline $\begin{array}{c}\text { Doses } \\
\mathrm{kGy}\end{array}$ & $10 \% \mathrm{WF} / \mathrm{PP}$ & $10 \% \mathrm{WF}+\mathrm{TiBa} / \mathrm{PP}$ & $\begin{array}{c}10 \% \mathrm{WF}+\mathrm{TiBa}+ \\
\mathrm{TPDGA} / \mathrm{PP}\end{array}$ \\
\hline 0 & $18,73 \%$ & $14,73 \%$ & $8,73 \%$ \\
10 & $29,76 \%$ & $30,94 \%$ & $15,99 \%$ \\
20 & $49,50 \%$ & $47,50 \%$ & $44,24 \%$ \\
\hline
\end{tabular}

Ao comparar as amostra de 10\%WF com o PP (puro) não irradiado, observouse que:

As amostras que apresentaram melhores resultados foram as amostras 10\%WF+TiBa+TPDGA/PP não irradiada e irradiada com dose de 10kGy.

As amostras 10\%WF+TiBa/PP e 10\%WF/PP também apresentaram bons resultados.

Tabela 29 - Resistência ao impacto $(\mathrm{J} / \mathrm{m})$ das amostras de 15\%WF/PP irradiadas e não irradiadas

\begin{tabular}{c|cccc}
\hline Amostras & PP (Puro) & $15 \% \mathrm{WF} / \mathrm{PP}$ & $\begin{array}{c}15 \% \mathrm{WF} / \mathrm{PP} \\
10 \mathrm{kGy}\end{array}$ & $\begin{array}{c}15 \% \mathrm{WF} / \mathrm{PP} \\
20 \mathrm{kGy}\end{array}$ \\
\hline 1 & 32,60 & 27,40 & 24,90 & 24,60 \\
2 & 35,10 & 29,60 & 23,00 & 21,10 \\
3 & 33,00 & 29,60 & 23,50 & 24,50 \\
4 & 34,40 & 29,90 & 19,14 & 25,20 \\
\hline Média & 33,78 & 22,67 & 22,64 & 23,85 \\
Desvio Padrão & 1,17 & 1,16 & 2,46 & 1,86 \\
\hline
\end{tabular}


Tabela 30 - Resistência ao impacto $(\mathrm{J} / \mathrm{m})$ das amostras de $15 \% \mathrm{WF}+\mathrm{TiBa} / \mathrm{PP}$ irradiadas e não irradiadas.

\begin{tabular}{c|cccc}
\hline \multirow{2}{*}{ Amostras } & PP (Puro) & $\begin{array}{c}15 \% \mathrm{WF}+\mathrm{TiBa} / \\
\text { PP }\end{array}$ & $\begin{array}{c}15 \% \mathrm{WF}+\mathrm{TiBa} / \\
\text { PP } 10 \mathrm{kGy}\end{array}$ & $\begin{array}{c}15 \% \mathrm{WF}+\mathrm{TiBa} / \\
\text { PP 20kGy }\end{array}$ \\
\hline 1 & 32,60 & 31,80 & 24,80 & 23,10 \\
2 & 35,10 & 30,10 & 24,10 & 22,10 \\
3 & 33,00 & 27,50 & 25,00 & 23,40 \\
4 & 34,40 & 28,80 & 24,30 & 18,37 \\
\hline Média & 33,78 & 29,55 & 24,55 & 21,74 \\
Desvio Padrão & 1,17 & 1,84 & 0,42 & 2,32 \\
\hline
\end{tabular}

Tabela 31 - Resistência ao impacto $(\mathrm{J} / \mathrm{m})$ das amostras de 15\%WF+TiBa+TPDGA/PP irradiadas e não irradiadas.

\begin{tabular}{c|cccc}
\hline \multirow{2}{*}{ Amostras } & PP (Puro) & $\begin{array}{c}15 \% \mathrm{WF}+\mathrm{TiBa}+ \\
\text { TPDGA/PP }\end{array}$ & $\begin{array}{c}15 \% \mathrm{WF}+\mathrm{TiBa}+ \\
\text { TPDGA/PP } \\
10 \mathrm{kGy}\end{array}$ & $\begin{array}{c}15 \% \mathrm{WF}+\mathrm{TiBa}+ \\
\text { TPDGA/PP } \\
20 \mathrm{kGy}\end{array}$ \\
\hline 1 & 32,60 & 22,20 & 23,80 & 21,50 \\
2 & 35,10 & 22,20 & 25,40 & 22,80 \\
3 & 33,00 & 21,10 & 26,20 & 20,50 \\
4 & 34,40 & 21,00 & 23,70 & 19,55 \\
\hline Média & 33,78 & 21,63 & 24,78 & 21,09 \\
Desvio Padrão & 1,17 & 0,67 & 1,23 & 1,39 \\
\hline
\end{tabular}

Na Figura 44 são mostrados os gráficos dos resultados de resistência ao impacto das amostras de PP (puro) e de diferentes composições de PP com 15\%WF irradiadas e não irradiadas. 


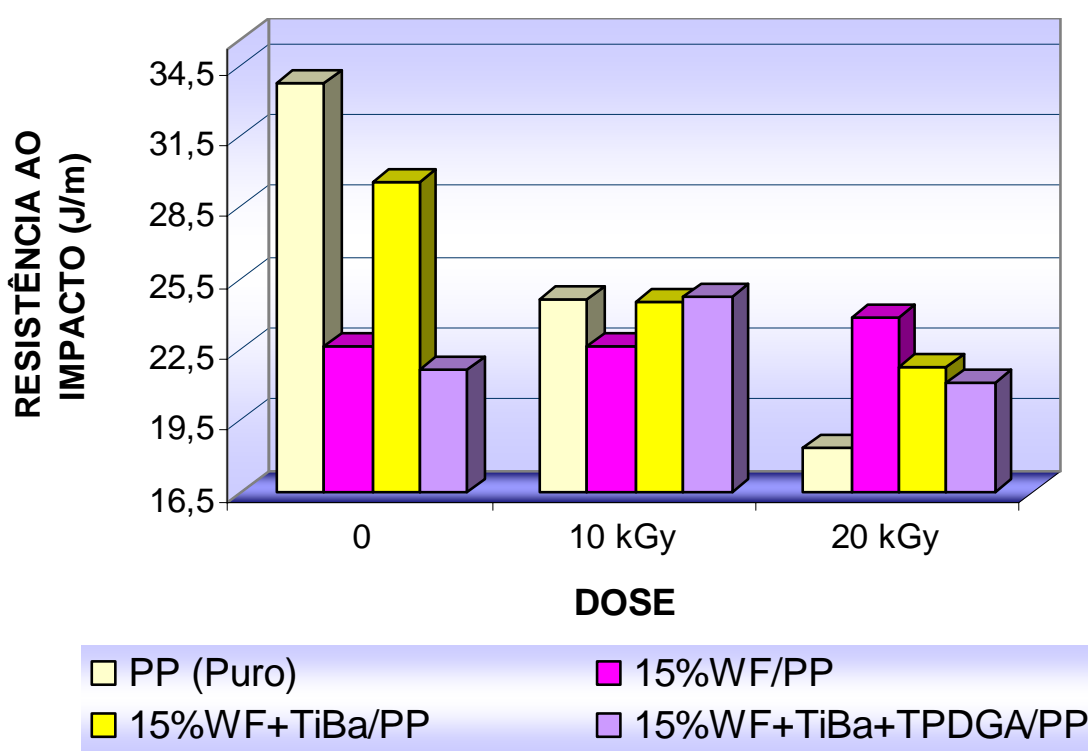

Figura 44 - Resistência ao impacto das amostras de PP (puro) e de diferentes composições de PP com 15\%WF irradiadas e não irradiadas.

Analisando os resultados apresentados nas Tabelas, 29, 30 e 31 e mostrado nas Figuras 44 à medida que se aumentou a dose de radiação observou-se que a resistência ao impacto diminuiu indicando que a rigidez do material aumentou tornando-se mais frágil, em razão da reticulação do $\mathrm{PP}$.

$\mathrm{Na}$ Tabela 32 são apresentados os resultados da porcentagem de decréscimo da resistência ao impacto para as diferentes composições de $15 \%$ WF submetidas a diferentes doses em comparação ao PP (puro) não irradiado.

Tabela 32 - Porcentagem de decréscimo da resistência ao impacto para as diferentes composições de $15 \% \mathrm{WF}$ submetidas a diferentes doses de radiação em relação ao PP (puro) não irradiado.

\begin{tabular}{cccc}
\hline $\begin{array}{c}\text { Doses } \\
\mathrm{kGy}\end{array}$ & $15 \% \mathrm{WF} / \mathrm{PP}$ & $15 \% \mathrm{WF}+\mathrm{TiBa} / \mathrm{PP}$ & $\begin{array}{c}15 \% \mathrm{WF}+\mathrm{TiBa}+ \\
\mathrm{TPDGA} / \mathrm{PP}\end{array}$ \\
\hline 0 & $32,88 \%$ & $12,51 \%$ & $35,97 \%$ \\
10 & $32,98 \%$ & $27,31 \%$ & $26,65 \%$ \\
20 & $29,39 \%$ & $35,63 \%$ & $37,56 \%$ \\
\hline
\end{tabular}

Ao comparar as amostras de 15\% WF ao PP (puro) não irradiado observou-se que:

A amostra que apresentou melhor resultado foi a de $15 \% \mathrm{WF}+\mathrm{TiBa} / \mathrm{PP}$. 
As amostras contendo $15 \% \mathrm{WF}$ foram as que apresentaram melhor desempenho.

Tabela 33 - Resistência ao impacto $(\mathrm{J} / \mathrm{m})$ das amostras de 20\%WF/PP irradiadas e não irradiadas.

\begin{tabular}{c|cccc}
\hline Amostras & PP (Puro) & $20 \% \mathrm{WF} / \mathrm{PP}$ & $\begin{array}{c}20 \% \mathrm{WF} / \mathrm{PP} \\
10 \mathrm{kGy}\end{array}$ & $\begin{array}{c}20 \% \mathrm{WF} / \mathrm{PP} \\
20 \mathrm{kGy}\end{array}$ \\
\hline 1 & 32,60 & 20,90 & 19,61 & 18,57 \\
2 & 35,10 & 21,00 & 23,20 & 19,90 \\
3 & 33,00 & 23,70 & 21,30 & 17,46 \\
4 & 34,40 & 20,90 & 23,50 & 15,60 \\
\hline Média & 33,78 & 21,63 & 21,90 & 17,88 \\
Desvio Padrão & 1,17 & 1,38 & 1,81 & 1,82 \\
\hline
\end{tabular}

Tabela 34 - Resistência ao impacto (J/m) das amostras de 20\%WF+TiBa/PP irradiadas e não irradiadas.

\begin{tabular}{c|cccc}
\hline \multirow{2}{*}{ Amostras } & PP (Puro) & $\begin{array}{c}20 \% \mathrm{WF}+\mathrm{TiBa} / \\
\text { PP }\end{array}$ & $\begin{array}{c}20 \% \mathrm{WF}+\mathrm{TiBa} / \\
\mathrm{PP} 10 \mathrm{kGy}\end{array}$ & $\begin{array}{c}20 \% \mathrm{WF}+\mathrm{TiBa} / \\
\text { PP 20kGy }\end{array}$ \\
\hline 1 & 32,60 & 20,30 & 23,50 & 19,78 \\
2 & 35,10 & 21,10 & 24,60 & 19,08 \\
3 & 33,00 & 20,20 & 23,20 & 16,25 \\
4 & 34,40 & 20,10 & 22,40 & 16,29 \\
\hline Média & 33,78 & 20,43 & 23,43 & 17,85 \\
Desvio Padrão & 1,17 & 0,46 & 0,91 & 1,85 \\
\hline
\end{tabular}

Tabela 35 - Resistência ao impacto $(\mathrm{J} / \mathrm{m})$ das amostras de 20\%WF+TiBa+TPDGA/PP irradiadas e não irradiadas.

\begin{tabular}{c|cccc}
\hline \multirow{2}{*}{ Amostras } & PP (Puro) & $\begin{array}{c}20 \% \mathrm{WF}+\mathrm{TiBa}+ \\
\text { TPDGA/PP }\end{array}$ & $\begin{array}{c}20 \% \mathrm{WF}+\mathrm{TiBa}+ \\
\text { TPDGA/PP } \\
10 \mathrm{kGy}\end{array}$ & $\begin{array}{c}20 \% \mathrm{WF}+\mathrm{TiBa}+ \\
\text { TPDGA/PP } \\
20 \mathrm{kGy}\end{array}$ \\
\hline 1 & 32,60 & 25,50 & 24,30 & 25,60 \\
2 & 35,10 & 19,86 & 24,00 & 22,00 \\
3 & 33,00 & 20,80 & 23,90 & 23,00 \\
4 & 34,40 & 23,00 & 24,90 & 23,00 \\
\hline Média & 33,78 & 22,29 & 24,28 & 23,40 \\
Desvio Padrão & 1,17 & 2,51 & 0,45 & 1,54 \\
\hline
\end{tabular}


$\mathrm{Na}$ Figura 45 são mostrados os gráficos dos resultados de resistência ao impacto das amostras de PP (puro) e de diferentes composições de PP com $20 \% \mathrm{WF}$ irradiadas e não irradiadas.

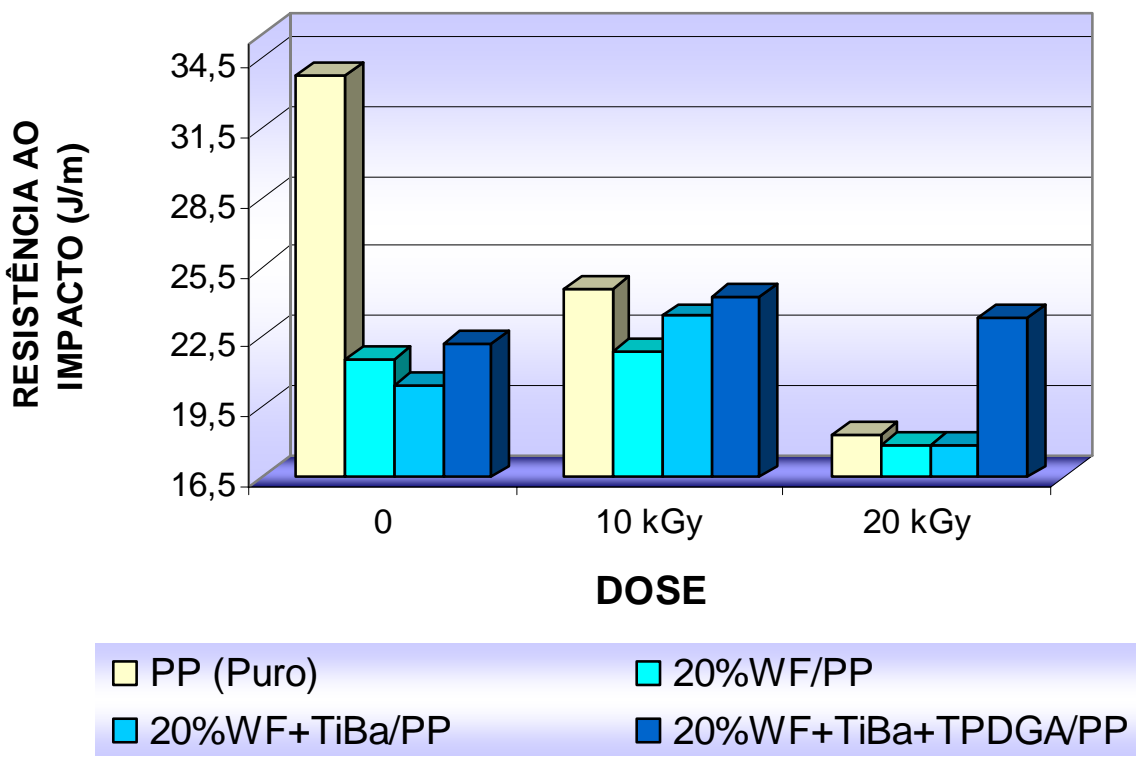

Figura 45 - Resistência ao impacto das amostras de PP (puro) e de diferentes composições de PP com 20\%WF irradiadas e não irradiadas.

Analisando os resultados apresentados nas Tabelas 33, 34 e 35 e mostrado na Figura 45 à medida que se aumentou a dose de radiação observou-se que a resistência ao impacto diminuiu indicando que a rigidez do material aumentou tornando-se mais frágil, em razão da reticulação do PP.

$\mathrm{Na}$ Tabela 36 são apresentados os resultados da porcentagem de decréscimo da resistência ao impacto para as diferentes composições com $20 \% \mathrm{WF}$ submetidas a diferentes doses em comparação ao PP (puro) não irradiado. 
Tabela 36 - Porcentagem de decréscimo da resistência ao impacto para as diferentes composições com $20 \%$ WF submetidas a diferentes doses de radiação em relação ao PP (puro) não irradiado.

\begin{tabular}{cccc}
\hline $\begin{array}{c}\text { Doses } \\
\mathrm{kGy}\end{array}$ & $20 \% \mathrm{WF} / \mathrm{PP}$ & $20 \% \mathrm{WF}+\mathrm{TiBa} / \mathrm{PP}$ & $\begin{array}{c}20 \% \mathrm{WF}+\mathrm{TiBa}+ \\
\mathrm{TPDGA} / \mathrm{PP}\end{array}$ \\
\hline 0 & $35,97 \%$ & $39,53 \%$ & $34,00 \%$ \\
10 & $35,15 \%$ & $30,64 \%$ & $28,13 \%$ \\
20 & $47,05 \%$ & $47,15 \%$ & $30,72 \%$ \\
\hline
\end{tabular}

Ao comparar as amostras com $20 \%$ WF em relação ao PP (puro) observou-se que:

As amostras de $20 \% \mathrm{WF}$ foram as que apresentaram resultados menores.

Como conclusão desses resultados de resistência ao impacto pode se dizer que:

A presença de TiBa e TPDGA nas amostras irradiadas a 10kGy e 20kGy melhorou a adesão do compósito. Pode ser observado que estas amostras apresentaram bons resultados em comparação ao PP (puro) irradiado.

A presença de reforço pode algumas vezes atuar como concentrador de tensão e como conseqüência pode reduzir a resistência de impacto.

A radiação ionizante reticula o PP e oxida o pó de madeira e por isso estas amostras apresentaram baixos resultados de resistência ao impacto. 


\subsection{ENSAIOS DE DUREZA}

Foi determinada a dureza para as seguintes composições de PP:

- PP (puro);

$-10 \% \mathrm{WF} / \mathrm{PP}$,

- 10\%WF+TiBa/PP,

- 10\%WF+TiBa+TPDGA/PP,

- 15\%WF/PP,

- 15\%WF+TiBa/PP,

- 15\%WF+TiBa+TPDGA/PP,

$-20 \% \mathrm{WF} / \mathrm{PP}$

- 20\%WF+TiBa/PP,

- 20\%WF+TiBa+TPDGA/PP.

Também foram determinadas a dureza para todas estas composições citadas anteriormente submetidas a doses de radiação de $10 \mathrm{kGy}$ e $20 \mathrm{kGy}$.

Nas Tabelas 37, 38, 39, 40, 42, 43, 44, 46, 47, 48 são apresentados os resultados obtidos no ensaio de dureza das amostras irradiadas e não irradiadas do PP (puro) e das diferentes composições de PP com 10\%WF, 15\%WF e 20\%WF.

Tabela 37 - Dureza Shore D das amostras de PP (puro) irradiadas e não irradiadas.

\begin{tabular}{c|ccc}
\hline Amostras & PP (Puro) & PP (Puro) 10kGy & PP (Puro) 20kGy \\
\hline 1 & 77,50 & 79,50 & 80,00 \\
2 & 77,00 & 79,50 & 81,00 \\
3 & 78,00 & 79,00 & 79,00 \\
4 & 77,50 & 80,00 & 80,00 \\
5 & 77,50 & 79,60 & 80,00 \\
\hline Média & 77,50 & 79,52 & 80,00 \\
Desvio Padrão & 0,35 & 0,36 & 0,71 \\
\hline
\end{tabular}

Na Figura 46 são mostrados os resultados de dureza das amostras de PP (puro) irradiadas e não irradiadas. 


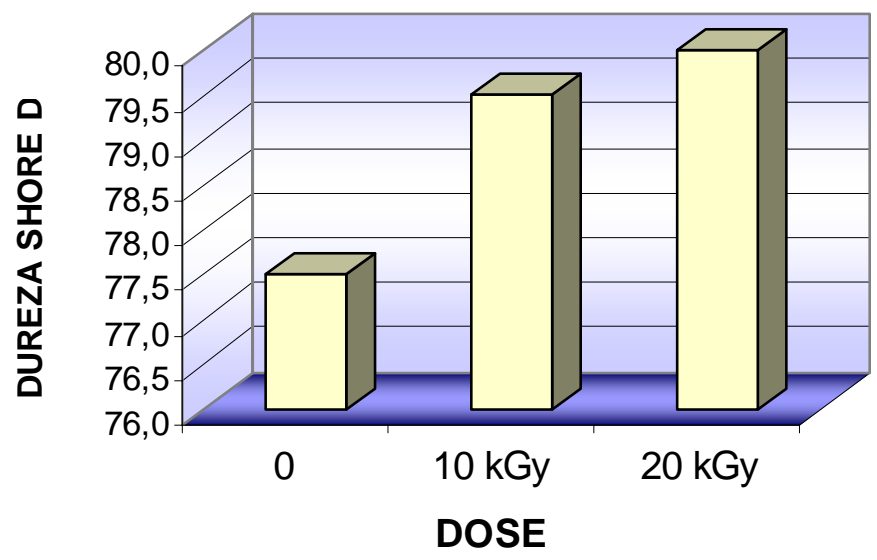

$\square$ PP (Puro)

Figura 46 - Dureza das amostras de PP irradiadas e não irradiadas.

Os resultados apresentados na Tabela 37 e mostrado na Figura 46 mostraram que:

Houve um acréscimo na dureza do PP (puro) conforme o aumento das doses de radiação este aumento foi de:

2,61\% nas amostras de PP irradiado com 10kGy;

$3,23 \%$ nas amostras de PP irradiado com 20kGy.

Este acréscimo na dureza significa que ocorreu reticulação no PP.

Tabela 38 - Dureza Shore D das amostras de 10\%WF/PP irradiadas e não irradiadas.

\begin{tabular}{c|cccc}
\hline \multirow{2}{*}{ Amostras } & & & $10 \% \mathrm{WF} / \mathrm{PP}$ & $10 \% \mathrm{WF} / \mathrm{PP}$ \\
& PP (Puro) & $10 \% \mathrm{WF} / \mathrm{PP}$ & $10 \mathrm{kGy}$ & $20 \mathrm{kGy}$ \\
\hline 1 & 77,50 & 78,500 & 78,00 & 80,00 \\
2 & 77,00 & 78,00 & 79,00 & 78,00 \\
3 & 78,00 & 79,00 & 78,10 & 79,00 \\
4 & 77,50 & 78,50 & 77,00 & 79,00 \\
5 & 77,50 & 78,50 & 78,00 & 79,00 \\
\hline Média & 77,50 & 78,50 & 78,02 & 79,00 \\
Desvio Padrão & 0,35 & 0,35 & 0,71 & 0,71 \\
\hline
\end{tabular}


Tabela 39 - Dureza Shore D das amostras de 10\%WF+TiBa/PP irradiadas e não irradiadas.

\begin{tabular}{c|cccc}
\hline \multirow{2}{*}{ Amostras } & PP (Puro) & $\begin{array}{c}10 \% \mathrm{WF}+\mathrm{TiBa} / \\
\text { PP }\end{array}$ & $\begin{array}{c}10 \% \mathrm{WF}+\mathrm{TiBa} / \\
\mathrm{PP} 10 \mathrm{kGy}\end{array}$ & $\begin{array}{c}10 \% \mathrm{WF}+\mathrm{TiBa} / \\
\mathrm{PP} 20 \mathrm{kGy}\end{array}$ \\
\hline 1 & 77,50 & 79,00 & 79,60 & 79,00 \\
2 & 77,00 & 80,00 & 78,60 & 80,00 \\
3 & 78,00 & 79,10 & 79,60 & 78,00 \\
4 & 77,50 & 79,00 & 80,60 & 79,00 \\
5 & 77,50 & 78,00 & 79,60 & 79,05 \\
\hline Média & 77,50 & 79,02 & 79,60 & 79,01 \\
Desvio Padrão & 0,35 & 0,71 & 0,71 & 0,71 \\
\hline
\end{tabular}

Tabela 40 - Dureza Shore D das amostras de 10\%WF+TiBa+TPDGA/PP irradiadas e não irradiadas.

\begin{tabular}{c|cccc}
\hline \multirow{2}{*}{ Amostras } & PP (Puro) & $\begin{array}{c}10 \% \mathrm{WF}+\mathrm{TiBa}+ \\
\text { TPGDA/PP }\end{array}$ & $\begin{array}{c}10 \% \mathrm{WF}+\mathrm{TiBa}+ \\
\text { TPGDA/PP } \\
10 \mathrm{kGy}\end{array}$ & $\begin{array}{c}10 \% \mathrm{WF}+\mathrm{TiBa}+ \\
\mathrm{TPDGA} / \mathrm{PP} \\
20 \mathrm{kGy}\end{array}$ \\
\hline 1 & 77,50 & 80,20 & 81,20 & 81,00 \\
2 & 77,00 & 80,30 & 79,80 & 82,00 \\
3 & 78,00 & 81,30 & 82,00 & 80,00 \\
4 & 77,50 & 79,30 & 81,00 & 81,00 \\
5 & 77,50 & 80,40 & 81,00 & 81,00 \\
\hline Média & 77,50 & 80,30 & 81,00 & 81,00 \\
Desvio Padrão & 0,35 & 0,71 & 0,787 & 0,71 \\
\hline
\end{tabular}

Na Figura 47 são mostrados os resultados de dureza das amostras de PP (puro) e de diferentes composições de PP com 10\%WF irradiadas e não irradiadas. 

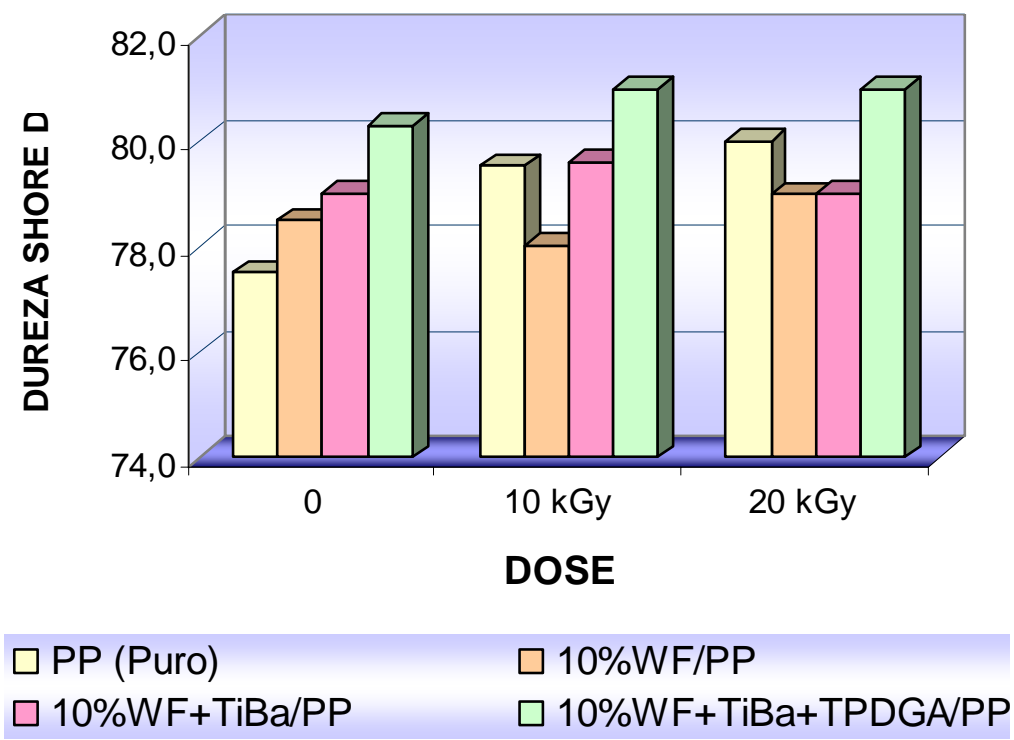

Figura 47 - Dureza das amostras de PP (puro) e de diferentes composições de PP com 10\%WF irradiadas e não irradiadas.

Analisando os resultados apresentados nas Tabelas 38, 39 e 40 e mostrado na Figura 47 observou-se que:

Houve um acréscimo na dureza nos compósitos contendo pó de madeira em relação aos compostos contendo somente PP.

$\mathrm{Na}$ Tabela 41, são apresentados os resultados da porcentagem de aumento da dureza para diferentes composições com 10\%WF submetidas a diferentes doses em comparação ao PP (puro) não irradiado.

Tabela 41 - Porcentagem de aumento da dureza para as diferentes composições com 10\%WF submetidas a diferentes doses de radiação em relação ao PP (puro) não irradiado.

\begin{tabular}{cccc}
\hline $\begin{array}{c}\text { Doses } \\
\mathrm{kGy}\end{array}$ & $10 \% \mathrm{WF} / \mathrm{PP}$ & $10 \% \mathrm{WF}+\mathrm{TiBa} / \mathrm{PP}$ & $\begin{array}{c}10 \% \mathrm{WF}+\mathrm{TiBa}+ \\
\mathrm{TPDGA} / \mathrm{PP}\end{array}$ \\
\hline 0 & $1,29 \%$ & $1,96 \%$ & $3,61 \%$ \\
10 & $0,67 \%$ & $2,71 \%$ & $4,52 \%$ \\
20 & $1,93 \%$ & $1,95 \%$ & $4,52 \%$ \\
\hline
\end{tabular}

Analisando os resultados das amostras $10 \% \mathrm{WF}$ irradiadas e não irradiadas e comparando com as amostras de PP (puro) não irradiado observou-se que:

Todas as amostras tiveram acréscimo em seus resultados de dureza em relação ao PP não irradiado. Observou-se que as amostras que apresentaram melhores resultados de acréscimo na dureza foram as amostras com o monômero TPDGA. 
Tabela 42 - Dureza Shore D das amostras de 15\%WF/PP irradiadas e não irradiadas.

\begin{tabular}{c|cccc}
\hline \multirow{2}{*}{ Amostras } & & & $15 \% \mathrm{WF} / \mathrm{PP}$ & $15 \% \mathrm{WF} / \mathrm{PP}$ \\
\hline 1 & PP (Puro) & $15 \% \mathrm{WF} / \mathrm{PP}$ & $10 \mathrm{kGy}$ & $20 \mathrm{kGy}$ \\
2 & 77,50 & 80,25 & 79,00 & 77,00 \\
3 & 77,00 & 81,20 & 80,00 & 78,00 \\
4 & 78,00 & 79,30 & 78,00 & 79,00 \\
5 & 77,50 & 80,25 & 79,00 & 78,00 \\
\hline Média & 77,50 & 80,25 & 79,00 & 78,00 \\
Desvio Padrão & 77,50 & 80,25 & 79,00 & 78,00 \\
\hline
\end{tabular}

Tabela 43 - Dureza Shore D das amostras 15\%WF+TiBa/PP irradiadas e não irradiadas.

\begin{tabular}{c|cccc}
\hline Amostras & PP (Puro) & $\begin{array}{c}15 \% \mathrm{WF}+\mathrm{TiBa} / \\
\text { PP }\end{array}$ & $\begin{array}{c}15 \% \mathrm{WF}+\mathrm{TiBa} / \\
\text { PP 10kGy }\end{array}$ & $\begin{array}{c}15 \% \mathrm{WF}+\mathrm{TiBa} / \\
\mathrm{PP} 20 \mathrm{kGy}\end{array}$ \\
\hline 1 & 77,50 & 81,30 & 79,00 & 77,50 \\
2 & 77,00 & 79,30 & 79,00 & 79,50 \\
3 & 78,00 & 80,30 & 78,00 & 78,50 \\
4 & 77,50 & 80,30 & 80,00 & 78,50 \\
5 & 77,50 & 80,30 & 79,00 & 78,50 \\
\hline Média & 77,50 & 80,30 & 79,00 & 78,50 \\
Desvio Padrão & 0,35 & 0,71 & 0,71 & 0,71 \\
\hline
\end{tabular}

Tabela 44 - Dureza Shore D das amostras de 15\%WF+TiBa+TPDGA/PP irradiadas e não irradiadas.

\begin{tabular}{c|cccc}
\hline \multirow{2}{*}{ Amostras } & PP (Puro) & $\begin{array}{c}15 \% \mathrm{WF}+\mathrm{TiBa}+ \\
\text { TPDGA/PP }\end{array}$ & $\begin{array}{c}15 \% \mathrm{WF}+\mathrm{TiBa}+ \\
\text { TPDGA/PP } \\
10 \mathrm{kGy}\end{array}$ & $\begin{array}{c}15 \% \mathrm{WF}+\mathrm{TiBa}+ \\
\text { TPDGA/PP } \\
20 \mathrm{kGy}\end{array}$ \\
\hline 1 & 77,50 & 80,40 & 82,00 & 79,75 \\
2 & 77,00 & 80,40 & 81,00 & 79,75 \\
3 & 78,00 & 79,40 & 81,00 & 78,70 \\
4 & 77,50 & 81,40 & 80,00 & 80,70 \\
5 & 77,50 & 80,40 & 81,00 & 79,75 \\
\hline Média & 77,50 & 80,40 & 81,00 & 79,73 \\
Desvio Padrão & 0,35 & 0,71 & 0,71 & 0,71 \\
\hline
\end{tabular}


Na Figura 48 são mostrados os resultados de dureza das amostras de PP (puro) e de diferentes composições de PP com 15\%WF irradiadas e não irradiadas.

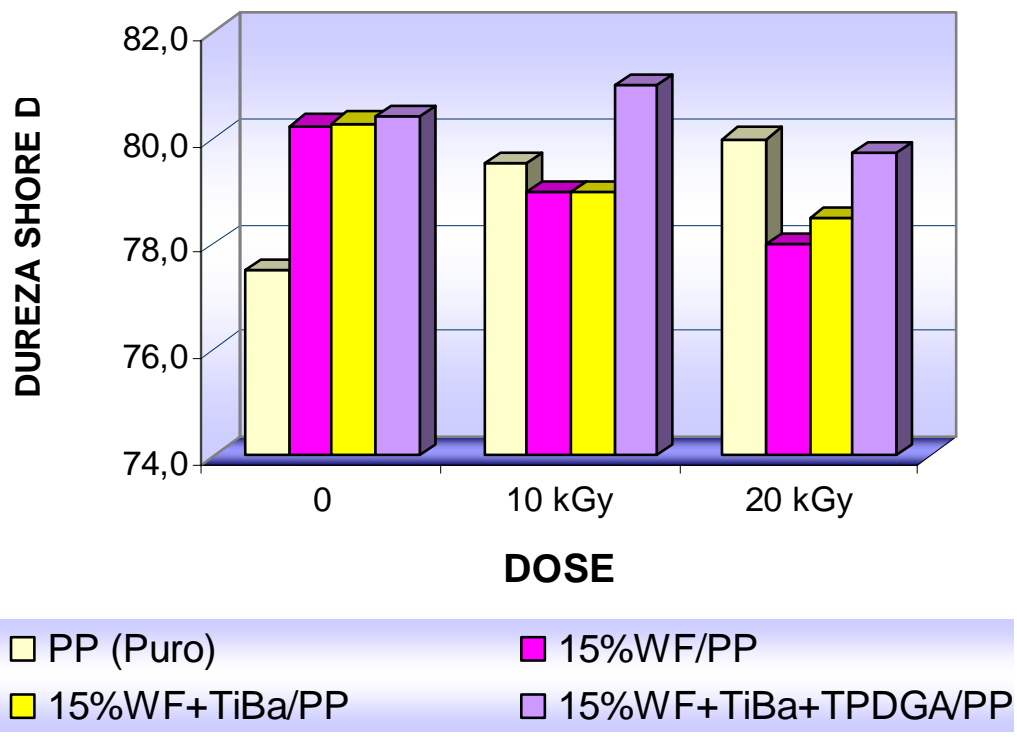

Figura 48 - Dureza das amostras de PP (puro) e de diferentes composições de 15\%WF irradiadas e não irradiadas.

Analisando os resultados apresentados nas Tabelas 42, 43 e 44 e mostrado na Figura 48 observou-se que:

Houve um acréscimo da dureza nos compósitos contendo pó de madeira em relação aos compostos contendo somente PP.

Na Tabela 45, são apresentados os resultados da porcentagem de aumento da dureza para diferentes composições com 15\%WF submetidas a diferentes doses em comparação ao PP (puro) não irradiado.

Tabela 45 - Porcentagem de aumento da dureza para as diferentes composições com $15 \%$ WF submetidas a diferentes doses de radiação em relação ao PP (puro) não irradiado.

\begin{tabular}{cccc}
\hline $\begin{array}{c}\text { Doses } \\
\mathrm{kGy}\end{array}$ & $15 \% \mathrm{WF} / \mathrm{PP}$ & $15 \% \mathrm{WF}+\mathrm{TiBa} / \mathrm{PP}$ & $\begin{array}{c}15 \% \mathrm{WF}+\mathrm{TiBa}+ \\
\mathrm{TPDGA} / \mathrm{PP}\end{array}$ \\
\hline 0 & $3,55 \%$ & $3,61 \%$ & $3,74 \%$ \\
10 & $1,93 \%$ & $1,93 \%$ & $4,52 \%$ \\
20 & $0,64 \%$ & $1,29 \%$ & $2,88 \%$ \\
\hline
\end{tabular}


Analisando os resultados das amostras $15 \% \mathrm{WF}$ irradiadas e não irradiadas e comparando com as amostras de PP (puro) não irradiado observou-se que:

As amostras não irradiadas tiveram acréscimos significativos em seus resultados de dureza em relação ao PP não irradiado.

A amostra 15\%WF+TiBa+TPDGA/PP apresentou melhor resultado.

Tabela 46 - Dureza Shore D das amostras de 20\%WF/PP irradiadas e não irradiadas.

\begin{tabular}{c|cccc}
\hline \multirow{2}{*}{ Amostras } & PP (Puro) & $20 \% \mathrm{WF} / \mathrm{PP}$ & $\begin{array}{c}20 \% \mathrm{WF} / \mathrm{PP} \\
10 \mathrm{kGy}\end{array}$ & $\begin{array}{c}20 \% \mathrm{WF} / \mathrm{PP} \\
20 \mathrm{kGy}\end{array}$ \\
\hline 1 & 77,50 & 80,20 & 78,75 & 78,80 \\
2 & 77,00 & 82,20 & 79,75 & 79,80 \\
3 & 78,00 & 81,20 & 77,75 & 77,80 \\
4 & 77,50 & 81,20 & 78,75 & 78,80 \\
5 & 77,50 & 81,25 & 78,76 & 78,80 \\
\hline Média & 77,50 & 81,21 & 78,75 & 78,80 \\
Desvio Padrão & 0,35 & 0,71 & 0,71 & 0,71 \\
\hline
\end{tabular}

Tabela 47 - Dureza Shore D das amostras 20\%WF+TiBa/PP irradiadas e não irradiadas.

\begin{tabular}{c|cccc}
\hline \multirow{2}{*}{ Amostras } & PP (Puro) & $20 \% \mathrm{WF}+\mathrm{TiBa} / \mathrm{PP}$ & $\begin{array}{c}20 \% \mathrm{WF}+\mathrm{TiBa} / \mathrm{PP} \\
10 \mathrm{kGy}\end{array}$ & $20 \mathrm{WF}+\mathrm{TiBa} / \mathrm{PP}$ \\
& & & 78,40 & 80,60 \\
\hline 1 & 77,50 & 82,40 & 79,60 & 79,60 \\
3 & 77,00 & 81,40 & 79,40 & 78,60 \\
4 & 78,00 & 80,20 & 80,10 & 79,70 \\
5 & 77,50 & 81,60 & 79,50 & 79,50 \\
\hline Média & 77,50 & 81,40 & 79,40 & 79,60 \\
Desvio Padrão & 77,50 & 81,40 & 0,62 & 0,71 \\
\hline
\end{tabular}


Tabela 48 - Dureza Shore D das amostras de 20\%WF+TiBa+TPDGA/PP irradiadas e não irradiadas.

\begin{tabular}{c|cccc}
\hline \multirow{2}{*}{ Amostras } & PP (Puro) & $\begin{array}{c}20 \% \mathrm{WF}+\mathrm{TiBa}+ \\
\text { TPDGA } / \mathrm{PP}\end{array}$ & $\begin{array}{c}20 \% \mathrm{WF}+\mathrm{TiBa}+ \\
\text { TPDGA/PP } \\
10 \mathrm{kGy}\end{array}$ & $\begin{array}{c}20 \% \mathrm{WF}+\mathrm{TiBa}+ \\
\text { TPDGA/PP } \\
20 \mathrm{~Gy}\end{array}$ \\
\hline 1 & 77,50 & 80,80 & 79,80 & 80,00 \\
2 & 77,00 & 82,80 & 79,80 & 79,00 \\
3 & 78,00 & 81,80 & 78,80 & 81,00 \\
4 & 77,50 & 81,80 & 80,80 & 80,00 \\
5 & 77,50 & 81,80 & 79,80 & 80,000 \\
\hline Média & 77,50 & 81,80 & 79,80 & 80,00 \\
Desvio Padrão & 0,35 & 0,71 & 0,71 & 0,71 \\
\hline
\end{tabular}

Na Figura 49 são mostrados os resultados de dureza das amostras de PP com $20 \% \mathrm{WF}$ irradiadas e não irradiadas.
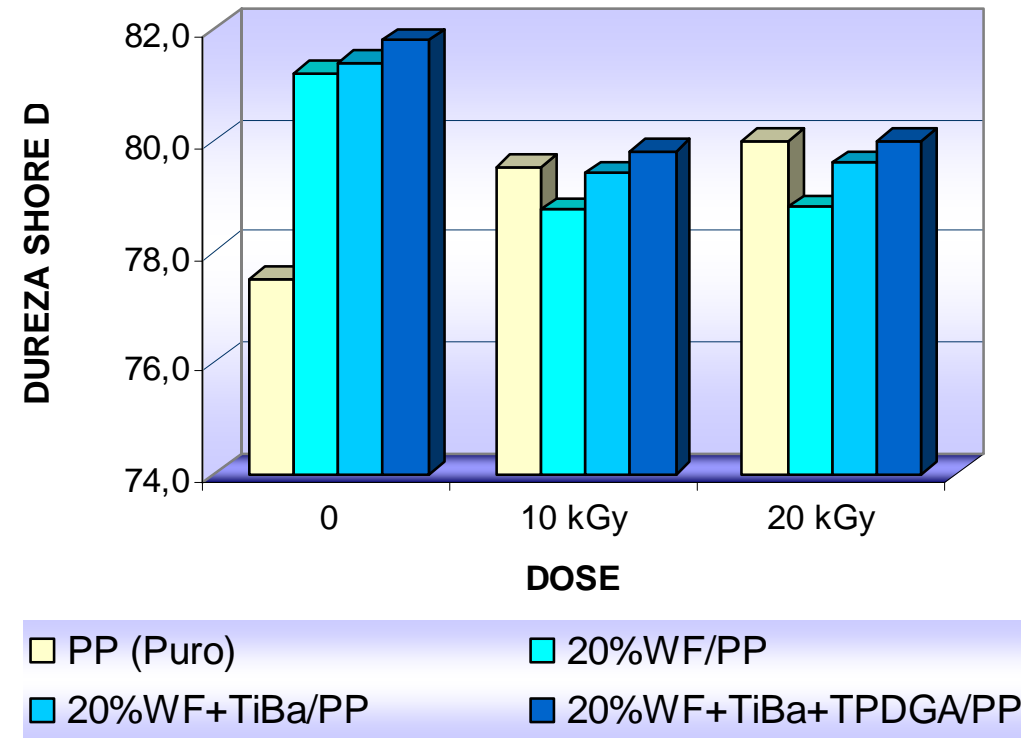

Figura 49 - Dureza das amostras de PP (puro) e de diferentes composições de PP com $20 \% \mathrm{WF}$ irradiadas e não irradiadas.

Analisando os resultados apresentados nas Tabelas 46, 47 e 48 e mostrado na Figura 49 observou-se que: 
Houve um acréscimo na dureza nos compósitos contendo pó de madeira em relação aos compostos contendo somente PP.

Na Tabela 49, são apresentados os resultados da porcentagem de aumento da dureza para diferentes composições com $20 \% \mathrm{WF}$ submetidas a diferentes doses em comparação ao PP (puro) não irradiado.

Tabela 49 - Porcentagem de aumento da dureza para as diferentes composições com $20 \%$ WF submetidas a diferentes doses de radiação em relação ao PP (puro) não irradiado.

\begin{tabular}{cccc}
\hline $\begin{array}{c}\text { Dose } \\
\mathrm{kGy}\end{array}$ & $20 \% \mathrm{WF} / \mathrm{PP}$ & $20 \% \mathrm{WF}+\mathrm{TiBa} / \mathrm{PP}$ & $\begin{array}{c}20 \% \mathrm{WF}+\mathrm{TiBa}+ \\
\mathrm{TPDGA} / \mathrm{PP}\end{array}$ \\
\hline 0 & $4,79 \%$ & $5,03 \%$ & $5,55 \%$ \\
10 & $1,62 \%$ & $2,45 \%$ & $2,97 \%$ \\
20 & $1,68 \%$ & $2,71 \%$ & $3,23 \%$ \\
\hline
\end{tabular}

Analisando os resultados das amostras de $20 \% \mathrm{WF}$ irradiadas e não irradiadas e comparando com as amostras de PP (puro) não irradiado observou-se que:

Todas as amostras tiveram acréscimo em seus resultados de dureza em relação ao PP (puro) não irradiado.

O acréscimo na dureza apresentou resultados significativos nas amostras não irradiadas.

As amostras com $20 \% \mathrm{WF}$ foram as que apresentaram resultados mais elevados de dureza, isso ocorreu porque possui maior quantidade de carga pó de madeira.

As amostras com o monômero TPDGA e irradiadas a 20kGy apresentaram maior acréscimo da dureza.

Como conclusão desses resultados de dureza pode-se dizer que:

Houve um acréscimo significativo na dureza dos compósitos WF/PP que não foram irradiados.

As amostras com $20 \% \mathrm{WF}$ foram as que apresentaram resultados mais elevados de dureza, isso porque quanto maior a quantidade de carga maior o módulo de dureza.

Nas amostras irradiadas a dureza aumentou devido à reticulação do PP frente à radiação. 
Observou-se que na presença de TiBa houve uma melhor reprodutividade nos valores obtidos para esta propriedade mostrando que este ajuda na homogeneização da carga fibrosa (pó de madeira) no PP.

A presença do monômero TPDGA na amostras não irradiadas contribuiu na melhor adesão entre carga e matriz e nas amostras irradiadas auxiliou na reticulação das amostras.

\subsection{ENSAIOS DE TEMPERATURA DE DEFLEXÃO TÉRMICA (HDT)}

A temperatura de deflexão térmica foi determinada para as seguintes composições de PP:

- PP (puro);

- 10\%WF/PP;

- 10\%WF+TiBa/PP;

- 10\%WF+TiBa+TPDGA/PP;

- 15\%WF/PP;

- 15\%WF+TiBa/PP;

- 15\%WF+TiBa+TPDGA/PP;

- 20\%WF/PP;

- 20\%WF+TiBa/PP;

- 20\%WF+TiBa+TPDGA/PP.

Também foram determinadas a temperatura de deflexão térmica para todas estas composições citadas anteriormente submetidas a doses de radiação de $10 \mathrm{kGy}$ e 20 kGy.

Nas Tabelas 50, 51, 52, 53, 55, 56, 57, 59, 60 e 61 são apresentados os resultados obtidos no ensaio de temperatura de deflexão térmica das amostras irradiadas e não irradiadas do PP (puro) e de diferentes composições de PP com 10\%WF, 15\%WF e $20 \% \mathrm{WF}$. 
Tabela 50 - Temperatura de deflexão térmica $\left({ }^{\circ} \mathrm{C}\right)$ - HDT para amostras de PP (puro) irradiadas e não irradiadas.

\begin{tabular}{c|ccc}
\hline Amostras & PP (Puro) & PP (Puro) 10kGy & PP (Puro) 20kGy \\
\hline 1 & 111,6 & 115,7 & 104,3 \\
2 & 114,2 & 111,8 & 113,7 \\
3 & 105,4 & 110,0 & 111,5 \\
\hline Média & 110,4 & 112,5 & 109,8 \\
Desvio Padrão & 4,5 & 2,9 & 4,9 \\
\hline
\end{tabular}

Na Figura 50 são mostrados os resultados de temperatura de deflexão térmica das amostras de PP (puro) irradiadas e não irradiadas.

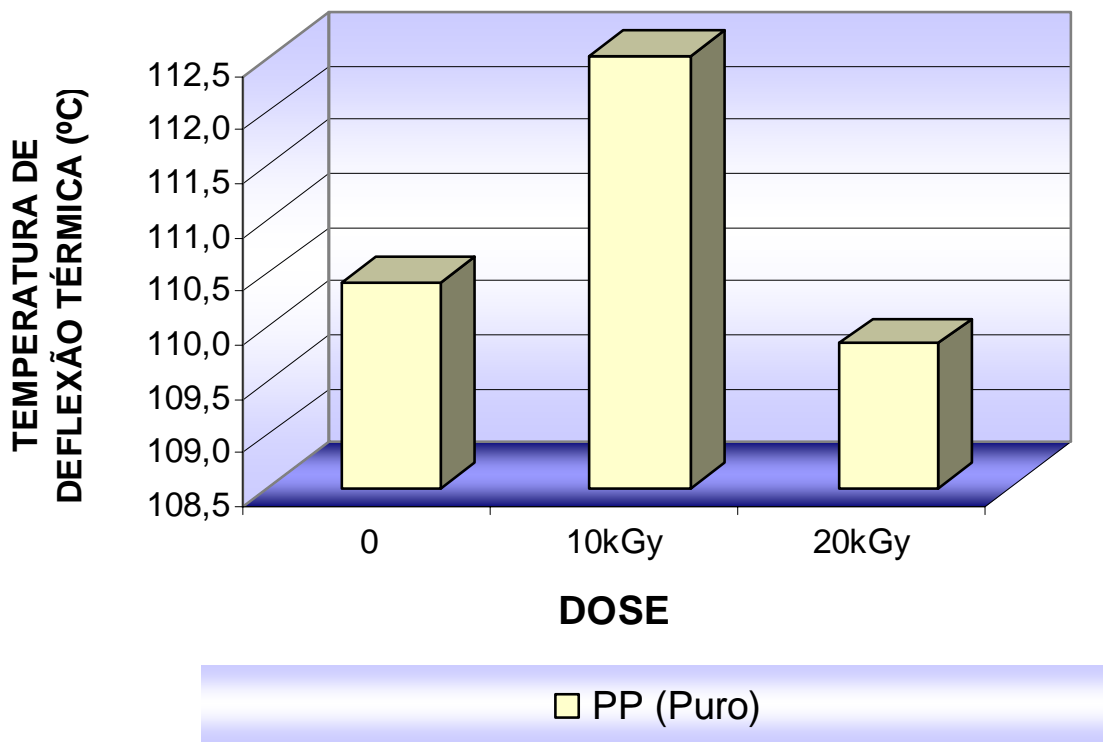

Figura 50 - Temperatura de deflexão térmica - HDT das amostras de PP (puro) irradiadas e não irradiadas.

Analisando os resultados apresentados nas Tabelas 50 e mostrado na Figura 50 observou-se que:

O PP quando submetido á radiação ionizante observou-se um aumento para as amostras com 10kGy e um decréscimo para as amostras com 20kGy. Porém estes resultados são foram significativos. 
Tabela 51 - Temperatura de deflexão térmica $\left({ }^{\circ} \mathrm{C}\right)$ - das amostras de 10\%WF/PP irradiadas e não irradiadas.

\begin{tabular}{c|cccc}
\hline \multirow{2}{*}{ Amostras } & PP (Puro) & $10 \% \mathrm{WF} / \mathrm{PP}$ & $10 \% \mathrm{WF} / \mathrm{PP}$ & $10 \% \mathrm{WF} / \mathrm{PP}$ \\
& & & $10 \mathrm{kGy}$ & $20 \mathrm{kGy}$ \\
\hline 1 & 111,6 & 101,4 & 110,8 & 105,6 \\
2 & 114,2 & 107,1 & 114,5 & 103,8 \\
3 & 105,4 & 103,1 & 109,9 & 109,6 \\
\hline Média & 110,4 & 103,9 & 111,7 & 106,3 \\
Desvio Padrão & 4,5 & 2,9 & 2,4 & 3,0 \\
\hline
\end{tabular}

Tabela 52 - Temperatura de deflexão térmica $\left({ }^{\circ} \mathrm{C}\right)$ das amostras de $10 \% \mathrm{WF}+\mathrm{TiBa} / \mathrm{PP}$ irradiadas e não irradiadas.

\begin{tabular}{c|cccc}
\hline Amostras & PP (Puro) & $\begin{array}{c}10 \% \mathrm{WF}+\mathrm{TiBa} / \\
\mathrm{PP}\end{array}$ & $\begin{array}{c}10 \% \mathrm{WF}+\mathrm{TiBa} / \\
\mathrm{PP} 10 \mathrm{kGy}\end{array}$ & $\begin{array}{c}10 \% \mathrm{WF}+\mathrm{TiBa} / \\
\mathrm{PP} 20 \mathrm{kGy}\end{array}$ \\
\hline 1 & 111,6 & 106,5 & 110,1 & 108,7 \\
2 & 114,2 & 112,5 & 105,0 & 105,8 \\
3 & 105,4 & 104,7 & 114,4 & 105,3 \\
\hline Média & 110,4 & 107,9 & 109,8 & 106,6 \\
Desvio Padrão & 4,5 & 4,1 & 4,7 & 1,8 \\
\hline
\end{tabular}

Tabela 53 - Temperatura de deflexão térmica $\left({ }^{\circ} \mathrm{C}\right)$ das amostras de $10 \% \mathrm{WF}+\mathrm{TiBa}+\mathrm{TPDGA} / \mathrm{PP}$ irradiadas e não irradiadas.

\begin{tabular}{c|cccc}
\hline \multirow{2}{*}{ Amostras } & PP (Puro) & $\begin{array}{c}10 \% \mathrm{WF}+\mathrm{TiBa}+ \\
\text { TPDGA/PP }\end{array}$ & $\begin{array}{c}10 \% \mathrm{WF}+\mathrm{TiBa}+ \\
\mathrm{TPDGA} / \mathrm{PP} \\
10 \mathrm{kGy}\end{array}$ & $\begin{array}{c}10 \% \mathrm{WF}+\mathrm{TiBa}+ \\
\mathrm{TPDGA} / \mathrm{PP} \\
20 \mathrm{kGy}\end{array}$ \\
\hline 1 & 111,6 & 106,0 & 108,2 & 112,1 \\
2 & 114,2 & 105,0 & 107,8 & 104,9 \\
3 & 105,4 & 105,4 & 106,0 & 107,7 \\
\hline Média & 110,4 & 105,5 & 107,3 & 108,2 \\
Desvio Padrão & 4,5 & 0,5 & 1,2 & 3,6 \\
\hline
\end{tabular}

Na Figura 51 são mostrados os resultados de temperatura de deflexão térmica das amostras de PP (puro) e de diferentes composições de PP com 10\%WF irradiadas e não irradiadas. 


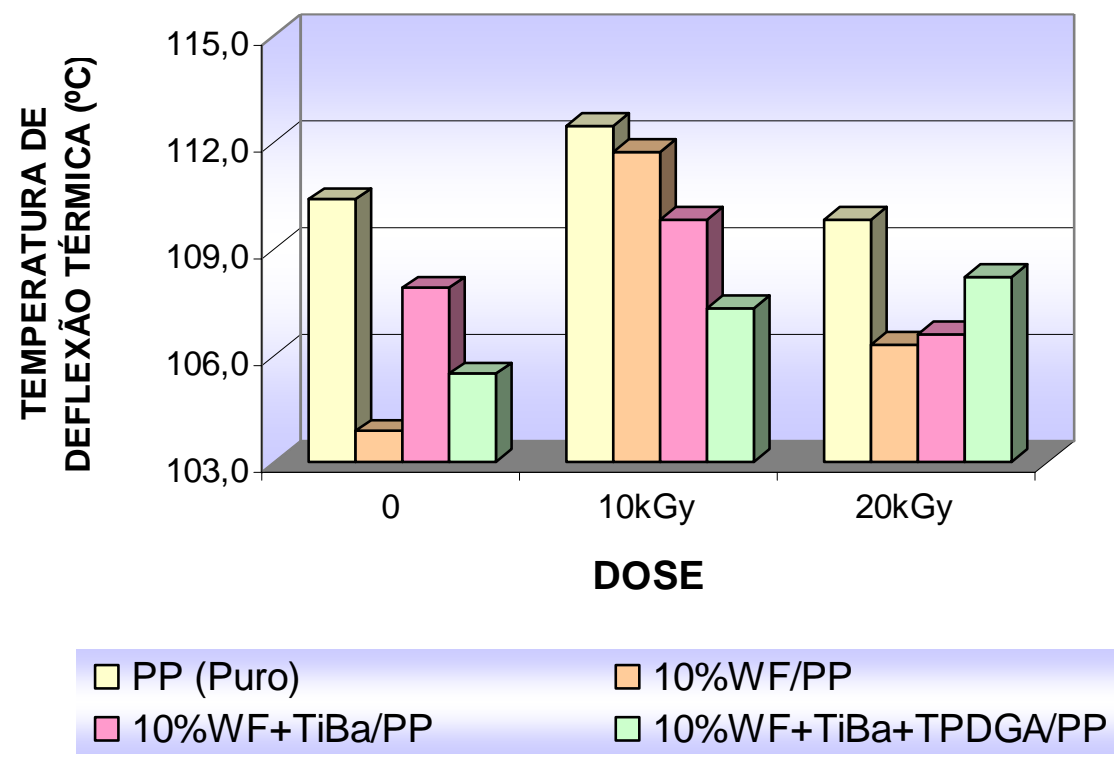

Figura 51 - Temperatura de deflexão térmica das amostras de PP (puro) e de diferentes composições de PP com 10\%WF irradiadas e não irradiadas.

Analisando os resultados apresentados nas Tabelas 51, 52 e 53 e mostrado na Figura 51 observou-se que:

Houve um decréscimo na temperatura de deflexão térmica dos compósitos contendo pó de madeira em relação aos compostos contendo somente PP.

Os resultados do ensaio de HDT para as amostras de PP com diferentes porcentagens com 10\%WF em relação ao PP (puro) são apresentados na Tabela 54. Os valores com sinal negativo significam que houve um decréscimo no resultado em comparação ao PP não irradiado.

Tabela 54 - Porcentagem dos resultados do ensaio de HDT para as diferentes composições com $10 \%$ WF submetidas a diferentes doses de radiação em relação ao PP (puro) não irradiado.

\begin{tabular}{cccc}
\hline $\begin{array}{c}\text { Doses } \\
\mathrm{kGy}\end{array}$ & $10 \% \mathrm{WF} / \mathrm{PP}$ & $10 \% \mathrm{WF}+\mathrm{TiBa} / \mathrm{PP}$ & $\begin{array}{c}10 \% \mathrm{WF}+\mathrm{TiBa} \\
+\mathrm{TPDGA} / \mathrm{PP}\end{array}$ \\
\hline 0 & $-5,9 \%$ & $-2,3 \%$ & $-4,5 \%$ \\
10 & $1,2 \%$ & $-0,5 \%$ & $-2,8 \%$ \\
20 & $-3,7 \%$ & $-3,4 \%$ & $-2,0 \%$ \\
\hline
\end{tabular}


Analisando os resultados das amostras $10 \% \mathrm{WF}$ irradiadas e não irradiadas e comparando com as amostras de PP (puro) não irradiado observou-se que:

A amostra 10\%WF/PP obteve melhor resultado.

O restante das amostras apresentou decréscimo nos resultados.

Tabela 55 - Temperatura de deflexão térmica $\left({ }^{\circ} \mathrm{C}\right)$ das amostras de 15\%WF/PP irradiadas e não irradiadas.

\begin{tabular}{c|cccc}
\hline \multirow{2}{*}{ Amostras } & PP (Puro) & $15 \% \mathrm{WF} / \mathrm{PP}$ & $15 \% \mathrm{WF} / \mathrm{PP}$ & $15 \% \mathrm{WF} / \mathrm{PP}$ \\
& & & $10 \mathrm{kGy}$ & $20 \mathrm{kGy}$ \\
\hline 1 & 111,6 & 100,1 & 104,8 & 118,0 \\
2 & 114,2 & 105,5 & 111,1 & 115,0 \\
3 & 105,4 & 99,4 & 110,5 & 112,9 \\
\hline Média & 110,4 & 101,7 & 108,8 & 115,3 \\
Desvio Padrão & 4,5 & 3,3 & 3,5 & 2,6 \\
\hline
\end{tabular}

Tabela 56 - Temperatura de deflexão térmica $\left({ }^{\circ} \mathrm{C}\right)$ das amostras de $15 \% \mathrm{WF}+\mathrm{TiBa} / \mathrm{PP}$ irradiadas e não irradiadas.

\begin{tabular}{c|cccc}
\hline Amostras & PP (Puro) & $\begin{array}{c}15 \% \mathrm{WF}+\mathrm{TiBa} / \\
\text { PP }\end{array}$ & $\begin{array}{c}15 \% \mathrm{WF}+\mathrm{TiBa} / \\
\text { PP 10kGy }\end{array}$ & $\begin{array}{c}15 \% \mathrm{WF}+\mathrm{TiBa} / \\
\text { PP 20kGy }\end{array}$ \\
\hline 1 & 111,6 & 114,1 & 110,3 & 118,6 \\
2 & 114,2 & 113,5 & 114,3 & 114,9 \\
3 & 105,4 & 117,3 & 120,6 & 119,4 \\
\hline Média & 110,4 & 115,0 & 115,1 & 117,6 \\
Desvio Padrão & 4,5 & 2,0 & 5,2 & 2,4 \\
\hline
\end{tabular}

Tabela 57 - Temperatura de deflexão térmica $\left({ }^{\circ} \mathrm{C}\right)$ das amostras de $15 \% \mathrm{WF}+\mathrm{TiBa}+\mathrm{TPDGA} / \mathrm{PP}$ irradiadas e não irradiadas.

\begin{tabular}{c|cccc}
\hline \multirow{2}{*}{ Amostras } & PP (Puro) & $\begin{array}{c}15 \% \mathrm{WF}+\mathrm{TiBa}+ \\
\text { TPDGA/PP }\end{array}$ & $\begin{array}{c}15 \% \mathrm{WF}+\mathrm{TiBa}+ \\
\text { TPDGA/PP } \\
10 \mathrm{kGy}\end{array}$ & $\begin{array}{c}15 \% \mathrm{WF}+\mathrm{TiBa}+ \\
\text { TPDGA/PP } \\
20 \mathrm{kGy}\end{array}$ \\
\hline 1 & 111,6 & 113,5 & 114,5 & 116,9 \\
2 & 114,2 & 118,6 & 118,8 & 111,3 \\
3 & 105,4 & 119,6 & 114,8 & 114,1 \\
\hline Média & 110,4 & 117,2 & 116,0 & 114,1 \\
Desvio Padrão & 4,5 & 3,3 & 2,4 & 2,8 \\
\hline
\end{tabular}


Na Figura 52 são mostrados os resultados de temperatura de deflexão térmica das amostras de PP (puro) e de diferentes composições de PP com 15\%WF irradiadas e não irradiadas.
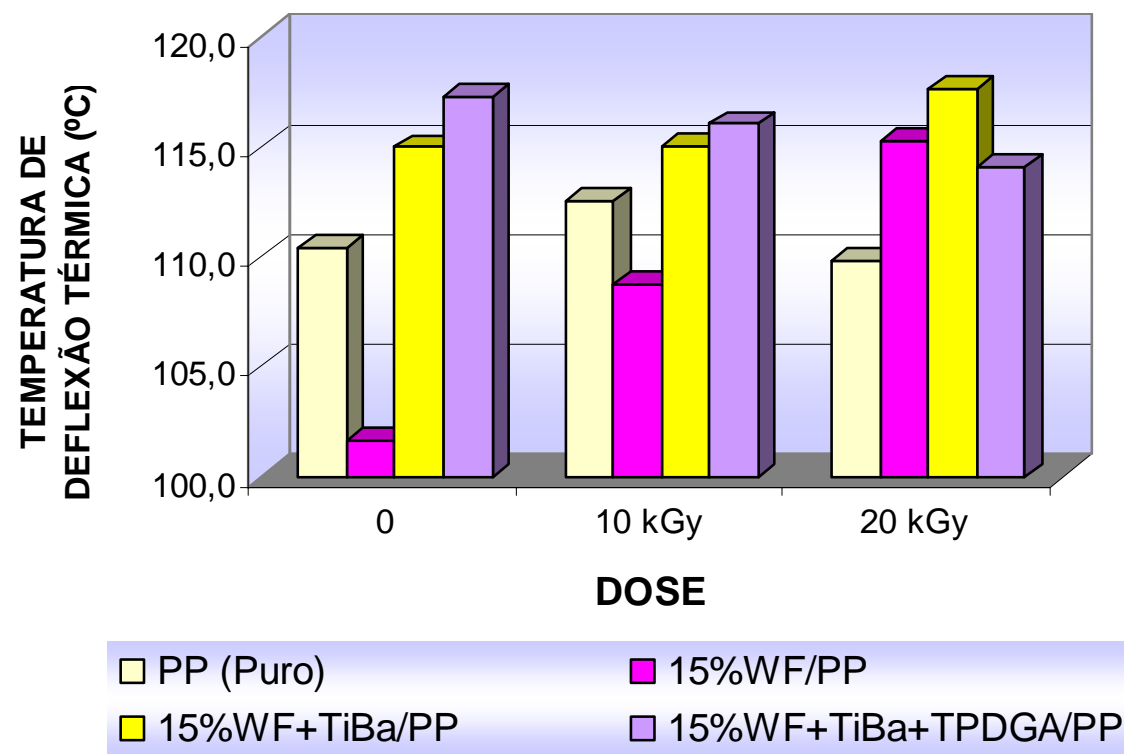

Figura 52 - Temperatura de deflexão térmica das amostras de PP (puro) e de diferentes composições de PP com 15\%WF irradiadas e não irradiadas.

Analisando os resultados apresentados nas Tabelas 55, 56 e 57 e mostrado na Figura 52 observou-se que:

Houve um acréscimo na temperatura de deflexão térmica dos compósitos contendo pó de madeira com TiBa e TPDGA em relação aos compostos contendo somente PP.

Os resultados do ensaio de HDT para as amostras de PP com 15\%WF são apresentados na Tabela 58. Os valores com sinal negativo significam que houve um decréscimo no resultado em comparação ao PP não irradiado.

Tabela 58 - Porcentagem dos resultados do ensaio de HDT para as diferentes composições com 15\%WF submetidas a diferentes doses de radiação em relação ao PP (puro) não irradiado.

\begin{tabular}{cccc}
\hline $\begin{array}{c}\text { Doses } \\
\mathrm{kGy}\end{array}$ & $15 \% \mathrm{WF} / \mathrm{PP}$ & $15 \% \mathrm{WF}+\mathrm{TiBa} / \mathrm{PP}$ & $\begin{array}{c}15 \% \mathrm{WF}+\mathrm{TiBa} \\
+\mathrm{TPDGA} / \mathrm{PP}\end{array}$ \\
\hline 0 & $-7,9 \%$ & $4,2 \%$ & $6,2 \%$ \\
10 & $-1,4 \%$ & $4,3 \%$ & $5,1 \%$ \\
20 & $4,4 \%$ & $6,5 \%$ & $3,4 \%$ \\
\hline
\end{tabular}


Analisando os resultados das amostras $15 \% \mathrm{WF}$ irradiadas e não irradiadas e comparando com as amostras de PP (puro) não irradiado observou-se que:

As amostras com o monômero e amostras que continham o TiBa obtiveram um acréscimo nos resultados de temperatura de deflexão térmica, porém estes resultados caem dentro do desvio padrão. Portanto estes resultados não são significativos.

Tabela 59 - Temperatura de deflexão térmica $\left({ }^{\circ} \mathrm{C}\right)$ - das amostras de $20 \% \mathrm{WF} / \mathrm{PP}$ irradiadas e não irradiadas.

\begin{tabular}{c|cccc}
\hline Amostras & PP (Puro) & $20 \% \mathrm{WF} / \mathrm{PP}$ & $\begin{array}{c}20 \% \mathrm{WF} / \mathrm{PP} \\
10 \mathrm{kGy}\end{array}$ & $\begin{array}{c}20 \% \mathrm{WF} / \mathrm{PP} \\
20 \mathrm{kGy}\end{array}$ \\
\hline 1 & 111,6 & 115,3 & 106,6 & 115,5 \\
2 & 114,2 & 108,9 & 114,8 & 107,4 \\
3 & 105,4 & 107,8 & 116,4 & 115,5 \\
\hline Média & 110,4 & 110,7 & 112,6 & 112,8 \\
Desvio Padrão & 4,5 & 4,0 & 5,3 & 4,7 \\
\hline
\end{tabular}

Tabela 60 - Temperatura de deflexão térmica $\left({ }^{\circ} \mathrm{C}\right)$ das amostras de $20 \% \mathrm{WF}+\mathrm{TiBa} / \mathrm{PP}$ irradiadas e não irradiadas.

\begin{tabular}{c|cccc}
\hline \multirow{2}{*}{ Amostras } & PP (Puro) & $\begin{array}{c}20 \% \mathrm{WF}+\mathrm{TiBa} / \\
\text { PP }\end{array}$ & $\begin{array}{c}20 \% \mathrm{WF}+\mathrm{TiBa} / \\
\text { PP } 10 \mathrm{kGy}\end{array}$ & $\begin{array}{c}20 \% \mathrm{WF}+\mathrm{TiBa} / \\
\text { PP 20kGy }\end{array}$ \\
\hline 1 & 111,6 & 106,0 & 107,6 & 110,5 \\
2 & 114,2 & 103,4 & 115,7 & 114,6 \\
3 & 105,4 & 105,1 & 111,3 & 112,1 \\
\hline Média & 110,4 & 104,8 & 111,5 & 112,4 \\
Desvio Padrão & 4,5 & 1,3 & 4,0 & 2,1 \\
\hline
\end{tabular}

Tabela 61 - Temperatura de deflexão térmica $\left({ }^{\circ} \mathrm{C}\right)$ das amostras de $20 \% \mathrm{WF}+\mathrm{TiBa}+\mathrm{TPDGA} / \mathrm{PP}$ irradiadas e não irradiadas

\begin{tabular}{c|cccc}
\hline \multirow{2}{*}{ Amostras } & PP (Puro) & $\begin{array}{c}20 \% \mathrm{WF}+\mathrm{TiBa}+ \\
\text { TPDGA/PP }\end{array}$ & $\begin{array}{c}\text { 20\%WF+TiBa }+ \\
\text { TPDGA/PP } \\
10 \mathrm{kGy}\end{array}$ & $\begin{array}{c}20 \% \mathrm{WF}+\mathrm{TiBa}+ \\
\text { TPDGA/PP } \\
20 \mathrm{kGy}\end{array}$ \\
\hline 1 & 111,6 & 117,6 & 107,0 & 114,3 \\
2 & 114,2 & 107,4 & 117,1 & 120,6 \\
3 & 105,4 & 111,8 & 113,0 & 112,7 \\
\hline Média & 110,4 & 112,3 & 112,4 & 115,9 \\
Desvio Padrão & 4,5 & 5,1 & 5,1 & 4,2 \\
\hline
\end{tabular}


Na Figura 53 são mostrados os resultados de temperatura de deflexão térmica das amostras de PP (puro) e de diferentes composições de PP com 20\%WF irradiadas e não irradiadas.

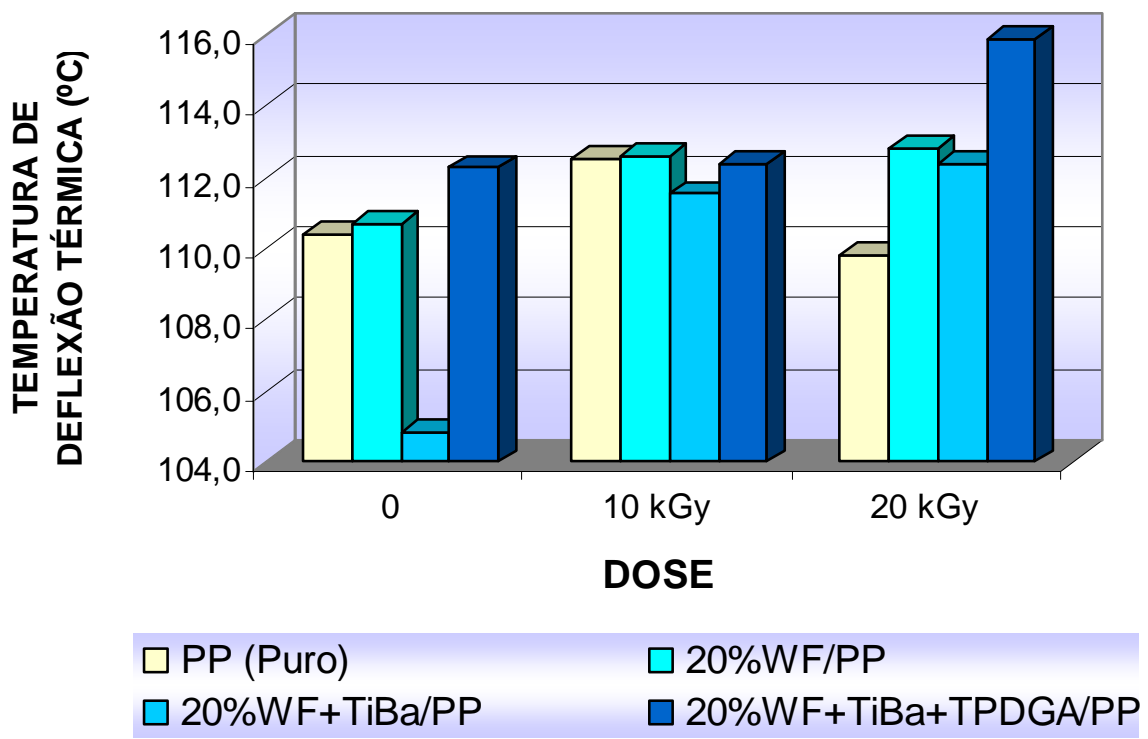

Figura 53 - Temperatura de deflexão térmica das amostras de PP (puro) e de diferentes composições de PP com 20\%WF irradiadas e não irradiadas.

Analisando os resultados apresentados nas Tabelas 59, 60 e 61 e mostrado na Figura 53 observou-se que:

Houve um acréscimo na temperatura de deflexão térmica dos compósitos contendo pó de madeira com TiBa e TPDGA em relação aos compostos contendo somente PP.

Os resultados do ensaio de HDT para as amostras de PP com 20\%WF são apresentados na Tabela 62. Os valores com sinal negativo significam que houve um decréscimo no resultado em comparação ao PP não irradiado.

Tabela 62 - Porcentagem dos resultados do ensaio de HDT para as diferentes composições com $20 \% \mathrm{WF}$ submetidas a diferentes doses de radiação em relação ao PP (puro) não irradiado.

\begin{tabular}{cccc}
\hline $\begin{array}{c}\text { Doses } \\
\mathrm{kGy}\end{array}$ & $20 \% \mathrm{WF} / \mathrm{PP}$ & $20 \% \mathrm{WF}+\mathrm{TiBa} / \mathrm{PP}$ & $\begin{array}{c}20 \% \mathrm{WF}+\mathrm{TiBa} \\
+\mathrm{TPDGA} / \mathrm{PP}\end{array}$ \\
\hline 0 & $0,3 \%$ & $-5,0 \%$ & $1,7 \%$ \\
10 & $2,0 \%$ & $1,0 \%$ & $1,8 \%$ \\
20 & $2,2 \%$ & $1,8 \%$ & $5,0 \%$ \\
\hline
\end{tabular}


Analisando os resultados das amostras com $20 \% \mathrm{WF}$ irradiadas e não irradiadas e comparando com as amostras de PP (puro) não irradiado observou-se que:

As amostras com o monômero obtiveram um acréscimo nos resultados de temperatura de deflexão térmica, porém estes resultados caem dentro do desvio padrão. Portanto estes resultados não são significativos.

Como conclusão desses resultados de temperatura de deflexão térmica pode-se dizer:

Foi observado que as amostras contendo $15 \% \mathrm{WF}+\mathrm{TiBa} / \mathrm{PP}$ principalmente a 20kGy apresentaram valores significativos de temperatura de deflexão térmica em todas as composições, mostrando que $15 \%$ de carga na matriz polimérica é a mais apropriada para esforços mecânicos sob temperatura.

Observou-se que em alguns casos o aumento na dose de radiação não influenciou na variação da temperatura de deflexão térmica tanto nas amostras com titanato quanto nas amostras com TPDGA. Isto indica que ocorreu reticulação nas amostras de compósitos.

Observou-se que a adição de TiBa e TPDGA influenciou nos resultados superiores do ensaio de da temperatura de deflexão térmica, melhorando a adesão entre carga e matriz.

Observou-se um aumento da temperatura, pois existe a presença de reforços aumentando-se a cristalinidade do compósito.

A adesão do pó de madeira tratado superficialmente na matriz polimérica alterou o grau de cristalinidade do compósito, permitindo utilizar estes compósitos em situações onde seja desejável o melhor comportamento mecânico nessas condições de temperatura. 


\subsection{ENSAIOS DE TEMPERATURA DE AMOLECIMENTO VICAT}

Foi determinada a temperatura de amolecimento Vicat as seguintes composições de PP:

$$
\begin{aligned}
& -\mathrm{PP} \text { (puro); } \\
& -10 \% \mathrm{WF} / \mathrm{PP} ; \\
& -10 \% \mathrm{WF}+\mathrm{TiBa} / \mathrm{PP} ; \\
& -10 \% \mathrm{WF}+\mathrm{TiBa}+\mathrm{TPDGA} / \mathrm{PP} ; \\
& -15 \% \mathrm{WF} / \mathrm{PP} ; \\
& -15 \% \mathrm{WF}+\mathrm{TiBa} / \mathrm{PP} ; \\
& -15 \% \mathrm{WF}+\mathrm{TiBa}+\mathrm{TPDGA} / \mathrm{PP} ; \\
& -20 \% \mathrm{WF} / \mathrm{PP} ; \\
& -20 \% \mathrm{WF}+\mathrm{TiBa} / \mathrm{PP} ; \\
& -20 \% \mathrm{WF}+\mathrm{TiBa}+\mathrm{TPDGA} / \mathrm{PP} .
\end{aligned}
$$

Também foram determinadas a temperatura de amolecimento Vicat para todas as composições citadas anteriormente submetidas a doses de radiação de $10 \mathrm{kGy}$ e $20 \mathrm{kGy}$.

Nas Tabelas 63, 64, 65, 66, 68, 69, 70, 72, 73, 74 são apresentados os resultados obtidos no ensaio de temperatura de amolecimento Vicat das amostras de PP (puro) e de diferentes composições de PP com 10\%WF, 15\%WF e 20\%WF irradiadas e não irradiadas.

Tabela 63 - Temperatura de Amolecimento Vicat $\left({ }^{\circ} \mathrm{C}\right)$ das amostras de PP (puro) em amostras irradiadas e não irradiadas

\begin{tabular}{c|ccc}
\hline Amostras & PP (Puro) & PP (Puro) 10kGy & PP (Puro) 20kGy \\
\hline 1 & 148,1 & 147,0 & 146,9 \\
2 & 147,5 & 146,9 & 146,6 \\
3 & 147,8 & 147,0 & 146,5 \\
\hline Média & 147,8 & 147,0 & 146,7 \\
Desvio Padrão & 0,3 & 0,1 & 0,2 \\
\hline
\end{tabular}

Na Figura 54 são mostrados os resultados de temperatura de amolecimento Vicat das amostras de PP irradiadas e não irradiadas. 


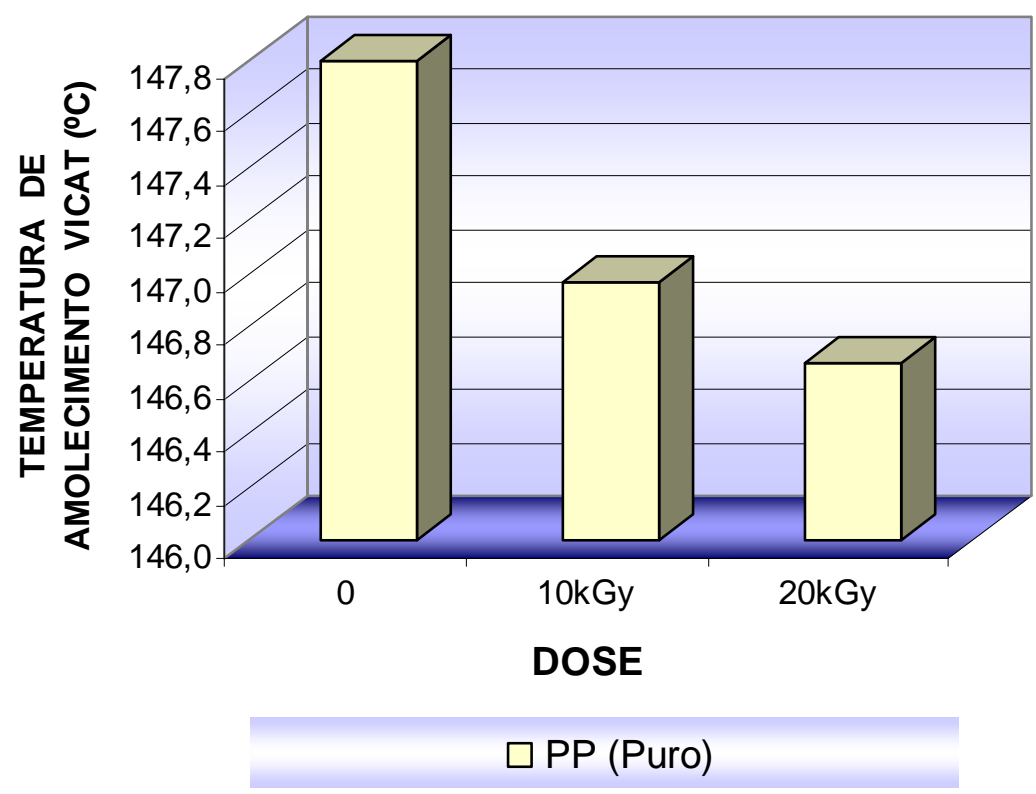

Figura 54 - Temperatura de amolecimento Vicat das amostras de PP irradiadas e não irradiadas.

Ao analisar os resultados apresentados na Tabela 63 e mostrados na Figura 54, observou-se que ao comparar as amostras de PP irradiado ao PP sem dose de radiação, observou-se um decréscimo da temperatura de amolecimento Vicat conforme o aumento da dose de radiação, este decréscimo foi de:

$$
\begin{aligned}
& 0,54 \% \text { na amostra PP com } 10 \mathrm{kGy} ; \\
& 0,74 \% \text { na amostra PP com } 20 \mathrm{kGy}
\end{aligned}
$$

O PP irradiado no ensaio de temperatura de amolecimento Vicat apresentou valores muito próximos ao PP (puro) não irradiado.

Tabela 64 - Temperatura de amolecimento Vicat $\left({ }^{\circ} \mathrm{C}\right)$ das amostras de $10 \% \mathrm{WF} / \mathrm{PP}$ irradiadas e não irradiadas.

\begin{tabular}{c|cccc}
\hline Amostras & PP (Puro) & $10 \% \mathrm{WF} / \mathrm{PP}$ & $\begin{array}{c}10 \% \mathrm{WF} / \mathrm{PP} \\
10 \mathrm{kGy}\end{array}$ & $\begin{array}{c}10 \% \mathrm{WF} / \mathrm{PP} \\
20 \mathrm{kGy}\end{array}$ \\
\hline 1 & 148,1 & 146,4 & 146,2 & 145,0 \\
2 & 147,5 & 146,1 & 146,7 & 144,2 \\
3 & 147,8 & 146,7 & 145,8 & 143,6 \\
\hline Média & 147,8 & 146,4 & 146,2 & 144,3 \\
Desvio Padrão & 0,3 & 0,3 & 0,5 & 0,7 \\
\hline
\end{tabular}


Tabela 65 - Temperatura de amolecimento Vicat $\left({ }^{\circ} \mathrm{C}\right)$ das amostras de $10 \% \mathrm{WF}+\mathrm{TiBa} / \mathrm{PP}$ irradiadas e não irradiadas.

\begin{tabular}{c|cccc}
\hline \multirow{2}{*}{ Amostras } & PP (Puro) & $\begin{array}{c}10 \% \mathrm{WF}+\mathrm{TiBa} / \\
\text { PP }\end{array}$ & $\begin{array}{c}10 \% \mathrm{WF}+\mathrm{TiBa} / \\
\text { PP 10kGy }\end{array}$ & $\begin{array}{c}10 \% \mathrm{WF}+\mathrm{TiBa} / \\
\text { PP 20kGy }\end{array}$ \\
\hline 1 & 148,1 & 146,0 & 145,7 & 145,0 \\
2 & 147,5 & 145,7 & 144,4 & 145,1 \\
3 & 147,8 & 145,6 & 145,5 & 144,2 \\
\hline Média & 147,8 & 145,8 & 145,2 & 144,8 \\
Desvio Padrão & 0,3 & 0,2 & 0,7 & 0,5 \\
\hline
\end{tabular}

Tabela 66 - Temperatura de amolecimento Vicat $\left({ }^{\circ} \mathrm{C}\right)$ das amostras de $10 \% \mathrm{WF}+\mathrm{TiBa}+\mathrm{TPDGA} / \mathrm{PP}$ irradiadas e não irradiadas.

\begin{tabular}{c|cccc}
\hline \multirow{2}{*}{ Amostras } & PP (Puro) & $\begin{array}{c}10 \% \mathrm{WF}+\mathrm{TiBa}+ \\
\text { TPGDA/PP }\end{array}$ & $\begin{array}{c}10 \% \mathrm{WF}+\mathrm{TiBa}+ \\
\text { TPGDA/PP } \\
10 \mathrm{kGy}\end{array}$ & $\begin{array}{c}10 \% \mathrm{WF}+\mathrm{TiBa}+ \\
\text { TPDGA/PP } \\
20 \mathrm{kGy}\end{array}$ \\
\hline 1 & 148,1 & 145,0 & 144,4 & 144,5 \\
2 & 147,5 & 146,1 & 146,7 & 145,0 \\
3 & 147,8 & 144,0 & 145,9 & 145,4 \\
\hline Média & 147,8 & 145,0 & 145,7 & 145,0 \\
Desvio Padrão & 0,3 & 1,0 & 1,2 & 0,5 \\
\hline
\end{tabular}

Na Figura 55 são mostrados os resultados de temperatura de amolecimento Vicat das amostras de PP (puro) e de diferentes composições de PP com 10\%WF irradiadas e não irradiadas. 

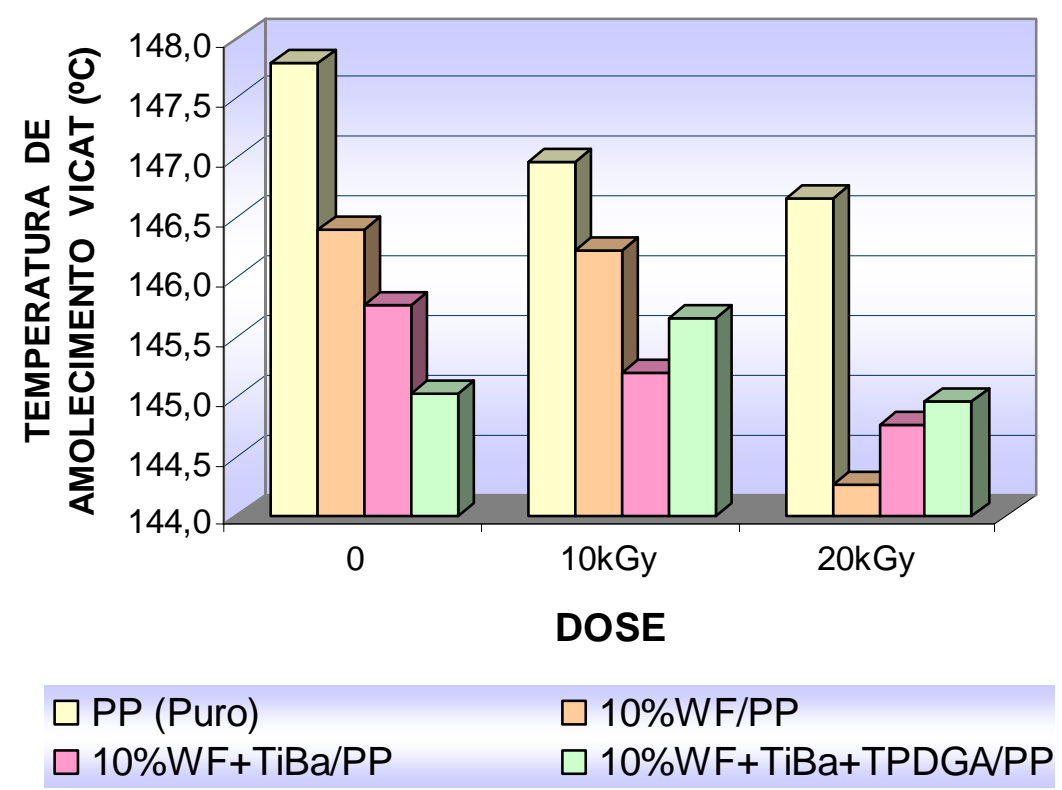

Figura 55 - Temperatura de amolecimento Vicat das amostras de PP (puro) e de diferentes composições de PP com 10\%WF irradiadas e não irradiadas.

Analisando os resultados apresentados nas Tabelas 64, 65 e 66 e mostrado na Figura 55 a medida que aumentou-se a dose de radiação observou-se que a temperatura de amolecimento Vicat diminuiu.

$\mathrm{Na}$ Tabela 67 são apresentados os resultados do ensaio de temperatura de amolecimento Vicat para as amostras de PP com diferentes porcentagens com 10\%WF em relação ao PP (puro) não irradiado.

Tabela 67 -. Porcentagem de decréscimo da temperatura de amolecimento Vicat para as diferentes composições com 10\%WF submetidas a diferentes doses de radiação em relação ao PP (puro) não irradiado.

\begin{tabular}{cccc}
\hline $\begin{array}{c}\text { Doses } \\
\mathrm{kGy}\end{array}$ & $10 \% \mathrm{WF} / \mathrm{PP}$ & $10 \% \mathrm{WF}+\mathrm{TiBa} / \mathrm{PP}$ & $\begin{array}{c}10 \% \mathrm{WF}+\mathrm{TiBa} \\
+\mathrm{TPDGA} / \mathrm{PP}\end{array}$ \\
\hline 0 & $0,9 \%$ & $1,4 \%$ & $1,9 \%$ \\
10 & $1,1 \%$ & $1,8 \%$ & $1,4 \%$ \\
20 & $2,4 \%$ & $2,1 \%$ & $1,9 \%$ \\
\hline
\end{tabular}

Analisando os resultados das amostras com $10 \% \mathrm{WF}$ e comparando com as amostras de PP (puro) não irradiado observou-se que: 
As amostras obtiveram resultados inferiores à amostra PP não irradiado, apesar da radiação ter afetado as amostras irradiadas os resultados não foram significativos.

Tabela 68 - Temperatura de amolecimento Vicat $\left({ }^{\circ} \mathrm{C}\right)$ das amostras de 15\%WF/PP irradiadas e não irradiadas.

\begin{tabular}{c|cccc}
\hline Amostras & PP (Puro) & $15 \% \mathrm{WF} / \mathrm{PP}$ & $\begin{array}{c}15 \% \mathrm{WF} / \mathrm{PP} \\
10 \mathrm{kGy}\end{array}$ & $\begin{array}{c}15 \% \mathrm{WF} / \mathrm{PP} \\
20 \mathrm{kGy}\end{array}$ \\
\hline 1 & 148,1 & 145,9 & 145,3 & 143,6 \\
2 & 147,5 & 146,7 & 145,0 & 143,7 \\
3 & 147,8 & 147,1 & 145,7 & 145,9 \\
\hline Média & 147,8 & 146,6 & 145,3 & 144,4 \\
Desvio Padrão & 0,3 & 0,6 & 0,4 & 1,3 \\
\hline
\end{tabular}

Tabela 69 - Temperatura de amolecimento Vicat $\left({ }^{\circ} \mathrm{C}\right)$ das amostras de $15 \% \mathrm{WF}+\mathrm{TiBa} / \mathrm{PP}$ irradiadas e não irradiadas.

\begin{tabular}{c|cccc}
\hline Amostras & PP (Puro) & $15 \% \mathrm{WF}+\mathrm{TiBa} / \mathrm{PP}$ & $15 \% \mathrm{WF}+\mathrm{TiBa} / \mathrm{PP}$ & $15 \% \mathrm{WF}+\mathrm{TiBa} / \mathrm{PP}$ \\
& & & $10 \mathrm{kGy}$ & $20 \mathrm{kGy}$ \\
\hline 1 & 148,1 & 145,3 & 145,8 & 145,4 \\
2 & 147,5 & 146,9 & 145,7 & 145,3 \\
3 & 147,8 & 146,7 & 146,5 & 145,4 \\
\hline Média & 147,8 & 146,3 & 146,0 & 145,4 \\
Desvio Padrão & 0,3 & 0,9 & 0,4 & 0,1 \\
\hline
\end{tabular}

Tabela 70 - Temperatura de amolecimento Vicat $\left({ }^{\circ} \mathrm{C}\right)$ das amostras de $15 \% \mathrm{WF}+\mathrm{TiBa}+\mathrm{TPDGA} / \mathrm{PP}$ irradiadas e não irradiadas.

\begin{tabular}{c|cccc}
\hline \multirow{2}{*}{ Amostras } & PP (Puro) & $\begin{array}{c}15 \% \mathrm{WF}+\mathrm{TiBa}+ \\
\text { TPDGA/PP }\end{array}$ & $\begin{array}{c}15 \% \mathrm{WF}+\mathrm{TiBa}+ \\
\text { TPDGA/PP } \\
10 \mathrm{kGy}\end{array}$ & $\begin{array}{c}15 \% \mathrm{WF}+\mathrm{TiBa}+ \\
\text { TPDGA/PP } \\
20 \mathrm{kGy}\end{array}$ \\
\hline 1 & 148,1 & 146,3 & 145,7 & 145,6 \\
2 & 147,5 & 147,5 & 145,4 & 146,5 \\
3 & 147,8 & 146,9 & 147,0 & 146,3 \\
\hline Média & 147,8 & 146,9 & 146,0 & 146,1 \\
Desvio Padrão & 0,3 & 0,6 & 0,8 & 0,5 \\
\hline
\end{tabular}


Na Figura 56 são mostrados os resultados de temperatura de amolecimento Vicat das amostras de PP (puro) e de diferentes composições de PP com 15\%WF irradiadas e não irradiadas.

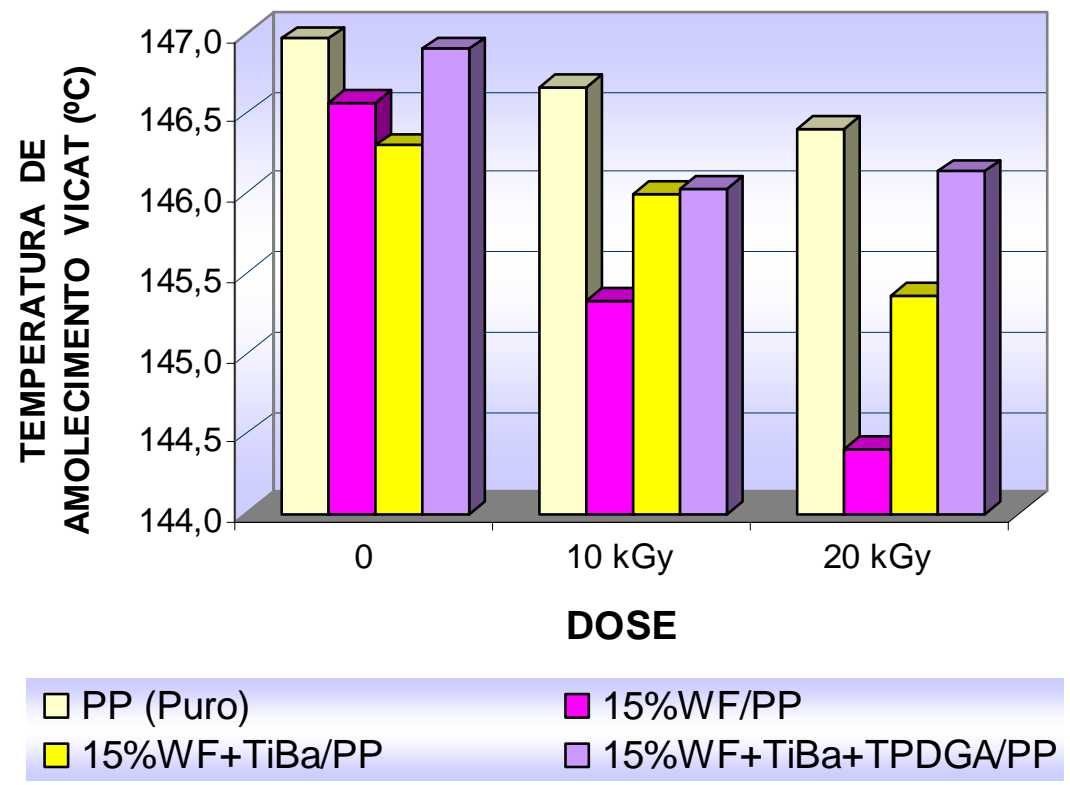

Figura 56 - Temperatura de amolecimento Vicat das amostras de PP (puro) e de diferentes composições de PP com 15\%WF irradiadas e não irradiadas.

Analisando os resultados apresentados nas Tabelas 67, 68 e 69 e mostrado na Figura 56 a medida que aumentou-se a dose de radiação observou-se que a temperatura de amolecimento Vicat diminuiu.

$\mathrm{Na}$ Tabela 71 são apresentados os resultados do ensaio de temperatura de amolecimento Vicat para as amostras de PP com diferentes porcentagens com $15 \% \mathrm{WF}$ em relação ao PP (puro) não irradiado. 
Tabela 71 - Porcentagem de decréscimo da temperatura de amolecimento Vicat para as diferentes composições com 15\%WF submetidas a diferentes doses de radiação em relação ao PP (puro) não irradiado.

\begin{tabular}{cccc}
\hline $\begin{array}{c}\text { Doses } \\
\mathrm{kGy}\end{array}$ & $15 \% \mathrm{WF} / \mathrm{PP}$ & $15 \% \mathrm{WF}+\mathrm{TiB} / \mathrm{PP}$ & $\begin{array}{c}15 \% \mathrm{WF}+\mathrm{TiBa} \\
+\mathrm{TPDGA} / \mathrm{PP}\end{array}$ \\
\hline 0 & $0,8 \%$ & $1,0 \%$ & $0,6 \%$ \\
10 & $1,7 \%$ & $1,2 \%$ & $1,2 \%$ \\
20 & $2,3 \%$ & $1,6 \%$ & $1,1 \%$ \\
\hline
\end{tabular}

Analisando os resultados das amostras com $15 \% \mathrm{WF}$ e comparando com as amostras de PP (puro) não irradiado observou-se que:

As amostras obtiveram resultados inferiores à amostra PP não irradiado, apesar da radiação ter afetado as amostras irradiadas os resultados não foram significativos.

Tabela 72 - Temperatura de amolecimento Vicat $\left({ }^{\circ} \mathrm{C}\right)$ das amostras de $20 \% \mathrm{WF} / \mathrm{PP}$ irradiadas e não irradiadas.

\begin{tabular}{c|cccc}
\hline \multirow{2}{*}{ Amostras } & PP (Puro) & $20 \% \mathrm{WF} / \mathrm{PP}$ & $\begin{array}{c}20 \% \mathrm{WF} / \mathrm{PP} \\
10 \mathrm{kGy}\end{array}$ & $\begin{array}{c}20 \% \mathrm{WF} / \mathrm{PP} \\
20 \mathrm{kGy}\end{array}$ \\
\hline 1 & 148,1 & 147,5 & 146,4 & 144,1 \\
2 & 147,5 & 148,1 & 146,6 & 144,0 \\
3 & 147,8 & 147,2 & 146,8 & 144,5 \\
\hline Média & 147,8 & 147,6 & 146,6 & 144,2 \\
Desvio Padrão & 0,3 & 0,5 & 0,2 & 0,3 \\
\hline
\end{tabular}

Tabela 73 - Temperatura de amolecimento Vicat $\left({ }^{\circ} \mathrm{C}\right)$ das amostras de 20\%WF+TiBa/PP irradiadas e não irradiadas.

\begin{tabular}{c|cccc}
\hline Amostras & PP (Puro) & $\begin{array}{c}20 \% \mathrm{WF}+\mathrm{TiBa} / \\
\text { PP }\end{array}$ & $\begin{array}{c}20 \% \mathrm{WF}+\mathrm{TiBa} / \\
\text { PP 10kGy }\end{array}$ & $\begin{array}{c}20 \% \mathrm{WF}+\mathrm{TiBa} / \\
\text { PP 20kGy }\end{array}$ \\
\hline 1 & 148,1 & 146,1 & 145,1 & 144,5 \\
2 & 147,5 & 144,8 & 145,3 & 144,1 \\
3 & 147,8 & 144,9 & 144,7 & 145,2 \\
\hline Média & 147,8 & 145,3 & 145,0 & 144,6 \\
Desvio Padrão & 0,3 & 0,7 & 0,3 & 0,6 \\
\hline
\end{tabular}


Tabela 74 - Temperatura de amolecimento Vicat $\left({ }^{\circ} \mathrm{C}\right)$ das amostras de 20\%WF+TiBa+TPDGA/PP irradiadas e não irradiadas.

\begin{tabular}{c|cccc}
\hline \multirow{2}{*}{ Amostras } & PP(Puro $)$ & $\begin{array}{c}\text { 20\%WF+TiBa }+ \\
\text { TPDGA/PP }\end{array}$ & $\begin{array}{c}\text { 20\%WF+TiBa }+ \\
\text { TPDGA/PP } \\
10 k G y\end{array}$ & $\begin{array}{c}20 \% \mathrm{WF}+\mathrm{TiBa}+ \\
\text { TPDGA/PP } \\
20 \mathrm{kGy}\end{array}$ \\
\hline 1 & 148,1 & 147,1 & 145,3 & 144,8 \\
2 & 147,5 & 147,1 & 146,1 & 144,8 \\
3 & 147,8 & 146,2 & 146,0 & 145,2 \\
\hline Média & 147,8 & 146,8 & 145,8 & 144,9 \\
Desvio Padrão & 0,3 & 0,5 & 0,4 & 0,2 \\
\hline
\end{tabular}

Na Figura 57 são mostrados os resultados de temperatura de amolecimento Vicat das amostras de PP (puro) e de diferentes composições de PP com 20\%WF irradiadas e não irradiadas.

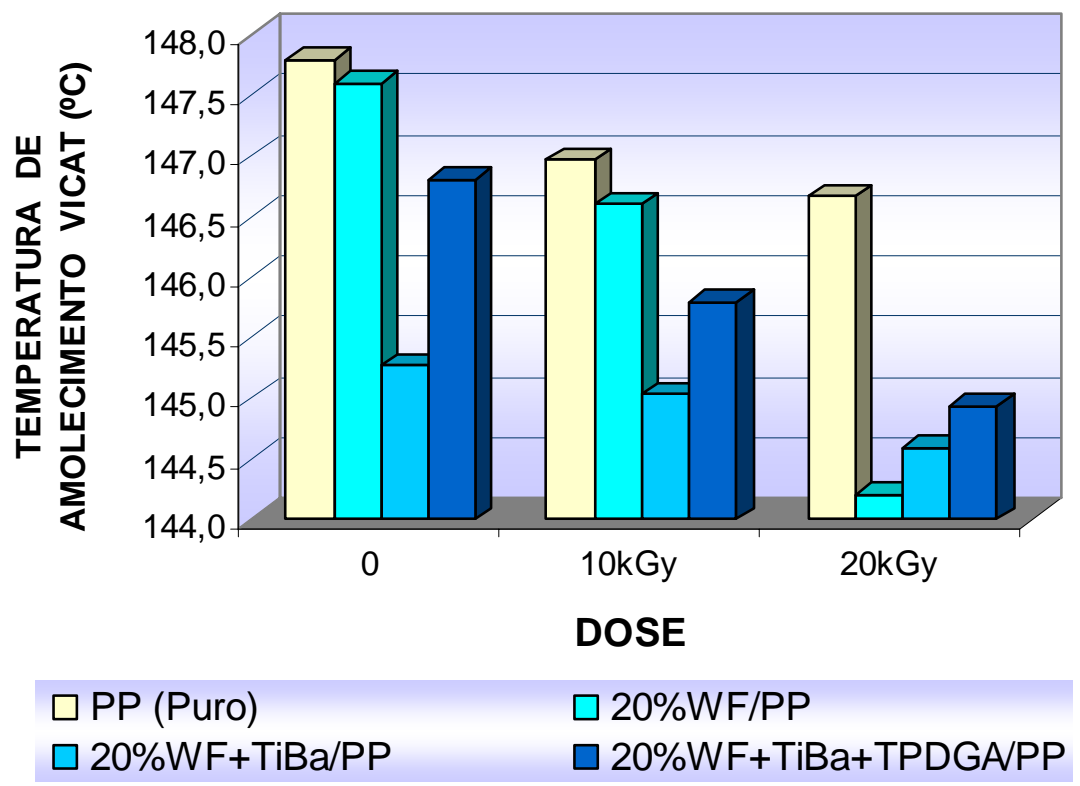

Figura 57 - Temperatura de amolecimento Vicat das amostras de PP (puro) e de diferentes composições de PP com 20\%WF irradiadas e não irradiadas.

Analisando os resultados apresentados nas Tabelas 72, 73 e 74 e mostrado na Figuras 57 a medida que aumentou-se a dose de radiação observou-se que a temperatura de amolecimento Vicat diminuiu. 
Nas Tabelas 75 são apresentados os resultados do ensaio de temperatura de amolecimento Vicat para as amostras de PP com diferentes porcentagens com 20\%WF em relação ao PP (puro) não irradiado.

Tabela 75 -. Porcentagem de decréscimo da temperatura de amolecimento Vicat para as diferentes composições com 20\%WF submetidas a diferentes doses de radiação em relação ao PP (puro) não irradiado.

\begin{tabular}{cccc}
\hline $\begin{array}{c}\text { Doses } \\
\mathrm{kGy}\end{array}$ & $20 \% \mathrm{WF} / \mathrm{PP}$ & $20 \% \mathrm{WF}+\mathrm{TiBa} / \mathrm{PP}$ & $\begin{array}{c}20 \% \mathrm{WF}+\mathrm{TiBa} \\
+\mathrm{TPDGA} / \mathrm{PP}\end{array}$ \\
\hline 0 & $0,1 \%$ & $1,7 \%$ & $0,7 \%$ \\
10 & $0,8 \%$ & $1,9 \%$ & $1,4 \%$ \\
20 & $2,4 \%$ & $2,2 \%$ & $1,9 \%$ \\
\hline
\end{tabular}

Analisando os resultados das amostras com $20 \% \mathrm{WF}$ e comparando com as amostras de PP (puro) não irradiado observou-se que:

As amostras obtiveram resultados inferiores à amostra PP não irradiado, apesar da radiação ter afetado as amostras irradiadas os resultados não foram significativos.

Como conclusão desses resultados de temperatura de amolecimento Vicat pode-se dizer:

A temperatura de amolecimento dos compósitos está bem próxima a do polipropileno puro, isto era esperado uma vez que a proporção de polipropileno utilizada é bem maior que a de reforço, prevalecendo às propriedades térmicas da matriz polimérica. 


\section{CONCLUSÃO}

Analisando-se os resultados para as propriedades avaliadas nas condições experimentais deste trabalho de pesquisa pode-se concluir que:

A mistura feita na calandra apresentou uma boa homogeneização carga/polímero, o que contribuiu na melhora na maioria das propriedades avaliadas.

Os compostos obtidos podem ser processados nas mesmas condições do polímero puro, obtendo-se moldados de boa qualidade quanto a cor e aspecto físico.

Houve uma redução do índice de fluidez para os compostos contendo pó de madeira, sendo esta redução mais efetiva na presença de TiBa, esta redução deve-se a presença de partículas na matriz que restringe a mobilidade das macromoléculas, dificultando o fluxo do polímero fundido e conseqüentemente aumentando sua viscosidade.

O tratamento superficial utilizando o monômero TPDGA influenciou nas amostras de compósitos, pois este agiu como aditivo plastificante tornando as amostras mais fáceis de processar aumentando a mobilidade entre as macromoléculas, diminuindo assim a viscosidade e aumentando o índice de fluidez.

Os resultados obtidos do ensaio de resistência à tração indicaram que o grupo de amostra de melhor desempenho foi a de $20 \% \mathrm{WF}$ e que o TiBa proporcionou valores altos tanto para as amostras irradiadas quanto não irradiadas.

A resistência à tração apresentou um acréscimo nos resultados em todas as amostras contendo pó de madeira.

O decréscimo na resistência ao impacto pode ter acontecido porque a presença de reforço de pó de madeira pode atuar como concentrador de tensões e como conseqüência reduzir a resistência de impacto. Além disso, a carga pode ter contribuído para um aumento na cristalinidade da matriz polimérica e como conseqüência houve um decréscimo na resistência ao impacto.

Nas amostras irradiadas além das razões descritas anteriormente a radiação ionizante reticula o PP e oxida o pó de madeira e por isso estas amostras apresentaram baixos resultados de resistência ao impacto. 
Houve um acréscimo na dureza nos compósitos contendo pó de madeira. O acréscimo na dureza foi significativo nos compósitos de WF/PP que não foram irradiados e esse acréscimo se deu principalmente nas composições de $20 \% \mathrm{WF} / \mathrm{PP}$. Isso porque quanto maior a quantidade de carga maior o módulo de dureza.

Nas amostras irradiadas a dureza aumentou devido à reticulação do PP frente à radiação.

Os resultados de temperatura de deflexão térmica nos compósitos apresentaram um aumento em relação ao PP não irradiado, estes resultados estão relacionados ao tratamento superficial realizado na carga pó de madeira com aditivos TiBa e TPDGA. Isto é observado, pois a temperatura é função da cristalinidade da matriz polimérica e da presença de reforços.

Observou-se que o aumento na dose de radiação não influenciou significativamente na variação da temperatura de deflexão térmica dos compósitos indicando que houve reticulação entre as moléculas promovido pelo TPDGA, e uma melhoria na adesão entre interfaces promovido pelo titanato.

A temperatura de amolecimento Vicat dos compósitos foi bem próxima a do polipropileno puro o que era esperado uma vez que a proporção de polipropileno utilizada é bem maior que a de reforço, prevalecendo às propriedades térmicas da matriz polimérica.

Na presença do TiBa ocorreu uma melhor interação entre o PP e a carga de WF, indicando a sua ação efetiva como agente de acoplagem entre a carga e a matriz polimérica. Observou-se que na presença de TiBa algumas propriedades teve uma melhora mais significativa.

O titanato de bário é um agente de acoplagem que favoreceu a compatibilização do PP e do WF.

O monômero TPDGA proporcionou boa interação entre o PP e a carga de WF, porém os resultados obtidos não o tornam um produto adequado para ser utilizado junto com o TiBa. O TPDGA não apresentou resultados que demonstrasse a ação efetiva como reticulante no compósito nas doses estudadas.

A radiação ionizante interagiu no material compósito reticulando o PP, obsevando-se assim um acréscimo em algumas propriedades e o decréscimo em outras.

A viabilidade do processamento para obtenção do compósito de WF/PP foi demonstrada no decorrer deste trabalho e também a motivação para se dar continuidade no estudo desses compósitos, buscando outros processamentos, novos aditivos capazes de auxiliar o TiBa, novas composições e doses de radiação. 


\section{REFERÊNCIAS BIBLIOGRÁFICAS}

ALBANO, C.; REYES J.; GONZALES J.; ICHAZO M.; POLEO R.; DAVIDSON E. Mathematical analysis of the mechanical behavior of 60Co-irradiated polyolefin blends with and without woodflour. Polym. Degrad. and Stab., n. 73 p. 39-45, 2001.

ALBUQUERQUE, J.A.C. Planeta plástico, tudo o que você precisa saber sobre plásticos, 1 ed., Porto Alegre, 2001.

AMERICAN SOCIETY FOR TESTING AND MATERIALS, Standard Test Method for Melt Flow Index (ASTM D1238-81).

AMERICAN SOCIETY FOR TESTING AND MATERIALS, Standard Test Method for Impact Resistance of Plastics and Eletrical Insulating Materials (ASTM D 256-94).

AMERICAN SOCIETY FOR TESTING AND MATERIALS, Standard Test Method for Rockwell Hardness of Plastics and Eletrical Insulating Materials (ASTM D 785-94).

AMERICAN SOCIETY FOR TESTING AND MATERIALS, Standard Test Method for Heat Distorcion Temperature (ASTM D 648-81).

AMERICAN SOCIETY FOR TESTING AND MATERIALS, Standard Test Method for Softning Point. (ASTM D 1525-81).

AMIM, P.R.P. Estudo de misturas de HDPE e fibra de coco como mecanismo de desenvolvimento limpo para utilização em madeira plástica. 2006. Dissertação (Mestrado) - Universidade Federal do Rio de Janeiro, Rio de Janeiro.

BNDES - GERÊNCIA SETORIAL DE QUÍMICA DO BNDES, p.03, 1996. Disponível em: $\leq$ http:www.propriedadesdopolipropileno/pdf $>$ Acesso 6 abr. 2007.

BRISTSH PLASTICS \& RUBBER. Growth in consumption of extruded wood-plastic composites, 2001. London: MCM Publishing Ltd., v.5, p.26.

CALLISTER, W.D.J.C. Ciência e engenharia de materiais: uma introdução. 5 ed. Rio de Janeiro, 2002.

CAULFIELD, D.F.; CLEMONS, C.; JACOBSON, R.E.; ROWELL, R.M. Wood thermoplastic composites. Handbook of Wood Chemistry and Wood Composites. CRC Press, 2005.2 Disponível em: $\leq$ http://www.fpl.fs.fed.us/documnts/pdf2005/fpl 2005 caulfield001.pdf $>$. Acesso em: 10 ago.2006. 
CLEMONS, C. Wood-plastic composites in the United States - the interfacing of two industries. Forest Products Journal, v.52, n.6, p.10-18, 2002. Disponível em:

$<$ http//www.fpl.fs.fed.us/documnts/techline/Wood-Plastic_Composites.pdf $>$. Acesso em: 09 set. 2004.

CLIMENHAGE, D. Recycled plastic lumber: A strategic assessment of its production, use and future prospects. Environment and Plastics Industry Council (EPIC) and Corporations Supporting Recycling (CSR). Jan., 2003. Disponível em: $\leq$ http://www.cpia.ca/files/files/files PlasticLumber-Final-Report.pdf $>$. Acesso em: 11 set. 2006.

CLOUGH, R.L. High-energy radiation and polymers: A review of commercial processes and emerging applications. Nucl. Instrum. and Methods in Phys. Res., Sect. B v. 185, p. 8-33, 2001.

CONCISE ENCYCLOPEDIA OF POLYMER PROCESSING AND APLICATION; Radiations effects on polymers. New York: Pergamom Press. p.581-588. 1992.

CORREA, C.A.; FONSECA, C.N.P.; NEVES, S. Compósitos Termoplásticos com Madeira. Polímeros Ciência e Tecnologia, v. 13, n.3, p. 154-165, 2003.

CZVIKOVSZKY, T. Electron-beam processing of wood fiber reinforced polypropylene. Radiat. Phys. Chem. v. 47, n. 3, p. 425-430, 1996.

DEKKER, M. Handbook of Polymer Synthesis. Part A. New York. 1992.

DOUGLAS, D.S.; DOUGLAS, J.G. Aspects of wood as a component of thermoplastic composites. Manufacturing News Directory - Plastics News. Jul. 2003. Disponível em: $\leq \mathrm{http}: / /$ www.jobwerx.com/news/Archives/thermoplastic_composites_2003 news_07_13 03.html>. Acesso em: 20 out. 2006.

EISENBERG, R.; RESNICK, R. Física Quantidade. Rio de Janeiro, 1988.

ENGLISH, B.; CLEMONS, C.M.; STARK, N.; SCHNIEDER, J.P. Waste-wood derived fillers for plastics. Gen. Tech. Rept. FPL-GTR-91. USDA FS, Forest Products Laboratory, p.282-291, 1996.

FERRO, W.P. Estudo do efeito da radiação ionizante nas propriedades da poliamida 6.6 com e sem reforço de fibra de vidro. 2003. Dissertação (Mestrado) - Instituto de Pesquisas Energéticas e Nucleares, São Paulo.

FURTADO, M. Vernizes formulações com secagem UV desbancam as convencionais. Química e Derivados, n. 465, 2004.

GARCIA, J.R. Efeitos dos agentes de acoplagem na processabilidade e nas propriedades mecânicas do polipropileno reforçado com wolastonita. 1999. Tese de (Doutorado) - Universidade Presbiteriana Mackenzie, São Paulo. 
GUADAGNINI, M.A. Madeiras plásticas como materiais alternativos para madeiras naturais. 2001. Dissertação (Mestrado) - Universidade Federal do Rio de Janeiro, Rio de Janeiro.

JORGE, C. Tecnologia produz Madeira Plástica. Revista Plástico Moderno, p. 18, 2000.

KOENIG, K.M.; SYPKENS, C.W. Wood-plastic composites for market share. Wood and Wood Products, v.107, n.5, p.49-58, 2002.

LANDI, T.R.L. Estudo do efeito da radiação ionizante por feixe de elétrons sobre o terpolímero acrilonitrila butadieno estireno ABS. 2003. Dissertação (Mestrado) Instituto de Pesquisas Energéticas e Nucleares, São Paulo.

LAMPO, R.; NOSKER, D.T. Development and testing of plastic lumber materials for construction applications. USACERL Technical Report 97/95. jun., 1997. Disponível em: $\leq$ http://www.cecer.army.mil/techreports/lamlum/LAMLUM post.PDF $>$ Acesso em: 22 ago. 2006.

MANO, E.B. Polímeros como materiais de engenharia, São Paulo, Edgard Blücher Ltda, 1991.

MASSON, T.J. Desenvolvimento e reciclagem do polipropileno modificado pela presença de cargas híbridas. 1998. Tese (Doutorado) - Universidade Presbiteriana Mackenzie, São Paulo.

MILES, D.C.; BRISTON, J.H. Tecnologia dos polímeros. Editora da Universidade de São Paulo Editora Polígono S.A.,1975.

MIRANDA, L.F. Estudos de parâmetros de processo para a síntese de membranas hidrofílicas a base de poli (N-vinil-2-pirrolidona). 1999. Tese (Doutorado) - Instituto de Pesquisas Energéticas e Nucleares, São Paulo.

O'DONNELL, J.H.; SANGSTER, D.F. Principles of radiation chemistry. New York: Arnold E., 1970.

PFAENDNER, R. Sistema de aditivação combina efeitos na melhoria de resinas recicladas. Plástico Industrial, set. 2001.

RABELLO, M. Aditivação de polímeros. São Paulo, Artiliber Editora, 2000.

RODOLFO, J.R.; JOHN, A.V.M. Desenvolvimento de PVC reforçado com resíduos de Pinus para substituir madeira convencional em diversas aplicações. Polímeros: Ciência e Tecnologia, v.16, n.1, 2006.

SINGH, A.; SILVEMAN, J. Radiation processing of polymers. In: CLELAND, M.R. High Power Electro Acceleration for Industrial Radiation Processing, New York, 1992. cap. 3.

SOARES, M.A. Reciclagem de plásticos. 1966. Dissertação (Mestrado) - Universidade Camilo Castelo Branco, Unicastelo, São Paulo. 
SPINKS, J.W.T. \& WOODS, R.J. An Introduction to radiation chemistry. New York: John Wiley e sons Inc, 1990.

STARK, N. M.; BERGER, M.J. Effect of particle size on properties of wood-flour reinforced composites. The Fourth Conference on Woodfiber-Plastic Composites, maio, 1997. Disponível em: <http://www.fpl.fs.fed.us/documnts/pdf1997/stark97d.pdf. $>$. Acesso em: 28 ago. 2006.

STASIEK, J. Extruders for recycling of waste thermoplastic materials. International polymer science and technology, v.24, n.5, p.96-103, 1997.

STEFFANI, E.; FINKLER, M. Uma avaliação das propriedades do polipropileno Reciclado. Plástico Industrial, abr. 1999.

ULLOA, M.E.P.; MAIORINO, R.A. Reciclagem de polipropileno com pó de madeira. 2003. Tese (Graduação interdisciplinar) - Universidade Presbiteriana Mackenzie, São Paulo.

WITT, A.E. Applications in Wood Plastics. Rad. Phys. Chem. v. 9, p. 271-288, 1977.

YAMAJI, F.M.; BOUNDUELLE A. Utilização da serragem na produção de compósitos plástico-madeira. Revista Floresta v.34, n.1, p. 59-66, 2004

YAMASAKI, M.C.R. A Cura de Tintas, Vernizes e Revestimentos por Ultravioleta e Feixe de Elétrons. Instituto de Pesquisas Energéticas e Nucleares - IPEN, 1997.

YOUNGQUIST, J.A. The marriage of wood and nonwood materials. Forest Products Journal, v.45, n.10, p.25-30, 1995. 